\title{
ipen
}

INSTITUTO DE PESQUISAS ENERGÉTICAS E NUCLEARES

Autarquia Associada à Universidade de São Paulo

\section{TECNOLOGIA DA INFORMAÇÃO, INOVAÇÃO E EMPREENDEDORISMO: FATORES CRÍTICOS DE SUCESSO NO USO DE FERRAMENTAS DE GESTÃO EM EMPRESAS INCUBADAS DE BASE TECNOLÓGICA}

FRANCISCO CARLOS PALETTA

Tese apresentada como parte dos requisitos para obtenção do Grau de Doutor em Ciências na Área de Tecnologia Nuclear - Materiais

Orientador:

Prof. Dr. Nilson Dias Vieira Junior

Co-orientador:

Prof. Dr. Guilherme Ary Plonski

São Paulo 


Paletta, Francisco Carlos
P156t Tecnologia da informação, inovação e empreendedorismo :
fatores críticos de sucesso no uso de ferramentas de gestão em
empresas incubadas de base tecnológica / Francisco Carlos
Paletta. - São Paulo, 2008.
143 p.
Tese (doutorado) - Instituto de Pesquisas Energéticas e
Nucleares. Universidade de São Paulo. Departamento de Tecnologia
Nuclear.
Orientador: Vieira Junior, Nilson Dias
Co-orientador : Plonski, Guilherme Ary
1. Inovações tecnológicas : Administração 2. Incubadoras
tecnológicas. 3. Empreendedorismo 4. Ferramentas de gestão
I. T. II. Vieira Junior, Nilson Dias, orientador. III. Plonski,
Guilherme Ary, co-orientador.
$\quad 658.577$ CDD


"O trabalho é o esforço aplicado; é qualquer coisa a que nos dedicamos, qualquer coisa em que gastamos energia para conquistar ou adquirir algo. O sentido fundamental do trabalho não é aquilo por que lutamos para viver, mas o que fazemos com nossa vida. A felicidade, como Aristóteles disse há muito tempo, reside na atividade tanto física como mental. Reside em fazer coisas de que se possa orgulhar para fazer bem e, portanto, que se tenha prazer em fazer." 


\section{AGRADECIMENTOS}

Ao Prof. Dr. Nilson Dias Vieira Junior, pela grande amizade, confiança e paciência nestes últimos anos, bem como pelas preciosas e sábias discussões acadêmicas, que tanto contribuíram para o desenvolvimento deste trabalho. A você, minha admiração pelo grande exemplo profissional de constante amor e dedicação à ciência e à vida acadêmica.

Ao Instituto de Pesquisas Energéticas e Nucleares (IPEN), pela oportunidade que me foi dada de concretizar este projeto, cujo valor se transforma numa dívida intelectual inestimável.

Ao Prof. Dr. Guilherme Ary Plonski, pelo incentivo à realização desta etapa em minha carreira profissional e pelo apoio determinante durante o seu desenvolvimento.

À Profa ${ }^{\mathrm{a}}$. Dr ${ }^{\mathrm{a}}$. Martha Marques Ferreira Vieira, pela colaboração, orientação, competência e valiosas sugestões.

Ao Prof. Dr. Afonso Rodrigues Aquino, pela receptividade e valiosas reflexões durante a execução deste trabalho.

Ao Prof. Dr Rodolfo Politano, pelo incentivo e valiosa colaboração.

Ao Centro Incubador de Empresas Tecnológicas (CIETEC), maior núcleo de incubação de empresas de base tecnológica da América Latina, que permitiu o acesso aos dados coletados neste trabalho.

À equipe da Gestão Executiva do CIETEC: Sérgio Wigberto Risola, Franco Margonari Lazzuri, José Carlos de Lucena, Maurício Susterás, pela cooperação, apoio e suporte fundamentais para a elaboração deste trabalho.

Aos empreendedores do CIETEC, pela paciência com que receberam os questionários, empregando ao projeto tempo, presteza e apoio, permitindo a inclusão das empresas na pesquisa, contribuindo valiosamente para a conclusão deste trabalho. 
Ao Prof. Dr. Cláudio Rodrigues, pelo apoio e incentivo para a realização deste trabalho.

Ao Prof. Dr. Spero Penha Morato, pela troca de idéias sobre a pesquisa e constante estímulo.

Ao Sr. Fernando Moreira, pela disponibilização de procedimentos, normas, processos e todo o apoio durante a execução do trabalho.

Ao Sr. Mauro Peres, diretor-geral da IDC Brasil, pelo apoio na pesquisa Inovação e Melhores Práticas de TI.

À Sra. Ilze C. Puglia e colaboradores, pela dedicação e apoio administrativo durante a realização do estudo.

À Sra. Elza Papp, pela delicadeza, solicitude e eficiência no decorrer deste trabalho.

À Faculdade de Economia, Administração e Contabilidade da Universidade de São Paulo (FEA/USP), por toda capacidade e competência multidisciplinar que puderam ser agregadas para a realização deste trabalho.

À Bain \& Company, pela disponibilização dos dados da Pesquisa Global sobre Ferramentas de Gestão.

Ao Prof. Dr. Martinho Isnard Ribeiro de Almeida, pela oportunidade concedida e trocas de idéias sobre empreendedorismo, inovação tecnológica e estratégia empresarial.

Ao Prof. Dr. Roberto Sbragia, pela orientação, estímulo e conhecimentos transmitidos.

Ao Prof. Dr. Sílvio Aparecido dos Santos, pelo apoio para a realização deste trabalho.

Ao Centro de Laser e Aplicações por ter me acolhido na execução deste trabalho.

A meus pais, irmão e sobrinhos pelo amor, apoio, incentivo e compreensão. Agradeço a vocês, por estarem sempre presentes em minha vida.

A Fátima, minha esposa, pela inesgotável dedicação, comentários, orientações, sugestões e paciência pelas inúmeras revisões ao longo do processo deste trabalho. 


\title{
RESUMO
}

\author{
PALETTA, F.C. Tecnologia da informação, inovação e empreendedorismo: \\ fatores críticos de sucesso no uso de ferramentas de gestão em empresas \\ incubadas de base tecnológica. 143 p. (Tese de Doutorado) - Instituto de Pesquisas \\ Energéticas e Nucleares. Autarquia Associada à Universidade de São Paulo (USP). \\ São Paulo, 2008.
}

Diante da crescente importância que as empresas de base tecnológica assumem na geração de riqueza e promoção do desenvolvimento econômico sustentável, destaca-se o papel das incubadoras de empresas na promoção da inovação. Imersas em ambientes tradicionalmente geradores de conhecimento, como institutos de pesquisa e universidades, propiciam não só recursos materiais como também os recursos humanos necessários à transformação de idéias em produtos em escala empresarial. No entanto, faz-se necessário adotar um conjunto de ações para dinamizar as oportunidades de sucesso de novos empreendimentos. $O$ modelo de incentivo à inovação e ao desenvolvimento de negócios posto em prática pelas incubadoras de empresas de base tecnológica permite ao empreendedor a obtenção de competências determinísticas de êxito que resultem em aumento do ciclo de vida da empresa. As incubadoras fornecem a estrutura necessária para o desenvolvimento da idéia até a consolidação do negócio. Utilizando como parâmetro de aferição a Pesquisa Global com empresas de sucesso, realizamos estudo com os empreendedores residentes no Centro Incubador de Empresas Tecnológicas. Este estudo visa identificar o potencial uso de ferramentas de gestão que permitam influenciar os fatores críticos de sucesso do empreendedorismo de base tecnológica. A Pesquisa Global, referência deste estudo, é realizada há mais de catorze anos e conta com um banco de dados de 8.504 empresas que sobreviveram ao teste do tempo. Em 2007, a pesquisa foca em 25 ferramentas e a amostra foi de 1221 gestores em todo o mundo, dos quais 101 no Brasil, na busca de identificar quais ferramentas de gestão eles utilizam e quais resultados elas têm gerado. Para fazer parte da Pesquisa Global, as ferramentas precisam ser consideradas importantes pelos gestores, ter aplicação específica e resultados mensuráveis. Neste trabalho, baseado na hierarquia entre inovação e valor, ao monitorar quais ferramentas os gestores das empresas incubadas de base tecnológica utilizam, em quais circunstâncias e com que intensidade e compará-las com as utilizadas pelas empresas da pesquisa global, busca-se identificar os fatores críticos de sucesso para o crescimento sustentável.

Palavras-chave: Inovação; Incubadora de base tecnológica; Empreendedorismo; Tecnologia da informação; Ferramentas de gestão. 


\begin{abstract}
PALETTA, F.C. Information technology, Innovation and entrepreneurship: success critical agents using management tools on based-technology incubators firms. São Paulo, 2008. 143 p. (Doctorate Degree) - Instituto de Pesquisas Energéticas e Nucleares. Associated Autarchy to São Paulo University (USP).
\end{abstract}

Since technology companies have become a significant source of income generation and sustainable economic development, business incubation centers have been standing out due to the support they offer to start-up innovation companies. As they are embedded in research institutes and universities, not only do these business incubation units take care of the material aspects needed to establish innovation companies, but they also provide the necessary human resources to turn ideas into products on a business scale. However, further action is required to augment the chances of success for those fledgling businesses. The business incentive model provided by technology-based incubation units with regard to fostering innovation and business development offer start-up business owners the necessary tools to succeed in their venture, thus guaranteeing that their companies enjoy a longer life cycle. Business incubation centers can provide the necessary structure from the development of an idea up to the consolidation of a business. For this study, we have considered successful new companies that are part of the Technology Business Incubation Center. Our goal was to identify potential management tools that could be critical in fostering the growth of such technology-based businesses. The Global Research used as reference for this study has been conducted for over 14 years, and counts on a database with over 8,504 companies that have survived the test of time. The research focused on 25 management tools in 2007. The sample consisted of 1,221 managers from all over the world - 101 of them located in Brazil - and the aim was to identify the management tools employed, and the results obtained from such tools. In order to be included in the global research, management tools have to be considered important by their users; moreover, their use has to be specific, and their results have to be measurable. In this study, based on hierarchy and value, we have monitored which management tools were employed by technology-based companies part of incubation units, under what circumstances and how frequently, in order to compare such tools with the ones used by companies included in the global research, thus identifying critical elements of success for their sustainable growth.

Key words: Innovation; Technology-based incubation center; Entrepreneurship; Information technology; Management tools. 


\section{Pesquisa de Campo Fase 1: Ferramentas de Gestão}

\section{GESTÃO DE EMPRESAS DE BASE TECNOLÓGICA. DEFINIÇÃO DE METAS E ELABORAÇÃO DE PLANO ESTRATÉGICO DE NEGÓCIO.}

\section{ESTE QUESTIONÁRIO É COMPOSTO DE TRÊS PARTES:}

- Técnicas de Gestão do Negócio

- Análise da Eficácia das Técnicas de Gestão Utilizadas

- Tendências em Gestão

\section{PARTE I- Técnicas de Gestão do Negócio}

O propósito desta seção é entender o uso que é feito por sua organização de ferramentas e técnicas de gestão.

Em suas respostas favor marcar para as três questões a seguir, a opção mais apropriada no relatório de Ferramentas e Técnicas abaixo:

Questões:

1a. Quais das seguintes técnicas a sua empresa utilizou nos últimos anos (2003-2007)?

1b. Em 2007 quais das técnicas listadas a sua empresa utilizou?

Favor indicar se a técnica não foi usada, foi usada de maneira limitada ou experimental, ou representou um importante esforço organizacional.

- Não Usada

- Uso Limitado

- Esforço Importante

1c. Até que ponto você acha que sua empresa usará cada técnica em 2008 ?

Favor indicar se, na sua opinião, a técnica não será absolutamente usada, será usada de maneira limitada ou experimental, ou representará um importante esforço organizacional.

- Não Usada

- Uso Limitado

- Esforço Importante

\section{PARTE II - Análise da Eficácia das Técnicas de Gestão Utilizadas}

Para esta seção, favor responder apenas para as técnicas que sua empresa tenha adotado nos últimos 5 anos e, pensando em seu grau de satisfação.

Favor considerar tanto os benefícios alcançados, quanto todos os custos associados ao uso de cada técnica. 
- Extremamente Satisfeito

- Relativamente Satisfeito

- Indiferente

- Relativamente Insatisfeito

- Extremamente Insatisfeito

Questões:

Q1.a - Uso de ferramentas nos últimos 5 anos

Q1.b - Uso de ferramentas em 2007

Q1.c - Uso de ferramentas esperado em 2008

Q2 - Satisfação com as ferramentas (somente para aquelas usadas nos últimos 5 anos)

TÉCNICAS

\begin{tabular}{|c|c|c|c|c|c|c|c|c|c|c|c|c|}
\hline Gestão de Processos & $\Gamma$ & $\mathbf{C}$ & C & $\mathrm{C}$ & C & $\mathbf{C}$ & $\mathbb{E}$ & C & $\mathbf{E}$ & $\mathbf{C}$ & C & $\mathbf{E}$ \\
\hline Governança & $\Gamma$ & $\mathbf{C}$ & C & $\mathbb{E}$ & $\mathbf{C}$ & $\mathbf{C}$ & $\mathbb{E}$ & $\mathbb{C}$ & $\mathbb{E}$ & C & C & $\mathbb{E}$ \\
\hline $\begin{array}{l}\text { Desenvolvimento de } \\
\text { Plano de Negócio }\end{array}$ & $\Gamma$ & $\mathbf{E}$ & $\mathbf{C}$ & $E$ & $\mathbf{E}$ & $\mathbf{C}$ & $\mathbb{E}$ & $\mathbf{E}$ & $\mathbf{E}$ & $\mathbf{E}$ & E & E \\
\hline Gestão de Mudanças & $\Gamma$ & $\mathbf{E}$ & $\mathbf{E}$ & C & $\mathrm{C}$ & $\mathrm{C}$ & $\mathbb{E}$ & $\mathbb{E}$ & $\mathrm{C}$ & $\mathbb{C}$ & C & C \\
\hline $\begin{array}{l}\text { Planejamento de } \\
\text { Cenários e Contingências }\end{array}$ & \ulcorner & C & C & E & C & E & $\mathbb{E}$ & $\mathbf{E}$ & $\mathbf{E}$ & $\mathbf{E}$ & $\mathbf{E}$ & E \\
\hline Competencias Essenciais & 5 & C & $\mathbf{C}$ & E & C & C & $\mathbf{E}$ & $\mathbf{C}$ & C & $\mathbf{C}$ & C & C \\
\hline $\begin{array}{l}\text { Códigos de Conduta - } \\
\text { Ética }\end{array}$ & $\Gamma$ & E & $\mathbf{C}$ & C & $\mathbf{E}$ & C & $\mathbf{E}$ & $\mathbf{C}$ & C & $\mathbf{C}$ & C & C \\
\hline $\begin{array}{l}\text { Gerenciamento da } \\
\text { Relação com o Cliente- } \\
\text { CRM }\end{array}$ & $\Gamma$ & C & C & $E$ & C & $\mathrm{E}$ & $\mathbb{E}$ & C & E & $\mathbf{E}$ & C & E \\
\hline $\begin{array}{l}\text { Segmentação da Base de } \\
\text { Clientes }\end{array}$ & $\Gamma$ & E & C & $E$ & C & $\mathrm{E}$ & E & $\mathbf{E}$ & $\mathrm{E}$ & $\mathbf{E}$ & E & $\mathrm{E}$ \\
\hline Pesquisas de Mercado & $\Gamma$ & C & $\mathrm{C}$ & C & C & C & $\mathbb{E}$ & C & C & C & C & C \\
\hline $\begin{array}{l}\text { Analise de Valor } \\
\text { Economico Agregado }\end{array}$ & $\Gamma$ & E & $\mathbf{C}$ & $\mathbb{E}$ & $\mathbf{E}$ & $\mathbf{C}$ & $\mathbf{C}$ & $\mathbf{E}$ & $\mathrm{E}$ & E & C & E \\
\hline Benchmarking & $\Gamma$ & $\mathbf{E}$ & $\mathbf{C}$ & E & $\mathbf{C}$ & $\mathbf{E}$ & $\mathbb{E}$ & $\mathbf{C}$ & $\mathbf{E}$ & $\mathbb{C}$ & $\mathbf{C}$ & E \\
\hline $\begin{array}{l}\text { Estratégias de } \\
\text { Crescimento }\end{array}$ & $\Gamma$ & E & C & $\mathbb{E}$ & $\mathbf{E}$ & $\mathrm{E}$ & $\mathbb{E}$ & $\mathbf{E}$ & E & $\mathbf{C}$ & C & E \\
\hline Gestão do Conhecimento & \ulcorner & $\mathbf{E}$ & $\mathbf{E}$ & E & $\mathbf{C}$ & $\mathbf{E}$ & $\mathbb{E}$ & $\mathbf{E}$ & $\mathbf{E}$ & $\mathbb{C}$ & $\mathbf{C}$ & E \\
\hline Gestão de Marcas & $\Gamma$ & $\mathbf{E}$ & $\mathbf{C}$ & $E$ & $\mathbf{C}$ & $\mathbb{E}$ & $\mathbb{E}$ & $\mathbf{E}$ & $\mathbf{E}$ & $\mathbb{C}$ & $\mathbf{C}$ & E \\
\hline Gestão de Patentes & \ulcorner & $\mathbf{C}$ & C & C & C & C & $\mathbb{E}$ & C & $\mathbf{C}$ & $\mathbf{C}$ & C & C \\
\hline $\begin{array}{l}\text { Definição de Avaliação } \\
\text { de Performance }\end{array}$ & $\Gamma$ & $\mathrm{E}$ & E & E & C & E & $\mathbb{E}$ & E & $\mathbf{E}$ & $\mathbf{E}$ & E & E \\
\hline Painel de Controle & $\Gamma$ & $\mathbf{C}$ & $\mathbf{C}$ & $\mathrm{C}$ & $\mathbf{C}$ & $\mathbf{C}$ & $\mathbb{E}$ & $\mathbf{C}$ & $\mathbf{C}$ & $\mathbf{C}$ & $\mathbf{C}$ & $\mathbf{C}$ \\
\hline Terceirização & $\Gamma$ & $\mathbf{C}$ & C & C & C & C & $\mathbb{E}$ & C & $\mathbf{C}$ & $\mathbf{C}$ & C & $\mathbf{C}$ \\
\hline
\end{tabular}




\begin{tabular}{|c|c|c|c|c|c|c|c|c|c|c|c|c|}
\hline $\begin{array}{l}\text { Remuneração por } \\
\text { Desempenho }\end{array}$ & $\Gamma$ & C & E & $\mathbf{E}$ & C & $\mathbf{C}$ & $\mathbb{E}$ & $\mathbb{C}$ & $\mathbf{E}$ & $\mathbf{E}$ & $\mathbf{E}$ & C \\
\hline Business Inteligence & \ulcorner & $\mathbf{E}$ & E & E & $\mathbb{E}$ & $\mathbf{C}$ & $\mathbb{E}$ & E & $\mathbb{C}$ & $\mathbb{E}$ & $\mathbb{E}$ & $\mathbb{E}$ \\
\hline $\begin{array}{l}\text { Tecnologia da } \\
\text { Informação }\end{array}$ & $\Gamma$ & $\mathbf{C}$ & E & $E$ & C & $\mathrm{E}$ & $\mathbb{E}$ & $\mathbf{E}$ & $\mathrm{E}$ & $\mathbf{E}$ & C & C \\
\hline Alianças Estratégicas & $\Gamma$ & C & $\mathbf{E}$ & E & C & $\mathrm{C}$ & $\mathbb{E}$ & C & $\mathrm{C}$ & C & E & C \\
\hline Planejamento Estratégico & $\Gamma$ & C & C & C & C & C & $\mathbb{E}$ & C & C & C & E & C \\
\hline $\begin{array}{l}\text { Gerenciamento de } \\
\text { Supply Chain }\end{array}$ & $\Gamma$ & E & $\mathbf{C}$ & E & C & C & $\mathbb{E}$ & C & C & $\mathbb{C}$ & C & E \\
\hline $\begin{array}{l}\text { Gestão de Qualidade } \\
\text { Total }\end{array}$ & $\Gamma$ & $\mathrm{C}$ & $\mathrm{C}$ & E & C & $\mathbf{E}$ & $\mathbb{E}$ & C & C & $\mathbb{E}$ & $\mathbf{C}$ & $\mathrm{C}$ \\
\hline Planejamento Financeiro & $\Gamma$ & E & $\mathbf{C}$ & E & E & E & $\mathbf{E}$ & C & C & $\mathbb{E}$ & E & E \\
\hline Missão e Visão & $\Gamma$ & C & $\mathbf{C}$ & E & E & C & $\mathbf{E}$ & C & C & C & E & E \\
\hline $\begin{array}{l}\text { Reengenharia de } \\
\text { Processos }\end{array}$ & $\Gamma$ & E & $\mathrm{C}$ & $E$ & C & C & $\mathbb{E}$ & C & C & $\mathbb{E}$ & E & E \\
\hline $\begin{array}{l}\text { Centro de Serviços } \\
\text { Compartilhado }\end{array}$ & $\Gamma$ & C & $\mathbf{C}$ & $\mathrm{C}$ & $\mathrm{C}$ & C & $\mathbb{E}$ & C & C & $\mathbb{E}$ & E & C \\
\hline Inovação Colaborativa & $\Gamma$ & C & $\mathbf{C}$ & E & C & $\mathbf{C}$ & $\mathbb{E}$ & E & E & $\mathbb{E}$ & E & E \\
\hline $\begin{array}{l}\text { Ferramentas de } \\
\text { Fidelização }\end{array}$ & $\Gamma$ & $\mathbf{C}$ & $\mathbf{E}$ & $E$ & $\mathrm{C}$ & $\mathbf{C}$ & $\mathbb{E}$ & C & $\mathbf{C}$ & $\mathbb{E}$ & E & E \\
\hline Fusões e Aquisições & $\Gamma$ & 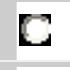 & C & E & $\mathbf{C}$ & $\mathbf{C}$ & $\mathbb{E}$ & 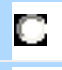 & $\mathbf{C}$ & $\mathbb{E}$ & E & $\boldsymbol{E}$ \\
\hline Seis Sigma & $\Gamma$ & C & C & E & $\mathbf{C}$ & $\mathbf{C}$ & $\mathbb{E}$ & C & $\mathbf{C}$ & $\mathbb{E}$ & E & E \\
\hline Offshoring & $\Gamma$ & C & C & E & $\mathbf{C}$ & $\mathbf{C}$ & $\mathbb{E}$ & C & $\mathbf{C}$ & $\mathbb{E}$ & E & E \\
\hline Balanced Scorecard & $\Gamma$ & $\mathbf{E}$ & C & E & $\mathbf{C}$ & $\mathbf{C}$ & $\mathbb{E}$ & C & C & $\mathbf{E}$ & E & $\boldsymbol{E}$ \\
\hline Outros & $\Gamma$ & $\mathbf{E}$ & E & $E$ & $\mathbf{C}$ & $\mathrm{C}$ & $\mathbb{E}$ & C & $\mathrm{E}$ & $\mathrm{E}$ & $\mathrm{C}$ & $\mathrm{C}$ \\
\hline
\end{tabular}

\section{PARTE III - Tendências em Gestão}

O propósito desta seção é entender as necessidades e prioridades de sua empresa com relação às ferramentas de gestão.

\section{Questão:}

Qual grau de concordância com as afirmações abaixo como descritivas da sua organização e do posicionamento estratégico de negócios.

\footnotetext{
- Concordo Plenamente

- Concordo Relativamente

- Indiferente

- Discordo Relativamente

- Discordo Totalmente
} 
Sinto orgulho do quando a empresa pratica a ética empresarial

Em 2008, estaremos mais focados em crescimento de receita que em redução de custos

Habilidade de adaptação a mudanças é uma vantagem competitiva significativa de nossa empresa

Nós usamos períodos de recessão para melhorar a posição

competitiva de nossa empresa

Inovação é mais importante que preço para o sucesso no longo prazo em nossa indústria

As ações que tomamos em período de crise econômica comprometem nossa performance no longo prazo

C $\mathrm{C} \subset \mathrm{C}$

Avaliamos que a motivação de nossos colaboradores com o projeto de inovação é alta

Aquisições fazem parte do nosso planejamento estratégico

Nossas receitas internacionais crescerão mais rapidamente que

nossas receitas domésticas em 2008

Nosso negócio principal está em turbulência: é possível que tenhamos que reinventar ou mudar nosso foco

Há indicadores que as condições econômicas estão melhorando em

nosso nicho de mercado

Nós cortamos nosso orçamento em pesquisa e desenvolvimento para investir em Tecnologia da Informação

Investimento em Tecnologia da Informação é estratégico para atingir

nossas metas de crescimento

$C \subset \mathbb{C} \mathrm{C}$

$\mathbb{C} \subset \subset \subset$

$\mathbb{C} \subset \mathbb{C} \mathrm{C}$

$\mathbb{C} \subset \subset \subset$

$\mathbb{C} \subset \mathbb{C} \mathrm{C}$

$\mathbb{E} \mathbb{C} \mathrm{C} \mathrm{C}$

Provavelmente precisaremos realizar cortes de pessoal em 2008

Poderíamos incentivar significativamente a inovação através de parcerias com outras empresas

O cuidado com clientes e funcionários deve vir antes do cuidado com

os acionistas

Nossa missão e nossos valores efetivamente dirigem nossas ações

Temos um modelo de desenvolvimento de produto: P\&D

C $\subset \square \square \square$

Gestão da Inovação faz parte de nosso planejamento estratégico

$\subset \subset \subset \subset \square$

$\mathrm{C} \subset \mathrm{CD} \mathrm{C}$

$\mathbb{C} \subset \subset \subset$

$\mathbb{C} \subset \mathbb{C} \mathrm{C}$

C $\mathbb{C E D}$

$C \subset \subset \subset \subset$

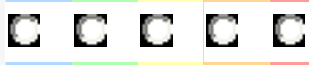

$\mathbb{C} \subset \mathbb{C} \mathrm{C}$

C $\mathbb{C} \subset \mathrm{C}$

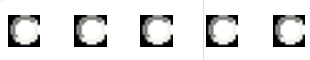

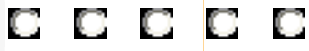

\section{Perfil da Empresa}

Todas as respostas permanecerão completamente confidenciais e serão usadas apenas de forma agregada.

Frisamos que respostas especificas jamais serão associadas a empresas individuais

Favor indicar os dados estatísticos básicos do negócio de sua empresa. 
Dados da Empresa:

*Receita 2007

até $72.000,00$

E E

de $R \$ 72.000,00$ até $R \$$

$500.000,00$

acima de $\mathrm{R} \$ 500.000,00$

*Ativos 2007

até $R \$ 50.000,00$

E C

de $\mathrm{R} \$ 50.000,00 \mathrm{a}$ $450.000,00$

acima de $R \$ 450.000,00$

Questão:

Em qual setor sua empresa está inserida?
E Agronegócio
C Bens de Consumo
C Energia
C Financeiro
C Governo
C Manufatura
C Saúde
C Serviços
E Tecnologia da Informação
C Telecomunicações
C Transporte
C Varejo
C Outros

Questão:

Qual rede de cooperação sua empresa participa:

[ Biotecnologia (Biotecnologia, Nanotecnologia, Químico Veterinário)

E Eletroeletrônico (Eletroeletrônico, Telecomunicações, Material e Componentes, Automação)

C Medicina e Saúde (Medicina, Saúde, Hospitalar, Farmacêutico) 
C Meio Ambiente (Energia, Recursos Hídricos, Agronegócio, Petróleo e Gás)

C TI (TI, Software e e-Learning)

Questões:

Estágio de desenvolvimento:

[ Desenvolvido $\mathbf{E}$ Em desenvolvimento

Sua empresa possui funcionários remunerados?

$\mathbb{E} \operatorname{Sim} \mathbb{E}$ Não

Sua empresa possui sócios remunerados?

[ $\operatorname{Sim} \mathbb{E}$ Não

Sua empresa recebeu suporte de capital?

[ $\operatorname{Sim} \mathbb{E}$ Não

Sua empresa está se preparando para receber investidores?

C $\operatorname{Sim} \mathbf{E}$ Não

Você gostaria de participar de uma discussão de acompanhamento deste assunto:

$\mathbb{E} \operatorname{Sim} \mathbf{E}$ Não

As informações abaixo são opcionais para este questionário

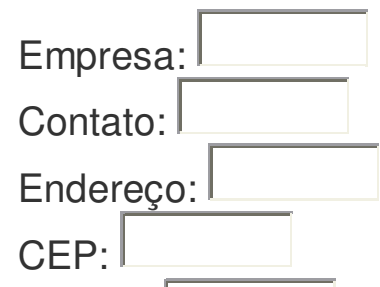

Cidade:

Estado: São Paulo

Telefone:

E-mail:

Enviar 


\section{LISTA DE SIGLAS}

\begin{tabular}{|c|c|}
\hline ANCE & Agência Nacional para Criação de Empresas \\
\hline ANPEI & $\begin{array}{l}\text { Associação Nacional de Pesquisa, Desenvolvimento e Engenharia das } \\
\text { Empresas Inovadoras }\end{array}$ \\
\hline ANVAR & Associação Nacional para Valorização de Pesquisas \\
\hline $\mathrm{B} 2 \mathrm{~B}$ & B2B (Business to Business) \\
\hline B2C & B2C (Business to Consumer) \\
\hline $\mathrm{BRIC}$ & Brasil, Rússia, Índia e China \\
\hline CBCE & Câmara Brasileira de Comércio Eletrônico \\
\hline CGI & Comitê Gestor da Internet no Brasil \\
\hline COEP & Comitê de Entidades no Combate à Fome e pela Vida \\
\hline CRM & Gerenciamento do Relacionamento com Clientes \\
\hline FAPESP & Fundação de Amparo à Pesquisa do Estado de São Paulo \\
\hline FBB & Fundação Banco do Brasil \\
\hline FIESP & Federação das Indústrias do Estado de São Paulo \\
\hline FINEP & Financiadora de Estudos e Projetos \\
\hline FNQ & Fundação Nacional da Qualidade \\
\hline GEM & Global Entrepreneurship Monitor \\
\hline IBGE & Instituto Brasileiro de Geografia e Estatística \\
\hline IBQP & Instituto Brasileiro da Qualidade e Produtividade \\
\hline ISI & Institute for Scientific Information \\
\hline ITCP & Incubadora Tecnológica de Cooperativas Populares \\
\hline ITV & Valor de Transformação Industrial \\
\hline MCT & Ministério de Ciência e Tecnologia \\
\hline MPEs & Micro e Pequenas Empresas \\
\hline OEA & Organização dos Estados Americanos \\
\hline OECD & Organisation for Economic Co-Operation and Development \\
\hline OMPI & Organização Mundial de Propriedade Intelectual \\
\hline ONU & Organização das Nações Unidas \\
\hline$P \& D$ & Pesquisa \& Desenvolvimento \\
\hline PINTEC & Pesquisa de Inovação Tecnológica \\
\hline PNI & Programa Nacional de Incubadoras \\
\hline RFID & Identificação por Radiofreqüência \\
\hline SEBRAE & Serviço de Apoio às Micro e Pequenas Empresas \\
\hline SOFTEX & Sociedade para Promoção da Excelência do Software Brasileiro \\
\hline TCP & Tratado de Cooperação de Patentes \\
\hline TEA & Taxa de Atividade Empreendedora \\
\hline TIC & Tecnologia da Informação e Comunicação \\
\hline UN & United Nations \\
\hline VOIP & Voz sobre o Protocolo Internet \\
\hline WIPO & World Intelectual Property Organisation \\
\hline WSIS & Cúpula Mundial da Sociedade da Informação \\
\hline WSIS & Cúpula Mundial da Sociedade da Informação \\
\hline
\end{tabular}




\section{LISTA DE FIGURAS}

Figura 1

Figura 2

Figura 3

Figura 4

Figura 5

Figura 6

Figura 7

Figura 8

Figura 9

Figura 10

Figura 11

Figura 12

Figura 13

Figura 14

Figura 15

Figura 16

Figura 17

Figura 18

Figura 19

Figura 20

Figura 21

Figura 22

Figura 23

Figura 24

Figura 25

Figura 26

Figura 27
Comparativo (\%) de alguns países, incluindo o Brasil, cujas

Página indústrias implementaram inovações entre 1998 e 2000

Artigos brasileiros publicados em periódicos científicos internacionais indexados no Institute for Scientific Information (ISI) entre 1981 e 2004

Participação percentual comparativa do número de

empresas que implementaram inovações no Brasil entre o triênio 1998-2000 e o triênio 2001-2003

Gestão e inovação (modelo de gestão em três eixos)

Esquema para a inovação: elementos essenciais para a

promoção da competitividade no setor produtivo

A utilização das ferramentas mostra como objetivos e

40

prioridades mudam ao longo do tempo

Taxa de mortalidade das empresas no Estado de São Paulo

59

(rastreamento out/dez 2004)

Comércio eletrônico no Brasil

66

Comércio eletrônico no mundo

66

Fatias de receita por setor das 250 maiores empresas de

TIC (2005)

Dimensões consideradas na pesquisa de campo

70

Perfil das empresas por estágio de desenvolvimento

81

Perfil das empresas por receita auferida em 2007

Perfil das empresas por inserção em redes de cooperação

85

Perfil das empresas por estar aberta ou não a receber suporte $\quad 86$ empresarial

Perfil das empresas em relação à preparação para admitir 86

investidores

Utilização de ferramentas de gestão pelo total de empresas

87

pesquisadas

Porcentagem de empresas em relação ao estágio de

87

desenvolvimento

Utilização de ferramentas por faixa de receita das empresas em

88

2007

EBT

Distribuição de utilização de ferramentas do Estudo no CIETEC de 2003 a 2007

Ferramentas de gestão consideradas somente no Estudo no 90

CIETEC

Distribuição de utilização de ferramentas na Pesquisa Global 90

Comparativo de utilização de ferramentas na Pesquisa no 91

CIETEC e na Pesquisa Global

Utilização de ferramentas nas empresas em estágio inicial 92

de desenvolvimento

Utilização de ferramentas nas empresas em estágio
8 0 4 19 0 9 6

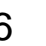

\section{1} 3 
Figura 28

Figura 29

Figura 30

Figura 31

Figura 32

Figura 33

Figura 34

Figura 35

Figura 36

Figura 37

Figura 38

Figura 39

Figura 40

Figura 41

Figura 42

Figura 43

Figura 44

Figura 45

Figura 46

Figura 47

Figura 48

Figura 49

Figura 50

Figura 51 avançado de desenvolvimento

Comparativo de utilização de ferramentas por empresas em

93

estágio inicial e avançado de desenvolvimento

Utilização de ferramentas por empresas do setor de TI no

94

CIETEC (2003/2007)

Utilização de ferramentas por EBT na Pesquisa CIETEC

94

(2003/2007)

Comparativo de utilização de ferramentas por empresas de

95

TI e EBT (2003/2007)

Utilização de ferramentas por empresas com receita em

96

2007 até $R \$ 500.000,00$

Utilização de ferramentas por empresas com receita em $2007 \quad 96$

acima de $\mathrm{R} \$ 500.000,00$

Comparativo de utilização de ferramentas por faixa de

97

receita no Estudo no CIETEC

Satisfação com a utilização de ferramentas (Estudo no 98

CIETEC 2003 a 2007)

Comparativo de satisfação de uso das ferramentas entre o

99

Estudo no CIETEC e o Estudo Global

Comparativo de utilização de ferramentas com satisfação (2003 100 a 2007)

Comparativo de utilização de ferramentas (de 2003 a 2007) 101 com expectativa de utilização em 2008

Comparativo de expectativa de utilização em 2008 com 102

satisfação na utilização de ferramentas

Tendências em gestão nas EBTs do Estudo no CIETEC 103

(grau de concordâncias com as afirmações)

Nível de percepção de práticas de inovação em relação à 104

concorrência

Expectativa de implementação de práticas inovadoras em 104

relação à condição atual

Importância atribuída às práticas inovadoras pela empresa e 105

envolvimento de TI

Investimento de capital e pessoal em práticas inovadoras 105

Expectativa de implementação de soluções de TI para $2008 \quad 106$

Atribuição de prioridade de aprovação para práticas inovadoras 106

de alto valor

Percepção de tendências de gestão em inovação 107

Engajamento da área de Tecnologia da Informação nos 108

negócios da empresa

Governança de Tecnologia da Informação 109

Tendências em Tecnologia da Informação 109

Tendências de investimento em TI

110 


\section{LISTA DE TABELAS}

Tabela 1 Fatores relacionados aos objetivos e efeitos da inovação

Página

Tabela 2 Taxa de Inovação da indústria brasileira (2001-2003)

Tabela 3 Maiores taxas de inovação da indústria brasileira em \% (2001-2003)

Tabela 4 Comparativo do Brasil e alguns países que solicitaram registro de patentes (2000 a 2008)

Tabela $5 \quad$ Vinte maiores empresas que solicitaram pedido de patente com base 23 no número de pedidos publicados internacionalmente em 2007

Tabela 6 Evolução da Taxa de Atividade Empreendedora (TEA) no Brasil 25

Tabela $7 \quad$ Evolução da taxa de empreendedores nascentes e novos no Brasil - 26 2001 a 2006

Tabela 8 Planejamento estratégico é a ferramenta nํ 1 no mundo com exceção da região Ásia-Pacífico

Tabela 9 Como os gestores brasileiros enxergam o futuro

46

Tabela 10 Mudança de paradigmas do estágio anterior para a época da 48 globalização

Tabela 11 Expansão da internet no Brasil e no mundo (jan./1998 e jan./2008) 68 
SUMÁRIO

Página

2 OBJETIVOS

3 FUNDAMENTAÇÃO TEÓRICA E REVISÃO DA LITERATURA 7

3.1 INOVAÇÃO

3.1.1 IMPACTOS DA INOVAÇÃO 10

3.1.1.1 Medidas dos impactos sobre desempenho na empresa 12

3.1.2 INOVAÇÃO INCREMENTAL E INOVAÇÃO RADICAL 17

3.1.3 ADQUIRIR OU PRODUZIR INOVAÇÃO 18

3.1.4 GESTÃO DE INOVAÇÃO E GESTÃO DO CONHECIMENTO 20

3.1.5 PESQUISA E DESENVOLVIMENTO (P\&D) 22

3.1.6 PATENTES 23

3.2 EMPREENDEDORISMO E INCUBADORAS DE BASE TECNOLÓGICA 26

3.2.1 EMPREENDEDORISMO NO MUNDO E NO BRASIL 26

3.2.2 COMPETÊNCIAS 28

3.2.3 INCUBADORAS DE BASE TECNOLÓGICA $\quad 29$

3.2.3.1 O processo de incubação de empresas 31

3.2.3.2 O processo de inovação global 31

3.2.4 CIÊNCIA, TECNOLOGIA E INOVAÇÃO 33

3.2.4.1 Reconhecimento do papel da ciência, tecnologia e inovação (CTI) 35

3.2.4.2 Inovação e competitividade 36

3.3 FERRAMENTAS DE GESTÃO 38

3.3.1 OBJETIVOS DAS PESQUISAS DE FERRAMENTAS DE GESTÃo 39

3.3.2 AS DEZ FERRAMENTAS MAIS USADAS 42

3.3.3. A PESQUISA NO BRASIL - FOCO NO CRESCIMENTO

3.3.4 PRÁTICAS DE GESTÃO 48

$\begin{array}{ll}\text { 3.3.4.1 Cliente } & 49\end{array}$

$\begin{array}{ll}\text { 3.3.4.2 Classe Mundial } & 50\end{array}$

3.3.4.3 Estratégias e planos $\quad 50$

3.3.4.4 Auto-avaliação e gestão de melhorias $\quad 51$

3.3.4.5 Liderança

3.3.4.6 Pessoas $\quad 54$

3.3.4.7 Processos $\quad 55$

3.3.4.7.a Tecnologia e processos $\quad 56$

3.3.4.8 Informação e conhecimento $\quad 57$

3.3.4.9 Cidadania e sustentabilidade $\quad 58$

3.3.5 MICROS E PEQUENAS EMPRESAS $\quad 61$

3.3.5.1 Gestão de pequenas empresas 63

3.4 TECNOLOGIA DA INFORMAÇÃO E COMUNICAÇÃO (TIC) 66

3.4.1 INDICADORES DE TIC 68

3.4.2. INTERNET E COMÉRCIO ELETRÔNICO 69

3.4.3 INTERNET E TIC NO BRASIL E NA OCDE

3.4.4 RISCOS E BENEFÍCIOS DO INVESTIMENTO EM TI

$\begin{array}{ll}\text { 3.4.5 CENÁRIOS DA TIC } & 76\end{array}$ 
4 METODOLOGIA $\quad 79$

4.1 MÉTODO DA PESQUISA $\quad 79$

4.2 O INSTRUMENTO DE PESQUISA $\quad 79$

4.2.1 PESQUISA DE CAMPO FASE I $\quad 80$

4.3 AMOSTRA E ESTRATÉGIA DE COLETA 81

4.3.1 TEORIA E PRÁXIS

5 ANÁLISE E DISCUSSÃO DE RESULTADOS 83

5.1 PERFIL DAS EMPRESAS 83

5.2 UTILIZAÇÃO DE FERRAMENTAS NAS EMPRESAS DO CIETEC

5.3 INOVAÇÃO E MELHORES PRÁTICAS DE TI 104

5.4 CONTRIBUIÇÕES DA PESQUISA 111

6 CONCLUSÃO 117

REFERÊNCIAS BIBLIOGRÁFICAS $\quad 119$

ANEXOS - QUESTIONÁRIOS APLICADOS 132

1 - PESQUISA DE CAMPO FASE I: FERRAMENTAS DE GESTÃO 133

2 - PESQUISA DE CAMPO FASE II: INOVAÇÃO E MELHORES PRÁTICAS DE TI 139 


\section{INTRODUÇÃO}

A incorporação da tecnologia da informação aos modos de produção, a abertura e expansão de exigentes e competitivos mercados e a necessidade vital principalmente das nações emergentes em se adequar à atual conformação mundial vêm transformando em protagonista um novo binômio: inovação e empreendedorismo.

Para o Brasil tirar partido das excelentes condições de crescimento possibilitadas atualmente pela globalização, é condição fundamental o desenvolvimento de instituições fortes e mecanismos modernos que permitam a atualização constante dos modelos de gestão.

A capacidade de gerar conhecimento e transformá-lo em riqueza e desenvolvimento social - metas impostergáveis para a própria sobrevivência dos países - depende da ação de agentes institucionais responsáveis por gerar e aplicar o conhecimento, quais sejam: governo, universidades e empresas.

De praxe, os modelos de política pública no Brasil são propostos por tais agentes. No caso de empresas, parte-se da identificação de um problema e da busca da solução inovadora. A seguir vem a fase de experimentação; e, uma vez bemsucedida a idéia, o empreendedor procurará sistematizá-la e reproduzi-la - ao ganhar escala, a solução inovadora pode vir a tornar-se um modelo.

Inovação é o uso de idéias para otimizar processos ou criar diferenciais em produtos e serviços: ou diminuir custos. Mas não basta apenas ter novas idéias, elas devem ser testadas e ser capazes de agregar valor aos negócios. Com a inovação, as empresas evoluem, lançam novos produtos e melhoram os serviços, abrem mercados e criam barreiras estratégicas. No mundo corporativo, partindo da observação e idealização, a tecnologia chega ao mercado por meio dos modelos de negócios. A cadeia de valores que fornece a metodologia para transmutar idéias em ação nos negócios é chamada de pipeline de inovação. 
Gestão da inovação é a gestão do pipeline da inovação - área multidisciplinar e multifuncional que compreende produção de idéias, pesquisa e desenvolvimento, experimentação, planejamento estratégico, produção em escala, modelos e eficiente administração de negócios, incluindo desenvolvimento organizacional e ações de marketing, para finalmente chegar ao mercado. A gestão da inovação é fundamental no desenvolvimento dos negócios, e o empreendedor é elo-chave no processo: é ele o gestor da inovação.

Para além do desenvolvimento de produtos ou processos de fabricação, a inovação é resultado de melhorias contínuas em ambientes relativamente estáveis. Empresas consolidadas envolvidas em atender à base de clientes, atuando apenas para melhorar os produtos que oferecem, desviam o foco da inovação negligenciando o impacto futuro de tecnologias de ponta e acabam suplantadas pelos novos concorrentes. Pequenas empresas, com capital físico menor e novos modelos de negócio, surgem a todo momento, estabelecendo parcerias para obter acesso a conhecimento complementar, e reformulam a economia dentro de um escopo que antes só podia ser atingido por hierarquias maiores.

A inovação é uma proposta inerentemente arriscada que exige significativos investimentos antecipados em Pesquisa \& Desenvolvimento (P\&D), além do fato de que a aceitação pelo mercado não é garantida. Candidatos a empreendedores com capacidade e domínio de fatores essenciais à elaboração de um plano de negócios que permita maximizar as oportunidades de sucesso constituem a exceção. Todavia, acredita-se ser possível agregar-lhes ferramentas de gestão empresarial e suporte na definição de estratégias para alavancagem do negócio, além de propiciar capital de risco para suportar um processo de crescimento sustentável da nova empresa.

As Incubadoras - entidades que oferecem o terreno fértil necessário para 0 surgimento e crescimento de novas empresas e negócios, gerando emprego, renda e desenvolvendo a cultura empreendedora nas comunidades em que estão inseridas - são como um porto seguro para quem quer empreender. Junto com os Parques Tecnológicos e sempre associadas a universidades, oferecem a estrutura necessária para o desenvolvimento do negócio e estão presentes ao longo do ciclo inicial de vida da empresa. Incubadoras alocam recursos e promovem as parcerias 
fundamentais para se alçar da idéia ao protótipo; e nos Parques Tecnológicos instalam-se empresas maduras, que, por exemplo, já desenvolveram tecnologia e a transformaram em produtos comercializáveis.

Assim, com objetivo de contribuir para orientar o potencial de inovação e empreendedorismo brasileiro, pretendemos neste trabalho identificar ferramentas de gestão que possam auxiliar na determinação dos fatores críticos para o sucesso e expansão da capacidade empreendedora de empresas incubadas de base tecnológica apoiadas pela tecnologia da informação. 


\section{OBJETIVOS}

Os fundamentos deste trabalho seguem duas vertentes.

De espectro abrangente:

- Diante da turbulência dos mercados e do processo de globalização, as empresas, que trafegavam num cenário de relativa estabilidade, mudança progressiva e linearidade, são forçadas a buscar conhecimento para enfrentar os novos desafios.

- As tradicionais escolas de administração precisam oferecer respostas rápidas e eficientes diante da nova ordem mundial e dos desafios da competitividade global. Os gestores lançam mão de novas teorias: as opções são muitas, e a dificuldade de escolher a mais adequada é imensa.

- A geração, a exploração e a difusão do conhecimento passam a ser fundamentais para o crescimento econômico e o desenvolvimento sustentável das nações.

De espectro específico:

- Incubadoras de base tecnológica enfrentam o desafio de desenvolver conhecimentos na área de gestão para superar as dificuldades dos anos iniciais das empresas que abrigam. Os altos investimentos do setor, que sempre envolvem capital de risco, demandam meios de diagnósticos eficientes para obter rápidas respostas diante das dificuldades de competir em um cenário globalizado.

- O Centro Incubador de Empresas Tecnológicas (CIETEC), instalado no campus na Universidade de São Paulo e a ela ligado por estreitos laços de cooperação entre empreendedores e cientistas, abriga 127 empresas responsáveis pelo emprego de 780 profissionais e com faturamento de 33 milhões de reais em 2007. 
- As ferramentas de gestão são uma das respostas ainda em experimentação, que parecem estar trazendo alguma orientação aos gestores das empresas incubadas ao indicar caminhos em busca da excelência operacional e financeira.

\section{Proposições da pesquisa}

O estudo visa identificar, de maneira sistematizada, por meio de aplicação de questionários respondidos pelos empreendedores, quais as dificuldades enfrentadas no período de incubação para que as empresas e as incubadoras tenham subsídios para planejamento e estabelecimento de modelos de gestão.

\section{Contribuições da proposta de investigação}

Identificação das dificuldades das empresas no período de incubação com relação à definição e utilização de ferramentas de gestão objetivando determinador fatores críticos de sucesso. Serão investigadas as preferências na utilização de ferramentas de gestão e feitas aferições para conhecer as que trazem resultados mais positivos e as expectativas de uso de ferramentas no futuro próximo por parte dos administradores.

\section{Objetivos Específicos}

Analisar os instrumentos à disposição da incubadora e das empresas incubadas para a superação das dificuldades nos anos iniciais e propor alternativas para mitigar os efeitos dessas dificuldades no desempenho, com vista à sustentação e perenidade de novas empresas abrigadas na incubadora.

\section{Contribuições no campo teórico}

O estudo contribui no levantamento de novas hipóteses a respeito da dinâmica do uso de ferramentas de gestão por empresas incubadas de base tecnológica. 


\section{Contribuições no campo de pesquisa}

Considerar como base de investigação os resultados de Pesquisa Global e o cruzamento com os resultados da pesquisa no CIETEC.

\section{Contribuições no campo da gestão}

Proposta de alternativa para acompanhamento de empreendimentos a ser utilizada pelas incubadoras de empresas em promover a inovação e a transformação de idéias tecnológicas em negócios bem-sucedidos. 


\section{FUNDAMENTOS TEÓRICOS E REVISÃO DA LITERATURA}

Este capítulo trata de assuntos relacionados ao sistema referencial dos fundamentos teóricos e à revisão da literatura que alicerçam os objetivos desta pesquisa.

Operacionalizado em função da contextualização do estudo proposto, o capítulo enfoca quatro temas: inovação; empreendedorismo e incubadoras de base tecnológica; ferramentas de gestão; e tecnologia da informação e comunicação (TIC).

\subsection{INOVAÇÃO}

Inovação é a implementação de um produto (bem ou serviço) novo ou significativamente melhorado, ou um processo, ou um novo método de marketing, ou um novo método organizacional nas práticas de negócios, na organização do local de trabalho ou nas relações externas (OECD, 2005, p 55).

As atividades de inovação tecnológica são o conjunto de etapas científicas, tecnológicas, organizativas, financeiras e comerciais, incluindo os investimentos em novos conhecimentos, que levam ou que tentam levar à implementação de produtos e de processos novos ou melhorados (MANUAL DE FRASCATI, 2007, p. 27).

A abrangente e moderna definição adotada pela Organisation for Economic CoOperation and Development (OECD) e traduzida no Manual de Oslo engloba o maior número possível de formas de inovação, o que inclui a área de produto, processo, marketing e organização. Entendem-se por atividades de inovação as "etapas científicas, tecnológicas, organizacionais, financeiras e comerciais, que conduzem, ou visam conduzir, à implementação de inovações” (OECD, 2005, p. 56.). Pesquisa e desenvolvimento (P\&D) não diretamente atrelados à inovação também se inserem na definição.

Para Plonski (2006), inovação é a "nova idéia implementada com sucesso produzindo efeitos econômicos ou sociais". De acordo com Morais (2007, p. 4), a inovação tecnológica representa um processo de aprendizagem contínuo e cumulativo das empresas para melhorar produtos/serviços, processos e formas de 
gestão, modelo de interação social, de modo a aumentar a produtividade, conhecimentos e competitividade. É preciso considerar que a inovação não ocorre num vazio e não se limita a uma empresa individualmente; visto que traz implicações políticas, econômicas e sociais, seus efeitos se estendem por toda a rede na qual esteja inserida.

Por outro lado, o mesmo contexto social exerce forte influência na adoção de novas tecnologias interagindo com o meio ambiente, gerando oportunidades e restrições para a inovação. "A inovação é o instrumento específico dos empreendedores, o processo pelo qual eles exploram a mudança como uma oportunidade para um negócio diferente ou um serviço diferente" Morais (2007) apud Drucker (1986).

De acordo com o Manual de Oslo (OECD, 2005, p.36), Schumpeter (1934) propôs cinco tipos de inovação:

1. introdução de novos produtos;

2. introdução de novos métodos de produção;

3. abertura de novos mercados;

4. desenvolvimento de novas fontes de matérias-primas e outros insumos;

5. criação de novas estruturas de mercado em uma indústria.

O Manual de Oslo (OECD, p. 57-60) exemplifica o conceito dos quatro tipos principais de inovação que atualmente compõem a definição utilizada pela OECD.

Inovação de produto - refere-se a bem ou serviço novo ou com melhoramento inquestionável em termos de especificação técnica, componente, material, software agregado, facilidade de utilização ou outras características funcionais. Pode ser a utilização de novas tecnologias e conhecimentos ou a combinação dos já existentes - é o caso dos pioneiros microprocessadores e câmeras digitais. O primeiro MP3 player portátil, por exemplo, combinou padrões de software existentes à tecnologia do disco rígido miniaturizado. Essa inovação pode advir do desenvolvimento de um novo uso para um produto já existente; assim como mudanças em materiais, componentes e outras características que aprimorem o desempenho.

Inovação de processo - introdução de um novo ou melhorado método de produção ou distribuição em técnicas, equipamentos e software, objetivando reduzir custos de 
produção e distribuição. Um exemplo é a utilização de uma ferramenta de gestão que consiste na identificação por radiofreqüência (RFID), tecnologia que utiliza ondas de rádio para identificar objetos e ler dados usada em cartões de acesso e identificação (que veio para substituir o método de leitura do código de barras). Novas ou otimizadas tecnologias de informação e comunicação (TIC) incluem-se no conceito de inovação de processo quando se busca tornar mais eficiente e elevar a qualidade de uma atividade auxiliar.

Inovação de marketing - traz mudanças significativas na concepção de um produto, embalagem, posicionamento, promoção ou fixação de preço, com o objetivo de atender às necessidades do consumidor, ou reposicionando um produto no mercado para vender mais. Inovação em marketing relaciona-se ao método que ainda não tenha sido utilizado pela empresa e envolve mudanças de design, como forma e aparência, desde que não haja alteração nas características funcionais. Entre os exemplos estão os métodos usados para vender bens e serviços, como a implantação de um sistema de franquias, venda direta ou exclusiva e licenciamento do bem ou serviço; ou exposições temáticas para comercialização de móveis ou materiais de construção, que permitem visualizar o ambiente. Veicular a marca em filmes ou programas de televisão, com o endosso de celebridades, ou associar a marca a um time de futebol, por exemplo, são também incluídas neste tópico.

Inovação organizacional - introdução de métodos organizacionais na empresa, local de trabalho ou relações externas que resultem em redução de custos administrativos ou de suprimentos ou que estimulem a satisfação (e a produtividade) no local de trabalho, com o ganho de ativos não negociáveis, como conhecimento externo não codificado. Novas práticas para melhorar o compartilhamento do aprendizado e do conhecimento internamente na empresa, como sistemas de educação e treinamento, assim como gerenciamento da cadeia de fornecedores, reengenharia de negócios e sistemas de controle de qualidade consideram-se inovação organizacional. Igualmente os novos métodos de distribuição de responsabilidades e poder de decisão, com o encorajamento de contribuição de idéias. 


\subsubsection{IMPACTOS DA INOVAÇÃO}

O impacto da inovação no desempenho das empresas varia desde efeitos sobre as vendas e fatia de mercado até mudanças em produtividade e eficiência, como aquisição de conhecimento a partir de inovações na esfera interna e aumento na quantidade de conhecimentos que circulam pelas redes de comunicação.

De acordo com o Manual de Oslo, "os resultados das inovações de produto podem ser medidos pela porcentagem das vendas dos produtos novos ou melhorados. Tratamento similar pode ser utilizado para medir os resultados de outros tipos de inovações" (OECD, p. 26). Indicadores adicionais dos resultados da inovação podem ser obtidos por meio de questões qualitativas sobre os efeitos das inovações.

Para Sbragia (2006, p.39), "no atual quadro econômico, marcado pela alta competitividade, qualidade dos produtos e concorrência acirrada, cada vez mais o êxito empresarial depende da capacidade de a empresa inovar tecnologicamente, colocando novos produtos no mercado, a um preço menor, com uma qualidade melhor e a uma velocidade maior do que seus concorrentes". A Figura 1 apresenta a comparação de alguns países, incluindo o Brasil, cujas indústrias implementaram inovações entre 1998 e 2000.

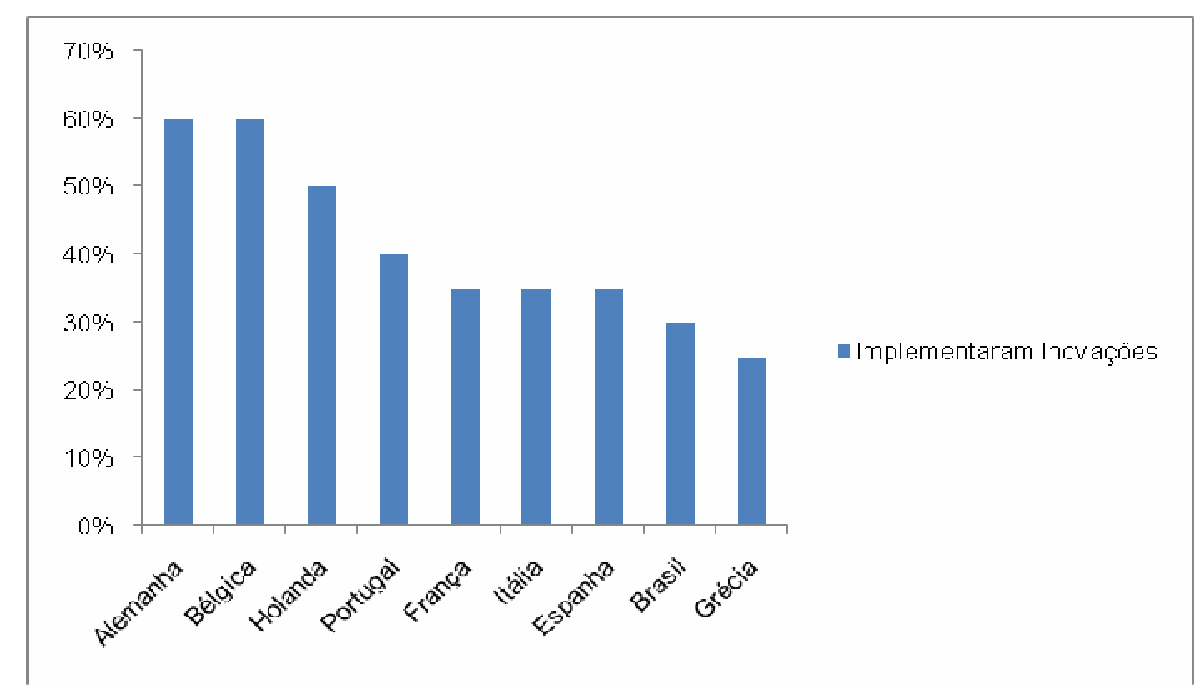

Figura 1 - Comparativo (\%) de alguns países, incluindo o Brasil, cujas indústrias implementaram inovações entre 1998 e 2000. Fonte: Sbragia (2006, p. 29) 
A falta de investimentos em inovação dentro das empresas brasileiras diminui a competitividade internacionalmente: “(...) a pauta de exportações brasileiras é composta principalmente por produtos primários, deixando o país em posição inferior à média mundial em relação aos produtos de alto conteúdo tecnológico" (SBRAGIA, 2006, p. 29).

"O mais grave é que as inovações continuam concentradas em poucos segmentos, cuja intensidade tecnológica é alta por sua própria natureza, e dependem cada vez mais de conhecimento do exterior" (Idem, p. 30).

Para o Ministério de Ciência e Tecnologia (BRASIL, 2006, p. 11), na área de biotecnologia "o Brasil possui inegáveis vantagens comparativas, devido à invejável biodiversidade", com inovações na “vegetalização" de cosméticos, desenvolvimento de medicamentos a partir da flora amazônica, criação comercial de peixes nativos, produção de biodiesel; assim como na área de organismos vivos, com o desenvolvimento de implantes de pele ou processos de produção de proteínas por DNA recombinante.

De acordo com o relatório do MCT Brasil Inovador, o país, "desde 1990, triplicou o número de cientistas nas instituições de pesquisa. Multiplicou-se o total de novos doutores formados anualmente no país. O Brasil dispõe de quase 3.000 cursos reconhecidos de pós-graduação, que em 2004 formaram 27.000 mestres e 8.000 doutores" (2006, p. 26).

De acordo com a Associação Nacional de Pesquisa, Desenvolvimento e Engenharia das Empresas Inovadoras (ANPEI), o Plano de Ação de Ciência, Tecnologia e Inovação para o Desenvolvimento Nacional apresentado em novembro de 2007 prevê o aporte de recursos federais para inovação nas empresas da ordem de 21,5 bilhões de reais, a ser aplicados até 2010 e organizado em quatro "prioridades estratégicas": expansão e consolidação do sistema de ciência e tecnologia; implementação da inovação tecnológica nas empresas; pesquisa e desenvolvimento em áreas estratégicas; e ciência, tecnologia e inovação para o desenvolvimento social (ENGENHAR, 2007, p. 3). 
A Figura 2, a partir de dados na base do Institute for Scientific Information (ISI), indica uma medida estimada da atividade científica do país.

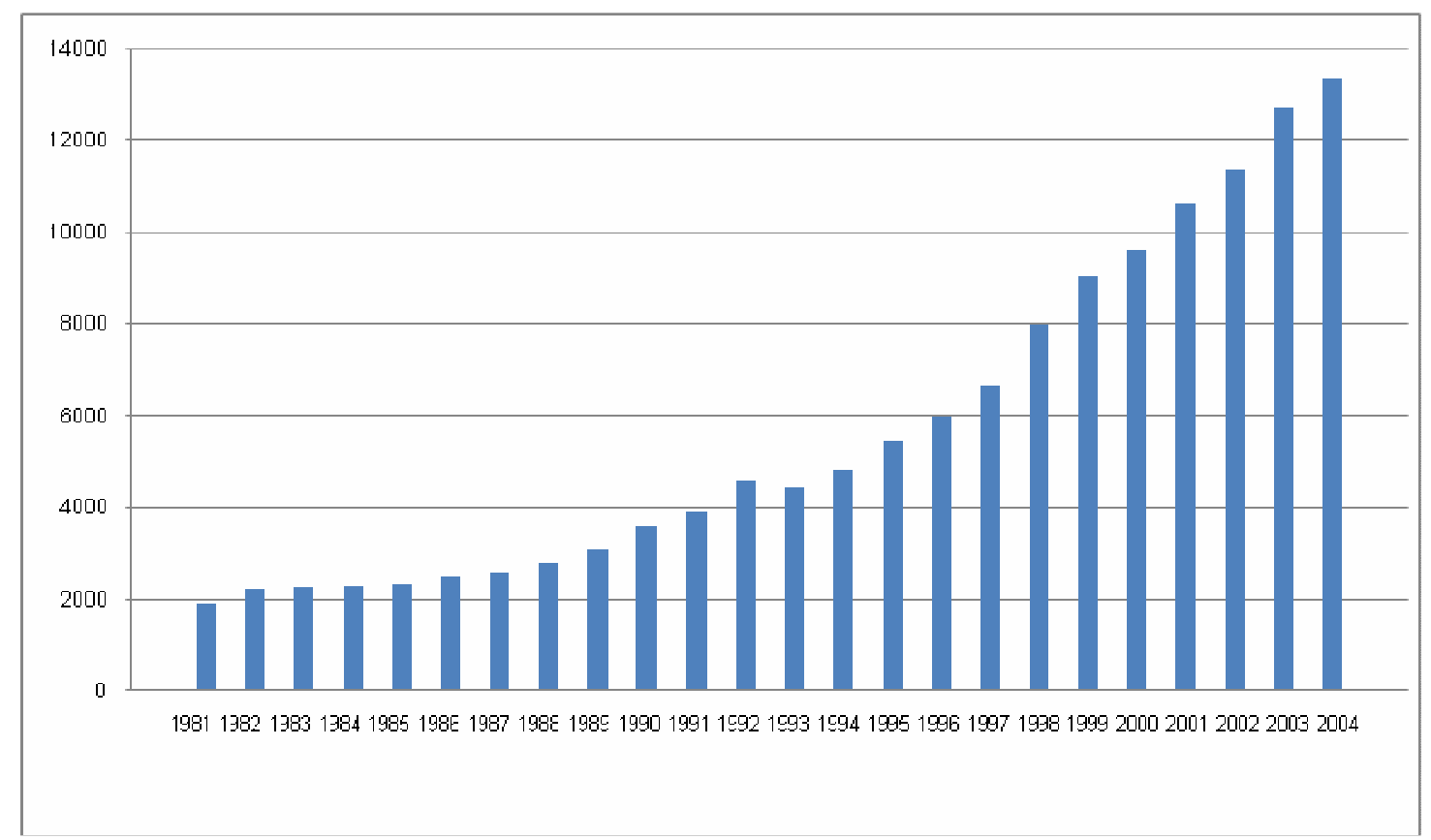

Figura 2 - Artigos brasileiros publicados em periódicos científicos internacionais indexados no Institute for Scientific Information (ISI) entre 1981 e 2004

Fonte: BRASIL (MCT, 2008)

\subsubsection{Medidas dos impactos sobre desempenho na empresa}

O sucesso de uma inovação pode depender de diversos fatores, entre eles a qualidade da inovação. O impacto das inovações pode também variar de setor para setor ou de região para região e de mudanças na empresa que favoreçam as inovações, como iniciativas de marketing para lançar um produto ou mudanças organizacionais para tirar vantagem de novos processos. Um exemplo é o impacto dos investimentos em tecnologia da informação e comunicação (TIC) sobre a produtividade empresarial (OECD, 2006, p. 123).

A Tabela 1 apresenta a relação entre os tipos de inovação e os objetivos da organização. 
Tabela 1 - Fatores relacionados aos objetivos e efeitos da inovação

\begin{tabular}{|c|c|c|c|c|}
\hline $\begin{array}{l}\text { Relevante para: } \\
\text { Competicão demanda e mercados }\end{array}$ & $\begin{array}{l}\text { Inovações } \\
\text { de produto }\end{array}$ & $\begin{array}{l}\text { Inovações } \\
\text { de processo }\end{array}$ & $\begin{array}{c}\text { Inovações } \\
\text { organizacionais }\end{array}$ & $\begin{array}{l}\text { Inovações } \\
\text { de marketing }\end{array}$ \\
\hline Competição, demanda e mercados & * & & & \\
\hline Aumento da gama de bens e serviços & * & & & \\
\hline Desenvolvimento de produtos não agressivos ao meio ambiente & * & & & \\
\hline Aumento ou manutenção da parcela de mercado & * & & & * \\
\hline Entrada em novos mercados & * & & & * \\
\hline Aumento da visibilidade ou da exposição dos produtos & & & & * \\
\hline Tempo reduzido de resposta às necessidades dos consumidores & & * & * & \\
\hline \multicolumn{5}{|l|}{ Produção e distribuição } \\
\hline Aumento da qualidade dos bens e serviços & * & * & * & \\
\hline Aumento da flexibilidade de produção ou provisão de serviços & & * & * & \\
\hline Aumento da capacidade de produção ou de provisão de serviços & & * & * & \\
\hline Redução dos custos unitários de produção & & * & * & \\
\hline Redução do consumo de materiais e energia & * & * & * & \\
\hline Redução dos custos de concepção dos produtos & & * & * & \\
\hline Redução dos tempos de produção & & * & * & \\
\hline Obtenção dos padrões técnicos industriais & * & * & * & \\
\hline Redução dos custos operacionais para a provisão de serviços & & * & * & \\
\hline $\begin{array}{l}\text { Aumento da eficiência ou da velocidade do } \\
\text { fornecimento e/ou distribuição de bens ou serviços }\end{array}$ & & * & * & \\
\hline Melhoria das capacitações de TI & & * & * & \\
\hline \multicolumn{5}{|l|}{ Organização do local de trabalho } \\
\hline $\begin{array}{l}\text { Melhoria da comunicação e da interação entre } \\
\text { as diferentes atividades de negócios }\end{array}$ & & & * & \\
\hline $\begin{array}{l}\text { Melhoria do compartilhamento e da transferência } \\
\text { de conhecimentos com outras organizações }\end{array}$ & & & * & \\
\hline $\begin{array}{l}\text { Melhoria da capacidade de adaptação } \\
\text { às diferentes demandas dos clientes }\end{array}$ & & & * & * \\
\hline Desenvolvimento de relações fortes com os consumidores & & & * & * \\
\hline Melhoria das condições de trabalho & & * & * & \\
\hline \multicolumn{5}{|l|}{ Outros } \\
\hline $\begin{array}{l}\text { Redução de impactos ambientais } \\
\text { ou melhoria da saúde e da segurança }\end{array}$ & * & * & * & \\
\hline Execução de exigências regulatórias & * & * & * & \\
\hline
\end{tabular}

Fonte: Manual de Oslo (OCDE, 2006, p. 124)

A Tabela 2, a seguir, apresenta uma síntese das taxas de inovação na indústria brasileira no período 2001-2003, considerando o universo de empresas com dez ou mais pessoas.

Tabela 2 - Taxa de Inovação da indústria brasileira (2001-2003)

\begin{tabular}{|l|l|l|l|}
\hline & Indústria Total & Indústria Extrativa & Indústria de Transformação \\
\hline № empresas industriais & 84.262 & 1.888 & 82.374 \\
\hline № empresas inovativas & 28.036 & 415 & 27.621 \\
\hline Taxa de inovação & $33,3 \%$ & $22,0 \%$ & $33,5 \%$ \\
\hline Taxa de inovação de produto & $20,3 \%$ & $6,3 \%$ & $20,7 \%$ \\
\hline Taxa de inovação de processo & $26,9 \%$ & $20,3 \%$ & $27,0 \%$ \\
\hline $\begin{array}{l}\text { Taxa de inovação de produto } \\
\text { para o mercado interno }\end{array}$ & $2,7 \%$ & $0,5 \%$ & $2,8 \%$ \\
\hline $\begin{array}{l}\text { Taxa de inovação de processos } \\
\text { para o mercado interno }\end{array}$ & $1,2 \%$ & $0,5 \%$ & $1,2 \%$ \\
\hline
\end{tabular}

Fonte: Anpei apud IBGE (Pintec 2003). 
$\mathrm{Na}$ Tabela 2, a taxa de inovação de processo maior do que a taxa de inovação de produto provavelmente reflete preocupação com redução de custo e com eficiência produtiva associadas às inovações de processo, característica estrutural da indústria brasileira. Todavia, quando o foco é o mercado interno, a taxa de inovação de produto é maior do que a taxa de inovação de processo.

O dinamismo no lançamento de novos produtos para o mercado interno é mais que o dobro do associado ao lançamento de novos processos de produção para o mercado interno (ARRUDA, 2006). Isso porque, em geral, inovações de processo ocorrem basicamente pela incorporação de máquinas e equipamentos já existentes no mercado interno, o que configura um processo de modernização de planta produtiva.

O que o Brasil vem realizando, dado o ambiente macroeconômico pouco favorável ao investimento produtivo, influenciado pelas altas taxas de juros, é a modernização da estrutura industrial, na busca de maior eficiência produtiva e de menores custos de produção. Investimentos mais ambiciosos em novos processos para o mercado interno exigiriam maiores investimentos em capital fixo. Assim, evidenciam-se os impactos do ajuste macroeconômico brasileiro sobre a estrutura industrial.

Se essa trajetória permanecer no longo prazo, o Brasil tenderá a ficar cada vez mais defasado internacionalmente em termos de estrutura produtiva e competitividade, o que poderá limitar o processo de crescimento econômico e geração de renda.

Em relação às inovações de produto para o mercado interno, o percentual de 2,7\%, embora bastante superior às inovações de processo para o mercado interno, revela dinamismo pouco alentador.

Viotti e Macedo (2003) mostram que no período de 1998 a 2000, economias como Alemanha e Itália detinham taxa de inovação de produto para o mercado interno da ordem de 22\%; e na Espanha o percentual era de $12 \%$.

A Tabela 3 apresenta o detalhamento da taxa de inovação por atividade industrial. 
Tabela 3 - Maiores taxas de inovação da indústria brasileira em \% (2001-2003)

\begin{tabular}{|c|c|c|c|}
\hline Atividade industrial & $\begin{array}{c}\text { Taxa de } \\
\text { inovação geral }\end{array}$ & $\begin{array}{c}\text { Taxa de inovação } \\
\text { em produto }\end{array}$ & $\begin{array}{c}\text { Taxa de inovação } \\
\text { em processo }\end{array}$ \\
\hline Fabricação de caminhões e ônibus & 72,5 & 72,5 & 54,9 \\
\hline $\begin{array}{l}\text { Fabricação de máquinas para escritório, } \\
\text { máquinas e equipamentos de informática }\end{array}$ & 71,2 & 70,4 & 47,1 \\
\hline $\begin{array}{l}\text { Fabricação de geradores, transformadores e } \\
\text { motores elétricos }\end{array}$ & 69,2 & 35,0 & 53,1 \\
\hline Fabricação de defensivos agrícolas & 66,9 & 66,9 & 55,7 \\
\hline $\begin{array}{l}\text { Fabricação de aparelhos e instrumentos de } \\
\text { medida, teste e controle }\end{array}$ & 64,3 & 54,6 & 31,7 \\
\hline Fabricação de material eletrônico básico & 61,7 & 43,3 & 44,1 \\
\hline $\begin{array}{l}\text { Fabricação de tratores, máquinas, e } \\
\text { equipamentos para a agricultura, avicultura e } \\
\text { obtenção de produtos animais }\end{array}$ & 60,5 & 46,2 & 46,8 \\
\hline Fabricação de máquinas-ferramentas & 59,7 & 16,8 & 51,2 \\
\hline $\begin{array}{l}\text { Fabricação de tintas, vernizes, esmaltes e } \\
\text { lacas }\end{array}$ & 59,0 & 41,2 & 44,6 \\
\hline Fabricação de tubos & 56,6 & 25,4 & 47,5 \\
\hline $\begin{array}{l}\text { Fabricação de aparelhos e instrumentos } \\
\text { para uso médico-hospitalar }\end{array}$ & 55,2 & 51,3 & 22,9 \\
\hline $\begin{array}{l}\text { Fabricação de aparelhos receptores de rádio e } \\
\text { televisão e de reprodução, gravação e } \\
\text { amplificação de som e vídeo }\end{array}$ & 53,1 & 42,3 & 27,7 \\
\hline $\begin{array}{l}\text { Fabricação de automóveis, camionetas e } \\
\text { utilitários }\end{array}$ & 51,5 & 47,4 & 44,1 \\
\hline $\begin{array}{l}\text { Fabricação, manutenção e reparação de } \\
\text { aparelhos e equipamentos de telefonia, rádio, } \\
\text { radiotelefonia, e transmissores de televisão }\end{array}$ & 50,6 & 46,4 & 28,5 \\
\hline Fabricação de produtos farmacêuticos & 50,4 & 35,4 & 36,0 \\
\hline Fabricação de produtos químicos inorgânicos & 49,9 & 40,1 & 32,4 \\
\hline Fabricação de cimento & 49,4 & 32,3 & 49,4 \\
\hline $\begin{array}{l}\text { Fabricação de resinas, elastômeros, fibras, } \\
\text { fios, cabos e filamentos }\end{array}$ & 47,8 & 33,0 & 32,0 \\
\hline $\begin{array}{l}\text { Fabricação de cronômetros e relógios } \\
\text { e manutenção e reparação de equipamentos } \\
\text { médico-hospitalares, instrumentos de precisão } \\
\text { e ópticos e automação industrial }\end{array}$ & 45,2 & 8,4 & 41,0 \\
\hline $\begin{array}{l}\text { Fabricação de peças e acessórios para } \\
\text { veículos automotores }\end{array}$ & 45,2 & 25,5 & 42,9 \\
\hline
\end{tabular}

Fonte: Anpei (2006) apud IBGE (Pintec 2003, p. 13).

Independentemente de se tratar de inovação para a empresa ou para o mercado interno, entre 2001 e 2003, o percentual das empresas industriais brasileiras que realizaram pelo menos uma inovação de produto e pelo menos uma inovação de processo foi de apenas $14 \%$ - tendo como base de comparação informações da Tabela 3 (Pintec 2003), pode-se dizer que é pequeno o número de empresas que realizaram ambos os tipos de inovação no mesmo período. 
De acordo com a Pesquisa de Inovação Tecnológica (Pintec, 2003) do IBGE, em 2000, havia 72.000 empresas industriais com dez ou mais pessoas ocupadas; em 2003, já eram 84.300. Por outro lado, o número de empresas que implementou produto e/ou processo tecnologicamente novo ou substancialmente aprimorado aumentou de 22.700 para 28.000 , num ritmo superior ao do universo pesquisado, 0 que fez a taxa de inovação elevar-se para 33,3\% no triênio 2001-2003.

A Figura 3 revela que houve mudança na composição da taxa de inovação. Se entre 1998 e 2000 predominava a orientação de inovar só em processo, entre 2001 e 2003 as empresas adotaram a estratégia de inovar em produto e processo.

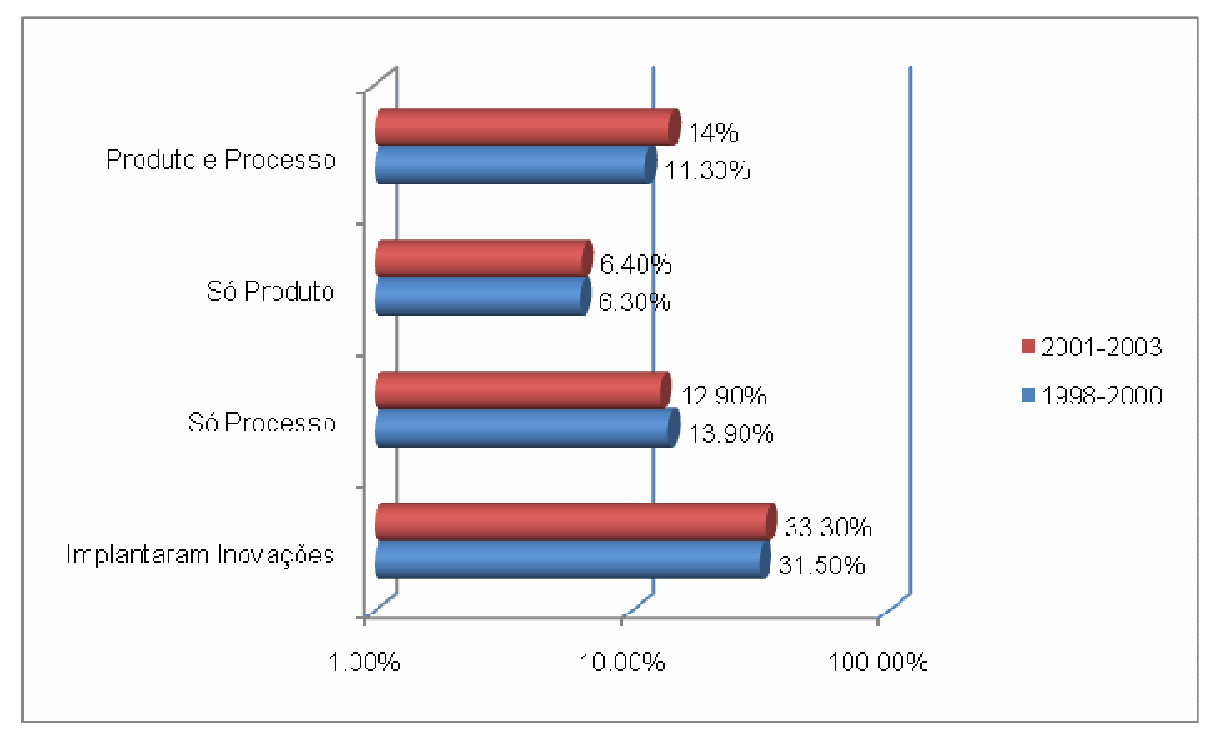

Figura 3 - Participação percentual comparativa do número de empresas que implementaram inovações no Brasil entre o triênio 1998-2000 e o triênio 2001-2003.

Fonte: IBGE (Pintec, 2003)

Somando os resultados das 11.800 empresas que inovaram concomitantemente produto e processo com os das que inovaram apenas em produto ou processo, obtém-se taxa de inovação para produto de $20,3 \%$ e para processo de $26,9 \%$.

Este último tipo de inovação permaneceu sendo o mais desenvolvido, entretanto o crescimento relativo mais significativo ocorreu particularmente na inovação de produtos novos para a empresa, que avançou 3,7 pontos percentuais. Por outro lado, as inovações para o mercado nacional apresentaram queda (IBGE, 2003, p. 32-33). 


\subsubsection{INOVAÇÃO INCREMENTAL E INOVAÇÃO RADICAL}

A opção das indústrias pela inovação incremental ou pela inovação radical cria um dilema que, se mal superado, pode levar empresas ao fracasso. Inovação incremental é, por exemplo, a reformulação na estrutura do produto, como a maioria das mudanças tecnológicas na indústria do disk drive (como a preferência pela tecnologia de cabeça leitora e do disco em película fina ou a opção de polir as tradicionais cabeça de ferrite), que tem mantido ou reforçado trajetórias estabelecidas de melhoria de desempenho (CHRISTENSEN, 2001, p. 10). Inovação radical exige competências tecnológicas muito diferentes. A magnitude da mudança tecnológica em relação à capacidade da empresa determinará quem triunfará após uma tecnologia invadir uma indústria.

"Os estudiosos que apóiam esse ponto de vista descobrem que as empresas estabelecidas tendem a ser boas na melhoria do que elas vêm realizando bem durante longo tempo, e que as empresas emergentes parecem adequadas para explorar radicalmente as novas tecnologias" (CHRISTENSEN, 2001, p. 34). "As inovações incrementais são introduzidas continuamente na produção como resultado da formação tecnológica (...). As inovações radicais são compreendidas nas tecnologias de ponta" (REIS, 2004, p. 49).

Christensen cita o exemplo americano da indústria da escavadeira mecânica, inicialmente movida por motor a vapor, com polias, cilindros e cabos; até que uma revolução tecnológica maior introduziu o motor movido a gasolina. Apesar da mudança radical, a tecnologia da gasolina teve impacto incremental na indústria da escavadeira mecânica.

Surgiu então o sistema articulado acionado hidraulicamente, inovação de ruptura que substituiu os cabos: apenas quatro dos trinta fabricantes estabelecidos obtiveram êxito - a maioria faliu (CHRISTENSEN, 2001, p. 65-81). O autor entende que o que saiu errado nas empresas que produziam escavadeiras a cabo foi deixar de investir em máquinas hidráulicas e não inserir parte da organização num esforço de atender à demanda destas por pequena que fosse. 
"Os padrões do sucesso e do fracasso que observamos entre as empresas que se depararam com a mudança de tecnologia incremental e de ruptura são o resultado natural ou sistemático de boas decisões administrativas" (CHRISTENSEN, 2001, p. 77).

\subsubsection{AdQUIRIR OU PRODUZIR INOVAÇÃO}

Devido à dificuldade de manter um centro de $P \& D$, as empresas se vêem diante da decisão estratégica de comprar ou fazer tecnologia. Para Sbragia (2006) apud Patel e Pavitt (1995), os dados coletados pela OECD mostram que países com P\&D de alta qualidade compram tecnologia de outras nações - Inglaterra, Itália e França, por exemplo, investem em tecnologia externa entre $20 \%$ e $25 \%$ do dispêndio total em P\&D.

Mas a idéia de que países em desenvolvimento devem explorar a tecnologia já desenvolvida por países industrializados pode ser equivocada, pois inovar requer esforço da mesma forma que importar tecnologia, e P\&D não só gera inovação como desenvolve a habilidade de identificar e explorar o conhecimento do ambiente.

"Possuir uma equipe interna de P\&D não somente é importante para uma melhor adaptação da tecnologia comprada (...) como a compra da tecnologia também auxilia o esforço interno de P\&D" (SBRAGIA, 2006, p. 56).

Para o autor, no caso brasileiro, as empresas ou adquirem tecnologia ou isoladamente desenvolvem inovação internamente, o que sugere disfunção no sistema de inovação, pois em países do leste asiático a importação de tecnologia é complementada com enorme esforço para desenvolver capacitações locais.

Mas isso é algo que vem mudando, pois, de acordo com dados da Pintec (IBGE, 2003), universidades e institutos de pesquisa obtiveram crescimento relativo de $16 \%$ em termos de alta e média importância dos parceiros das relações de cooperação no período 1998-2000 (25,6\%) em comparação a 2001-2003 (29,7\%).

Ao responder sobre a alta e média importância dada a empresas ou instituições com as quais realizaram cooperação, "as empresas identificaram como seus parceiros privilegiados os fornecedores $(55,6 \%)$ e os clientes ou consumidores 
$(42,4 \%)$, demonstrando a relevância de seus relacionamentos interindustriais" (IBGE, Pintec, 2003).

A opção de organização em redes para minimizar custos de P\&D intensifica a negociação entre universidade, empresa e governo. Assim, a pesquisa de alto custo, que é majoritariamente financiada pelo setor público, recebe aporte direto e indireto de recursos privados por meio de contratação de pesquisas, acordos cooperativos, consórcios, mecanismos de transferência de tecnologia e outras formas de alianças estratégicas (SBRAGIA, 2006, p. 59).

Há também o consenso entre especialistas e empresários de que o Estado brasileiro precisa não apenas investir mais dinheiro, mas sobretudo criar políticas capazes de estimular a inovação dentro das empresas para avançar em três frentes: a primeira é alocar recursos destinados à inovação diretamente nas empresas; a segunda visa estimular universidades e centros de pesquisa a desempenhar o papel de ajudar as empresas a produzir inovação; a terceira é a participação estatal em sociedade com empresas privadas voltada a propósitos específicos, como políticas de encomendas tecnológicas (BRASIL, MCT, 2006, p. 33).

Além de P\&D, as empresas podem adquirir tecnologia e conhecimento de diversas formas e de várias fontes juntamente com o desenvolvimento e a implementação de inovações. Isso também inclui aquisições originárias de unidades estrangeiras de multinacionais.

A aquisição de conhecimento e tecnologia externa pode assumir a forma de patentes, invenções não patenteadas, licenças, divulgação de conhecimentos, marcas registradas, desenho industrial (design) e padrões (OECD, 2005, p. 106).

A recomendação de Sbragia (2006, p. 61) é que as empresas tanto comprem tecnologia como mantenham uma equipe de $\mathrm{P} \& \mathrm{D}$, ou, se não puderem arcar com os custos, devem optar por compor arranjos corporativos com outras empresas, institutos de pesquisa ou organização em rede. 


\subsubsection{Gestão de InOVAÇÃo e GestÃo do CONHECIMENTO}

Na história da industrialização, é partindo do âmbito das idéias e observações que se passa à experimentação, depois ao desenvolvimento tecnológico para alcançar o mercado via modelo de negócios. Gestão da inovação é a gestão da cadeia de valores que envolve idéias, modelos de negócio e mercado.

Com base nas definições da OECD, inovações do tipo organizacionais podem envolver a implementação de mudanças significativas nas práticas de gestão do conhecimento, e algumas informações sobre a gestão do conhecimento podem ser obtidas a partir das questões sobre a inovação organizacional.

De acordo com o Manual de Oslo (OECD, 2005, p. 100), gestão do conhecimento envolve aquisição, utilização e compartilhamento de conhecimentos. Trata-se de administrar interações externas e fluxos de conhecimento, incluindo métodos e procedimentos de busca de conhecimento externo e estabelecimento de relacionamentos mais estreitos com empresas (fornecedores, concorrentes), consumidores ou instituições de pesquisa.

São práticas de gestão do conhecimento políticas e estratégias, liderança, captura de conhecimento, treinamentos e comunicações. A gestão do conhecimento envolve práticas de aquisição de conhecimentos externos e interação com outras empresas e de compartilhamento e utilização do conhecimento no interior da empresa. Para o Manual de Oslo, as práticas de gestão do conhecimento voltadas para a melhoria do fluxo interno e do uso das informações incluem (OECD, 2005, p. 101):

- bases de dados sobre as "melhores práticas";

- educação regular ou programas de treinamento;

- grupos de trabalho formais e informais para promover a comunicação entre os trabalhadores e sua interação;

- atividades de integração entre empregados de diferentes áreas.

Reis (2004, p. 61) afirma que "o processo de inovação não pode ser representado por uma seqüência linear de eventos, a partir apenas de um único fator". 
Trata-se de um processo que ocorre de forma interativa, que envolve múltiplas relações e aspectos, como domínio de conhecimento; necessidades sociais; procura pelo mercado; apoio governamental; disponibilidade de capital; serviços de apoio como marketing e desenho industrial (design) entre outros.

"As decisões sobre como usar e trocar os conhecimentos existentes e como obter novos conhecimentos são fundamentais para a operação das empresas. Assim, os sistemas adequados à gestão do conhecimento podem melhorar a competitividade $\mathrm{e}$ a capacidade inovadora" (OECD, 2005, p. 100).

Ceballos (2005) propõe um modelo de gestão e inovação em três eixos: ambiente organizacional; inovação e ação. O modelo de inovação proposto permite estruturar estratégias e indicadores de inovação e então inseri-los na gestão de uma organização ou de uma sociedade.

O modelo na Figura 4 acrescenta aos dois eixos usuais nas estruturas matriciais um terceiro, para a gestão da inovação, tornando-se um modelo em três eixos - do ambiente organizacional, da ação e da inovação.

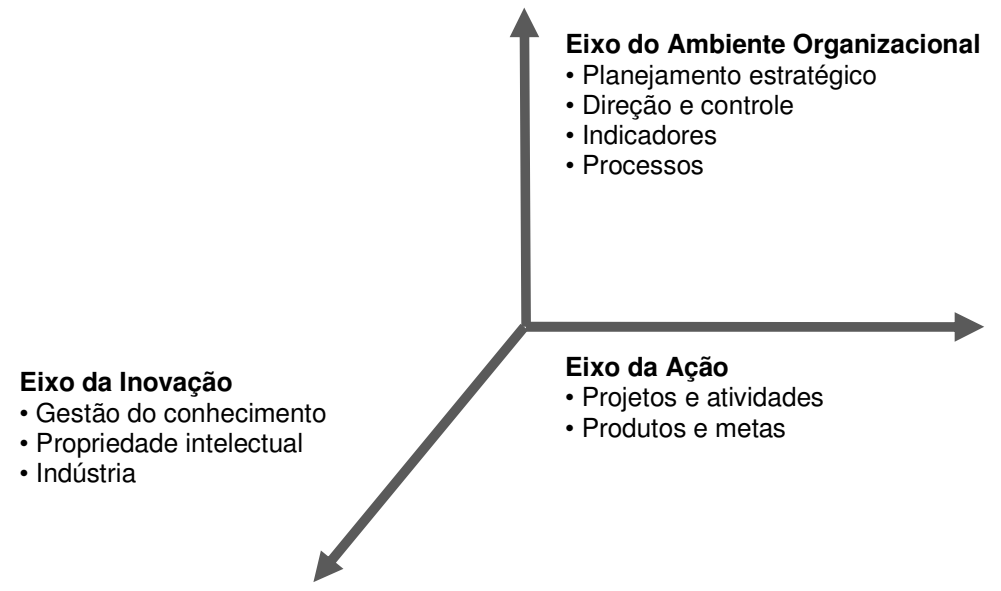

Figura 4 - Gestão e inovação (modelo de gestão em três eixos). Fonte: CEBALLOS (2005)

"A principal conclusão é que a gestão da inovação tecnológica precisa ser inserida como uma das dimensões dos modelos de planejamento e gestão das organizações ou dos Estados" (CEBALHOS, 2005). 


\subsubsection{Pesquisa e DesenVolvimento (P\&D)}

"As atividades de inovação tecnológica são o conjunto de etapas científicas, tecnológicas, organizacionais, financeiras e comerciais, incluindo os investimentos em novos conhecimentos, que levam ou que tentam levar à implementação de produtos e de processos novos ou melhorados. P\&D não é mais do que uma destas atividades e pode ser desenvolvida em diferentes fases do processo de inovação, não sendo utilizada apenas enquanto fonte de idéias criativas, mas também para resolver os problemas que podem surgir em qualquer fase até a sua implementação" (Manual de Frascati, OECD, 2007, p. 27).

"A investigação e o desenvolvimento experimental incluem o trabalho criativo levado a cabo de forma sistemática para aumentar o campo dos conhecimentos, incluindo o conhecimento do homem, da cultura e da sociedade, e a utilização desses conhecimentos para criar novas aplicações" (OECD, 2007c, p. 43).

P\&D é apenas uma etapa no processo de inovação. A inovação envolve várias atividades não incluídas em P\&D, tais como a fase final de desenvolvimento para a pré-produção; produção e distribuição; atividades de desenvolvimento com menor grau de novidade; atividades de suporte como treinamento e preparação de mercado para inovações de produto; desenvolvimento e implementação de atividades para novos métodos de marketing ou organizacionais. Além disso, para o Manual de Oslo, empresas podem possuir atividades de inovação que não envolvem P\&D (OECD, 2005, p. 104).

A realização de atividades de $P \& D$ descritas exige a captação de fundos, e o projeto e o financiamento têm de ser geridos. Atividades de financiamento de P\&D por organismos tais como Ministério da Ciência e Tecnologia ou Conselho de Pesquisa não constituem propriamente P\&D de acordo com Frascati (OECD, 2007e, p. 28).

No desenvolvimento de software, por exemplo, segundo o Manual de Frascati: "Uma atualização, adição ou mudança em um programa existente ou sistema pode ser classificado como P\&D se incorpora avanços científicos e/ou tecnológicos que resultem em aumento de conhecimento. O uso de um software para uma aplicação nova ou propósito não constitui por si só um avanço" (OECD, 2007e, p. 65). 
Por outro lado, pode-se conseguir avanço científico ou tecnológico em desenvolvimento de software mesmo quando o projeto não tenha êxito, porque um fracasso pode trazer maior conhecimento sobre a tecnologia do software ao mostrar, por exemplo, que mediante determinada abordagem não se podem conseguir os resultados satisfatórios esperados (OECD, 2007e, p. 65).

De acordo com o Manual de Frascati (OECD, 2007e, p. 66), atividades de informática de rotina que não implicam avanço científico ou técnico ou não resolvam incertezas tecnológicas não devem ser consideradas como P\&D. Vejamos alguns exemplos de atividades de informática não consideradas P\&D:

- software de aplicação comercial e desenvolvimento de sistemas de informação que utilizem métodos conhecidos e ferramentas de informática já existentes;

- manutenção de sistemas existentes;

- conversão ou tradução de linguagem de computador;

- adição de funções para o usuário em aplicações de informática;

- depuração de sistemas de informática;

- adaptação de software existente;

- preparação de documentação para o usuário.

\subsubsection{PATENTES}

O Manual de Frascati define patente como um direito de propriedade intelectual sobre uma invenção de caráter tecnológico. Uma patente pode ser concedida por um gabinete de patentes a uma empresa, indivíduo ou entidade pública.

Um pedido de patente tem de cumprir certos requisitos: a invenção deve ser uma novidade, o resultado de uma atividade inventiva (de caráter não óbvio) e ser aplicável industrialmente. Uma patente é válida num determinado país e durante um período de tempo limitado, geralmente vinte anos (OECD, 2007e, p. 266).

Estatísticas de patentes são cada vez mais utilizadas como indicadores do resultado das atividades de pesquisa. De acordo com o Manual de Oslo (OECD, 2005a, p. 30), 
o número de patentes concedidas a uma dada empresa ou país pode refletir o dinamismo tecnológico; e exames sobre o crescimento das classes de patentes podem fornecer alguma pista acerca da direção da mudança tecnológica.

Em contrapartida, os problemas referentes ao uso de patentes como indicadores de inovação são bem conhecidos: muitas inovações não são patenteadas, enquanto algumas são protegidas por patentes múltiplas.

Para resolver os problemas associados aos indicadores de patentes tradicionais, a OECD vem trabalhando no desenvolvimento de um novo tipo de indicador baseado em patentes: a contagem por famílias de patentes.

Uma família de patentes é definida como um conjunto de patentes obtidas em vários países para proteger uma única invenção (que se caracteriza por um primeiro pedido de proteção num país - designada pedido de prioridade - e se estende posteriormente a outros escritórios de patentes).

O Tratado de Cooperação de Patentes (PCT), administrado pela Organização Mundial de Propriedade Intelectual (OMPI, ou WIPO em inglês), torna possível buscar a proteção da patente de uma invenção simultaneamente em vários países com o preenchimento de apenas um pedido internacional de patente.

A solicitação e o registro no PCT são bons indicadores indiretos para avaliar a transformação do conhecimento em inovação tecnológica.

Neste particular, o desempenho brasileiro é incipiente. O Brasil solicitou o registro de apenas 394 patentes em 2007 (0,25\% em relação ao mundo), contra 52.719 dos EUA (33,4\%); 27.722, Japão (17,6\%); 17.801, Alemanha (11,3\%); 7.066, Coréia $(4,49 \%) ; 6.223$, França (3,95\%); 5.458, China (3,46\%); 2.052, Austrália (1,30\%); 33, Argentina $(0,02 \%)$, de acordo com dados da Ompi.

A Tabela 4 mostra o número de pedidos de registro de patentes de 2000 a 2008 feitos pelo Brasil e alguns países. 
Tabela 4 - Comparativo do Brasil e alguns países que solicitaram registro de patentes (2000 a 2008)

\begin{tabular}{|l|r|r|r|r|r|r|r|r|r|}
\hline & 2000 & 2001 & 2002 & 2003 & 2004 & 2005 & 2006 & 2007 & $\begin{array}{l}2008 \text { (até a } \\
\text { data atual) }\end{array}$ \\
\hline Total & 93.238 & 108.230 & 110.392 & 115.202 & 122.629 & 136.736 & 149.597 & 157.520 & 23.154 \\
\hline Estados Unidos & 38.007 & 43.054 & 41.295 & 41.031 & 43.351 & 46.810 & 51.242 & 53.147 & 7.785 \\
\hline Japão & 9.567 & 11.904 & 14.063 & 17.414 & 20.264 & 24.869 & 27.021 & 27.732 & 4.310 \\
\hline Alemanha & 12.582 & 14.031 & 14.326 & 14.662 & 15.214 & 15.984 & 16.727 & 17.889 & 2.772 \\
\hline Coréia & 1.580 & 2.324 & 2.520 & 2.949 & 3.558 & 4.688 & 5.945 & 7.066 & 1.193 \\
\hline França & 4.138 & 4.707 & 5.090 & 5.171 & 5.184 & 5.748 & 6.241 & 6.523 & 389 \\
\hline China & 784 & 1.731 & 1.018 & 1.295 & 1.706 & 2.503 & 3.948 & 5.470 & 804 \\
\hline Austrália & 1.576 & 1.664 & 1.759 & 1.680 & 1.837 & 1.996 & 2.002 & 2.071 & 265 \\
\hline Brasil & $\mathbf{1 7 8}$ & $\mathbf{1 7 3}$ & $\mathbf{2 0 1}$ & $\mathbf{2 1 9}$ & $\mathbf{2 7 8}$ & $\mathbf{2 7 1}$ & $\mathbf{3 3 3}$ & $\mathbf{3 9 4}$ & $\mathbf{6 4}$ \\
\hline Argentina & 9 & 9 & 9 & 15 & 11 & 20 & 20 & 33 & 2 \\
\hline
\end{tabular}

Fonte: Organização Mundial de Propriedade Intelectual (Ompi, 2008).

A Tabela 5 apresenta as vinte maiores empresas que solicitaram pedido de patente baseada no número de pedidos publicados internacionalmente em 2007.

Tabela 5 - Vinte maiores empresas que solicitaram pedido de patente com base no número de pedidos publicados internacionalmente em 2007.

\begin{tabular}{|l|l|l|l|}
\hline Classificação & \multicolumn{1}{|c|}{ Empresa } & \multicolumn{1}{|c|}{ País } & Pedidos em 2007 \\
\hline 1 & Matsushita Electric Industrial Co., Ltd. & Japão & 2.100 \\
\hline 2 & Koninklijke Philips Electronics N.V. & Holanda & 2.041 \\
\hline 3 & Siemens Aktiengesellschaft & Dinamarca & 1.644 \\
\hline 4 & Huawei Technologies Co., Ltd. & Canadá & 1.365 \\
\hline 5 & Robert Bosch Gmbh & Dinamarca & 1.146 \\
\hline 6 & Toyota Jidosha Kabushiki Kaisha & Japão & 997 \\
\hline 7 & Qualcomm Incorporated & USA & 974 \\
\hline 8 & Microsoft Corporation & USA & 845 \\
\hline 9 & Motorola, Inc. & USA & 824 \\
\hline 10 & Nokia Corporation & Finlândia & 822 \\
\hline 11 & Basf Aktiengesellschaft & Dinamarca & 810 \\
\hline 12 & 3M Innovative Properties Company & USA & 769 \\
\hline 13 & LG Electronics Inc. & Coréia & 719 \\
\hline 14 & Fujitsu Limited & Japão & 708 \\
\hline 15 & Sharp Kabushiki Kaisha & Japão & 702 \\
\hline 16 & NEC Corporation & Japão & 626 \\
\hline 17 & Intel Corporation & USA & 623 \\
\hline 18 & Pioneer Corporation & Japão & 611 \\
\hline 19 & International Business Machines Corporation & USA & 606 \\
\hline 20 & Samsung Electronics Co., Ltd. & Coréia & 598 \\
\hline
\end{tabular}

Fonte: Organização Mundial de Propriedade Intelectual (Ompi, 2008).

Em 2007, as vinte empresas internacionais que mais solicitaram registro totalizaram 19.530 patentes. As cinco principais empresas que representam 42,8\% desse total são: Matsushita do Japão, a holandesa Philips, Siemens da Dinamarca, a 
multinacional chinesa Huawei e a dinamarquesa Bosh. Desde 1978, 1,47 milhão de patentes foram requeridas à Ompi.

O baixo desempenho brasileiro pode ser explicado pela dificuldade e pelos custos de obtenção de patentes principalmente para pequenas e médias empresas. Num estudo de Sbragia e Pereira (2003), três empresas afirmaram que não tinham nem pretendiam obtê-las, pois achavam o processo muito burocrático e custoso.

Sbragia e Pereira (2003) apud Dodgson e Rothwell (1992) "afirmam que existem custos muito altos com a solicitação de patentes, sendo esse um dos motivos pelos quais as pequenas empresas não a buscam". Além disso, havia receio de expor publicamente a composição ou a forma de elaborar os produtos, exposição que se faz necessária em uma solicitação de patente.

\subsection{EMPREENDEDORISMO E INCUBADORAS DE BASE TECNOLÓGICA}

Este capítulo irá rever inicialmente a literatura sobre empreendedorismo e, num segundo momento, examinará as incubadoras de base tecnológica para finalizar com o trinômio ciência, tecnologia e inovação (CTI).

\subsubsection{EMPREENDEDORISMO NO MUNDO E NO BRASIL}

"A inovação, propensão ao risco e proatividade são considerados os principais constituintes da orientação empreendedora. Por sua vez, as capacidades tecnológicas referem-se à origem da vantagem competitiva sustentável, na medida em que incluam proteção de patentes, aprendizagem tecnológica e que contemple um produto valioso e de difícil imitação aos competidores" (LUZZARDI, 2005, p. 16).

A organização Global Entrepreneurship Monitor (GEM) avalia o nível anual de atividade empreendedora em 42 países, com base na participação e papel do empreendedor no crescimento das economias nacionais. No Brasil, conta com a colaboração do Instituto Brasileiro da Qualidade e Produtividade (IBQP), além do 
SEBRAE e outras instituições, com o objetivo de estimar a prevalência de indivíduos envolvidos em atividade empreendedora em determinado momento e avaliar as condições que levam à criação bem-sucedida de uma empresa.

Os resultados da pesquisa de 2006 colocam o brasileiro como um dos povos mais empreendedores do planeta, "à custa de sua luta pessoal para superar as dificuldades inerentes ao ato de iniciar e manter vivo um negócio" (SCHLEMM, 2006, p. 6). O documento, que reflete o resultado de pesquisa com cidadãos anônimos assim como a opinião de especialistas nacionais, analisa em detalhe diversas qualidades e iniciativas que dizem respeito ao empreendedor como indivíduo, no Brasil e no mundo.

A Tabela 6, produzida pelo Global Entrepreneurship Monitor, mostra a atividade empreendedora recente no Brasil.

Tabela 6 - Evolução da Taxa de Atividade Empreendedora (TEA) no Brasil

\begin{tabular}{|l|l|}
\hline \multicolumn{2}{|l|}{ Evolução da Taxa de Atividade Empreendedora } \\
\hline 2001 & $14,21 \%$ \\
\hline 2002 & $13,52 \%$ \\
\hline 2003 & $12,89 \%$ \\
\hline 2004 & $13,48 \%$ \\
\hline 2005 & $11,30 \%$ \\
\hline 2006 & $11,65 \%$ \\
\hline
\end{tabular}

Fonte: GEM Brasil (2001 a 2006) - Pesquisa de campo.

“(...) as experiências passadas do empreendedor, sejam provenientes de sua vida pessoal ou dos negócios, são de vital importância para que ele identifique as lacunas de mercado não atendidas. De fato, é com base na sua experiência que ele reconhece oportunidades aos seus interesses profissionais, ou seja, relativos ao seu negócio. Esse vislumbrar de oportunidades constitui componente essencial à geração de lucratividade da empresa como mecanismo de sobrevivência e crescimento do negócio" (FONSÊCA, 2006, p.5).

A estabilidade da taxa de empreendedores iniciantes demonstra estagnação da atividade empreendedora no Brasil, apesar das "características estruturais, as quais correspondem aos aspectos macro da economia, da política e da cultura. (SCHLEMM, 2006, p. 43). 
A taxa de atividade empreendedora (TEA) apresenta enorme variação entre os países do GEM, indo de 40,2\% no Peru, até 2,7\% na Bélgica. O Brasil situa-se na décima posição no ranking (com TEA de 11,65\%), como se pode ver na tabela 6 . A Tabela 7 apresenta a evolução da Taxa de Empreendedores no Brasil no período de 2001 a 2006.

Tabela 7 - Evolução da taxa de empreendedores nascentes e novos no Brasil - 2001 a 2006

\begin{tabular}{|l|l|l|}
\hline & Empreendedores nascentes & Empreendedores novos \\
\hline 2001 & $9,2 \%$ & $5,0 \%$ \\
\hline 2002 & $5,7 \%$ & $8,5 \%$ \\
\hline 2003 & $6,5 \%$ & $6,9 \%$ \\
\hline 2004 & $5,0 \%$ & $8,9 \%$ \\
\hline 2005 & $3,2 \%$ & $8,2 \%$ \\
\hline 2006 & $3,5 \%$ & $8,6 \%$ \\
\hline
\end{tabular}

Fonte: Pesquisa de campo - GEM Brasil (2001-2006)

As definições de empreendedorismo não são propriamente mensuráveis. "Mensurações existem, mas não refletem necessariamente os objetivos do empreendedorismo que os agentes responsáveis pelos modelos de políticas públicas propõem" (OECD, 2006d, p. 3).

De acordo com a OECD, enquanto há considerável interesse em empreendedorismo dos países-membros da organização, não há macroestatísticas, com conceitos e definições, nem ao menos uma relação de indicadores-chave indispensáveis ao entendimento coletivo do empreendedorismo e os impactos resultantes.

\subsubsection{COMPETÊNCIAS}

Os governos prestam cada vez mais atenção à capacitação e ao treinamento para as iniciativas empresariais. Não há um modelo único para ensinar a iniciativa empresarial por meio de instrução e treinamento: os jovens devem aprender a abrir o próprio comércio? Ou devem ser orientados a manifestar o consentimento para modificar o comportamento e correr riscos? Os Estados-Unidos tendem a favorecer a primeira abordagem; enquanto a Suécia prefere a segunda. O Reino-Unido utiliza as duas abordagens (OECD, 2005, p.3). 
De acordo com as competências, a formação é desenvolvida em diferentes níveis: individual, em grupos e organizacional de forma integrada. No que se refere aos empreendimentos de start-up, o desenvolvimento de competências e capacidades está relacionado, em um primeiro momento, à figura do empreendedor. O grande desafio das incubadoras e dos empreendedores emerge da necessidade de transferência dessas competências individuais em competências organizacionais (LUZZARDI, 2005, p. 52).

\subsubsection{INCUBADORAS DE BASE TECNOLÓGICA}

Empresas em setores de tecnologia avançada são aquelas "que operam com processos, produtos ou serviços em que a tecnologia é considerada inovadora" (SANTOS, 2004, p. 17).

O relatório de 2003 do Departamento de Comércio e Tecnologia dos EUA (2003, p. 2) constatou que, enquanto algumas comunidades procuram estratégias cujo foco são grandes companhias de tecnologia, outras estão começando a tentar estratégias paralelas, do tipo "faça você mesmo". Nestas, os esforços estão centrados em criar um ambiente que conduza à formação de empresas start-up de base tecnológica.

Alguns dos componentes e atores do "faça você mesmo" são:

- universidades, laboratórios federais, pesquisa corporativa, desenvolvimento de instalações, com produção de propriedade intelectual de base tecnológica, orientada para transferência de tecnologia (por exemplo, patentes e licenciamentos), o que enfatiza o viés empreendedor;

- cientistas e engenheiros empreendedores que querem comercializar tecnologias criando empresas próprias;

- profissionais que têm familiaridade com os problemas de implantação de empresas de base tecnológica;

- Institutos e organizações de fomento - públicos e privados - que podem capitalizar o desenvolvimento inicial de empreendimento de base tecnológica;

- concentração de companhias de tecnologia pode oferecer profissionais experientes para assumir posição de liderança em empresas start-up. 
Incubadoras de base tecnológica abrigam empresas cujos produtos, processos e/ou serviços são resultado de pesquisa científica que representam alto valor agregado. Apóiam empresas de biotecnologia, tecnologia da informação, eletroeletrônico, meio ambiente, medicina e saúde, dentre outras, e são centros de excelência que reúnem profissionais com capacidade técnica, gerencial e administrativa com o objetivo comum de fornecer suporte às micro e pequenas empresas no desenvolvimento e consolidação empresarial. Disponibilizam infra-estrutura e serviços de apoio financeiro, marketing e administração, de forma que todas as empresas sejam assessoradas com foco na sustentabilidade empresarial.

Os principais objetivos de uma incubadora são:

- atender à demanda por produtos e serviços associados ao parque industrial, suprindo deficiências existentes;

- promover mecanismos de integração universidade-empresa, ampliando e difundindo a cultura empreendedora no meio acadêmico;

- promover a capacitação de empreendedores na comunidade científica;

- garantir que novos produtos e serviços resultantes da pesquisa básica e tecnológica possam chegar ao mercado consumidor;

- contribuir para o desenvolvimento regional por meio da criação de empregos e geração de renda;

- oferecer oportunidade aos acadêmicos de transformar idéias em produtos, processos e serviços baseados em tecnologias inovadoras, pelo acesso a uma infra-estrutura de apoio empresarial;

- fortalecer empresas na fase "embrionária", enfatizando a formação do empreendedor, o amadurecimento do projeto e a estruturação do negócio

- possibilitar aos empreendedores o uso de serviços, infra-estrutura e espaço físico, sob obrigações e condições estabelecidas;

- facilitar o acesso a inovações tecnológicas e gerenciais. 


\subsubsection{O processo de incubação de empresas}

O surgimento nos Estados Unidos de empresas de tecnologia foi conseqüência do desenvolvimento da pesquisa científica e tecnológica associado ao nascimento da microeletrônica, o que permitiu baixar o preço de chips, processadores, memória, disco rígido, entre outras tecnologias. A transferência dos resultados da pesquisa resultou na oportunidade de abertura de empresas que exploravam novas oportunidades de mercado. A ascensão do Vale do Silício, na Califórnia, deve-se em grande parte ao esforço planejado da Stanford University.

\footnotetext{
"Existe um relacionamento profundo entre o surgimento deste conjunto de empresas de alta tecnologia e a proximidade das grandes universidades e instituições de pesquisa tecnológica existentes nas localidades ou imediações onde esta aglomeração ocorreu" (SANTOS, 2004, p. 29).
}

Na década de 1970, no Vale do Silício, um mecanismo de fomento criado oferecia infra-estrutura a universitários recém-graduados para abrir empresas, recebendo assessoria gerencial, jurídica, de comunicação, administrativa e tecnológica até o empreendimento tornar-se auto-sustentável - essa estrutura ganhou o nome de incubadora de empresas.

\subsubsection{O processo de inovação global}

Na França, na década de 1970, o governo, preocupado com a intermitência das empresas, reuniu uma comissão de banqueiros e empresários para entender a taxa de mortalidade das empresas. As proposições da comissão centravam-se na figura do empreendedor e na valorização da empresa pelo papel social. Os governos seguintes deram seqüência ao que fora acordado, instituindo a Agência Nacional para Criação de Empresas (ANCE); estimulando escolas e universidades na formação de empreendedores; simplificando a burocracia para abertura e regularização de empresas; isentando as empresas de impostos nos exercícios iniciais. Atualmente, as indústrias francesas de alta tecnologia têm recebido atenção especial do governo, com a criação de vilas científicas em torno de universidades, a exemplo da experiência americana. (SANTOS, 2004, p. 35). 
$\mathrm{Na}$ Inglaterra, os "Science Parks", junto ao campus de universidades, que abrigam indústrias nascentes de tecnologia de ponta, são patrocinados pelo governo municipal e empresas privadas. Empreendedores têm livre acesso e compartilham o uso de computadores e laboratórios. Complementarmente, o "New Enterprise Programm" oferece cursos gratuitos de três meses para estímulo e capacitação de pessoas interessadas em abrir um negócio (SANTOS, 2004, p. 37).

Na Alemanha, a chamada "cultura de empreendimentos" leva a uma iniciativa de grandes dimensões. Com o apoio da Universidade Técnica de Berlim, em 1980 um programa chamado BIG foi instalado numa antiga indústria e reúne $2 \%$ das empresas recém-criadas. A vocação empreendedora é estimulada por meio de um acordo entre a Prefeitura e a Universidade de Berlim (SANTOS, 2004, p. 39).

O Brasil, já em 1966, fundava a Agência Brasileira de Inovação do Ministério de Ciência e Tecnologia, a Financiadora de Estudos e Projetos (FINEP): 42 anos "de fomento à geração do conhecimento, apoiando a pesquisa básica, a infra-estrutura acadêmica, o desenvolvimento de novas tecnologias em um ciclo completo da inovação" (BRASIL, 2006, p. 7). No documento citado, há uma seleção de quarenta empresas de êxito na área de tecnologia emergente, como biotecnologia, nanotecnologia, software, aeronáutica - "uma pequena fração do universo inovador brasileiro".

De acordo com o Ministério de Ciência e Tecnologia (MCT), em 2000, das 72.000 empresas industriais:

“(..) 19.000 implementaram produtos e/ou processos tecnologicamente novos ou substancialmente aprimorados investindo, para tanto, 22,3 bilhões de reais. Mais de 7.000 empresas realizaram dispêndios em atividades internas de pesquisa e desenvolvimento - P\&D ocupando mais de 20.000 técnicos de nível superior, dentre eles, quase 3.000 com pós-graduação. Em 2003 (com 84.262 empresas) o número de empresas que implementaram inovações cresceu 23\%, mostrando uma tendência, confirmada nos dispêndios em atividades internas de P\&D, que cresceu $36 \%$, e no número de técnicos de nível superior ocupados em atividades de P\&D que cresceu 8\%" (BRASIL, 2008, p.7). 
De acordo com o Ministério de Ciência e Tecnologia, 93,1\% do investimento foi proveniente de recursos próprios; $2,7 \%$ de terceiros privados; $4,2 \%$ públicos, quadro que reflete a posição tímida dos agentes de fomento das incubadoras em universidades e institutos de pesquisa. Brandão et al. explicitam a importância desse tipo de associação (BRASIL, 2006, p. 12).

"Os casos bem-sucedidos de parceria universidade-empresa não devem ser tomados como a regra geral, mas demonstram que este caminho pode e deve ser trilhado. Várias empresas desta coletânea nasceram de projetos acadêmicos e passaram por incubadoras empresariais, como a LaserTools. A história da LaserTools está intimamente ligada ao nascimento e desenvolvimento da inovação tecnológica do país. Empresa do primeiro grupo de projetos que se associou à Incubadora, em 1998, três anos mais tarde, tornava-se a segunda graduada e, desde então, mantém uma ligação estreita com o CIETEC. Atualmente a LaserTools atua como prestadora de serviços para diversas empresas e está presente nos setores médico, odontológico, agroindustrial, promocional, automotivo e de plásticos". (CIETEC, 2008, p. 17).

O Ministério de Ciência e Tecnologia, por meio da FINEP, criou o Programa Nacional de Incubadoras (PNI), que tem por objetivo apoiar o surgimento e a consolidação de incubadoras de empresas (tecnológicas, mistas e tradicionais) e parques tecnológicos. Dessa forma, busca acelerar o crescimento de micro e pequenas empresas (MPEs), bem como otimizar o conteúdo tecnológico de produtos e serviços. O PNI destaca, portanto, a incubadora como agente nucleador do processo de geração e consolidação de micro e pequenas empresas (BRASIL, 2008).

\subsubsection{CIÊNCIA, TECNOLOGIA E INOVAÇÃO}

Ciência, tecnologia e inovação (CT\&l) são elementos-chave para o crescimento e competitividade de indústrias. Igualmente, são fundamentais na determinação do escopo de desenvolvimento de regiões ou nações e na forma como este afeta no presente e afetará no futuro a qualidade de vida da população e seus diversos segmentos; podem contribuir para a criação ou a solução de problemas humanos e ambientais; influenciam a educação, informação, cultura, costumes e a saúde; como têm papel relevante nos desígnios da política e de segurança pública. 
Por tudo isso, a busca da compreensão e do monitoramento dos processos de produção, difusão e uso de conhecimentos científicos, tecnologias e inovações, assim como dos fatores que os influenciam e das conseqüências, é tarefa que se impõe (VIOTTI \& MACEDO, 2003, p. 45).

O investimento em conhecimento é a base da inovação e do progresso tecnológico. Em vista disso, os investimentos em P\&D, software e educação continuam a crescer na maioria das economias da OECD, embora P\&D se tenha desenvolvido mais lentamente que na segunda metade da década de 1990, em parte devido ao reajustamento do investimento após a aceleração de finais da década de 1990 e ao abrandamento no investimento em P\&D nos Estados Unidos (OECD, 2007b, p. 2).

As medidas de CT\&I são importantes porque podem:

- alimentar as pesquisas sobre a natureza e os determinantes dos processos de produção, difusão e uso de conhecimentos científicos, tecnologias e inovações (razão científica);

- informar a formulação, acompanhamento e avaliação de políticas públicas (razão política);

- informar as estratégias tecnológicas de empresas, assim como as atitudes de trabalhadores, instituições e do público em geral em relação a temas de CT\&I (razão pragmática).

Argumenta-se que, apesar das dificuldades intrínsecas para implantá-los e mantêlos, os sistemas de indicadores de CT\&I são especialmente importantes para países em desenvolvimento, como o Brasil. Isso decorre não só da importância da contribuição que os indicadores podem dar para a eficácia de políticas e estratégias dirigidas para a superação das carências e limitações dos sistemas de CT\&I, como da necessidade de melhor compreender as especificidades do processo de desenvolvimento científico, tecnológico e econômico (VIOTTI \& MACEDO, 2003, p. 45).

A missão de uma política de ciência, tecnologia e inovação deveria aumentar, de maneira sustentável, a competitividade do setor produtivo mediante o desenvolvimento de novas capacitações por meio do valor agregado de 
conhecimentos oriundos de inovação sistêmica, dinâmica e integrada. Isso significa ter em vista um modelo experimental de inovação baseado na interação entre ciência e tecnologia, processos de melhoria da qualidade, estratégias de mercado e nova plataforma de instrumentos de política que possam associar, mediante estímulos estratégicos, o desenvolvimento de vínculos a novos comportamentos que levem à inovação e à competitividade (OEA, 2006, p. 32).

\subsubsection{Reconhecimento do papel da ciência, tecnologia e inovação (CTI)}

Inovação, ciência e tecnologia são conceitos importantes na cultura corporativa do século XXI, de maneira que as empresas, independentemente de tamanho, setor e contexto de atividade produtiva, possam ser capazes de competir na nova ordem mundial. A inovação é uma vantagem competitiva que deve ser desenvolvida e adotada e não pode estar dissociada de ciência e tecnologia. De maneira semelhante, os governos devem atualizar a percepção. Já não é mais suficiente o apoio fragmentado aos sistemas de ciência e tecnologia; impõe-se a implementação de um sistema integrado de inovação, o que implica novas atitudes, formas de organização e promoção de maior colaboração entre setor público e privado. Os centros de P\&D tecnológico também devem revisar e ampliar as formas de apoio ao setor produtivo, a fim de se integrarem ao processo mais amplo (OEA, 2006, p. 33).

O reconhecimento do papel da ciência, tecnologia e inovação (CTI) na competitividade do setor produtivo deve ser apoiado de diversas maneiras, o que inclui programas de conscientização para as diferentes partes envolvidas com o processo de inovação; programas para a difusão dos conceitos de inovação nas comunidades interessadas em atividades produtivas, de modo que a ciência e a tecnologia possam ser conhecidas e entendidas e, desse modo, melhor utilizadas; capacidade de resposta dos centros de pesquisa em ciência e tecnologia às demandas do setor produtivo; aferição de resultados mediante sistemas de intercâmbio, retroalimentação e monitoração; e apropriação, ou seja, a capacidade das empresas não somente de usar mas também de contribuir para o aperfeiçoamento das tecnologias transferidas (OEA, 2006, p. 33). 


\subsubsection{Inovação e competitividade}

Não é suficiente que a inovação seja um modelo partilhado pelo setor produtivo, governamental e de pesquisa científica e tecnológica. O modelo deve evoluir como resultado de um aprendizado coletivo e da necessidade de constante adaptação em resposta à demandas que tem origem na transição e nas forças do mercado.

É fundamental a convergência do processo de inovação com o papel desempenhado pelos governos na promoção e apoio a estes. O desenvolvimento de vantagens competitivas no setor produtivo consiste, em parte, no acesso a um modelo de inovação adaptado à realidade atual, internalizando e colocando em prática um modelo que inclua não somente ciência e tecnologia, mas as relações críticas com o processo de geração de valor agregado. Alguns elementos formam a base da reformulação do modelo de inovação, dentre os quais:

- vínculo entre competitividade e inovação, constituindo um círculo virtuoso;

- pesquisa e desenvolvimento relevantes para a estratégia de inovação;

- importância da transferência de tecnologia na relação crítica entre P\&D e o setor produtivo, um elo no processo de agregação de valor;

- intensidade da interação entre os atores para a inovação;

- relação entre centros de avaliação da conformidade e a competitividade do setor produtivo (OEA, 2006, p. 34).

A busca de vantagem competitiva apoiada pela inovação precisa estar fundamentada no planejamento estratégico adotado pela empresa. Existe a necessidade de haver uma integração para aquilo que é planejado em nível estratégico seja refletido para o nível administrativo e, também para o nível operacional (ALMEIDA, 2003, p. 48).

Segundo o autor, o planejamento é dividido em três níveis:

- estratégico, em que são planejadas as decisões que afetam o todo da empresa. Além disso não se pode voltar atrás, uma vez que essas decisões a afetam no longo prazo; 
- administrativo, também conhecido como tático ou interativo, que faz a ligação entre decisões estratégicas e operacionais;

- operacional, em que as ações realmente acontecem.

Os elementos essenciais para a promoção da competitividade no setor produtivo segundo a OEA são apresentados na Figura 5.

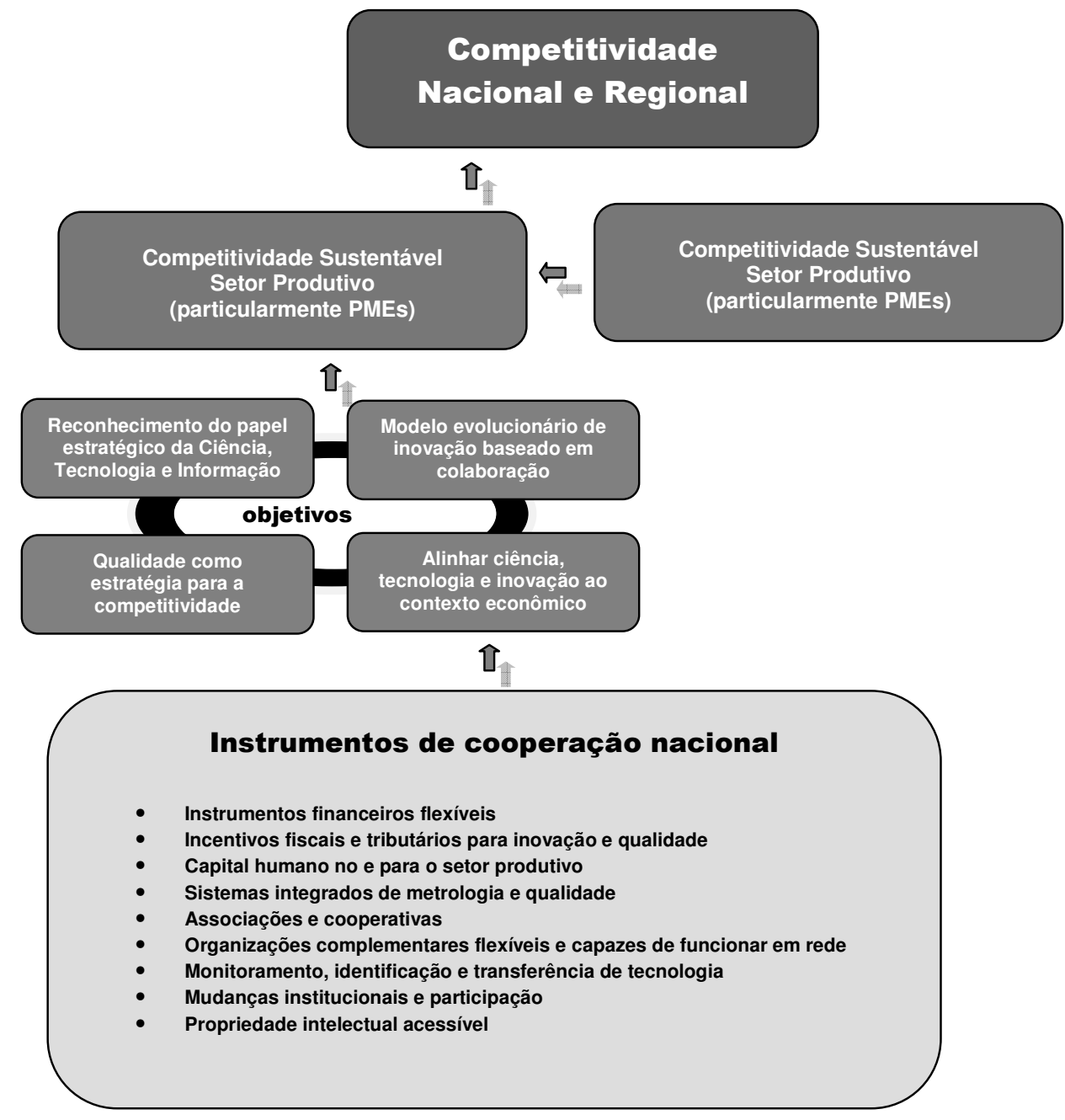

Figura 5 - Esquema para a inovação: elementos essenciais para a promoção da competitividade no setor produtivo.

Fonte: OEA (2006, p. 34) 


\subsection{FERRAMENTAS DE GESTÃO}

Em razão da necessidade de enfrentar a crescente competição dos mercados sob pressão da globalização, tem havido uma avalanche de ferramentas de gestão, que abrange desde a busca pela excelência em administração a alianças estratégicas, como fusões e aquisições.

Para que as empresas possam competir em um cenário global com crescimento sustentável, é necessário cada vez mais conhecimento em administração, para tomar decisões em termos de estratégia, governança, tecnologia, fusões e aquisições, entre outras importantes questões, o que impulsiona a demanda por conhecimento e aperfeiçoamento no uso das ferramentas de gestão (RIGBY, 2007, p.10).

O interesse por ferramentas de gestão se justifica por um conjunto de expectativas conflitantes nos negócios: por um lado, continua havendo grande pressão por redução de custos impulsionados pela desaceleração de crescimento e recessão nos principais mercados mundiais; por outro lado, não é menor a exigência por crescimento, instância talvez não tão razoável em tempos recessivos.

$E$, mais do que nunca, os gestores se vêem obrigados a entregar resultados de forma consistente (idem).

Entre os desafios dos gestores está a escolha das ferramentas de gestão de modo a obter sustentabilidade empresarial. O requisito essencial para tanto é aprender qual mecanismo usar, como e onde. Muitas empresas e instituições vêm realizando pesquisas para verificar como os administradores lidam com a questão de escolha e aplicação dessas ferramentas. 


\subsubsection{Objetivos das Pesquisas de Ferramentas de Gestão}

De acordo com Rigby e Bilodeau (2007, p.10), o objetivo das pesquisas de ferramentas de gestão tem como foco:

a) compreender "como a aplicação atual, por parte dos gestores, das ferramentas de gestão e subseqüentes resultados se compara a outras organizações e indústrias ao redor do globo"; e

b) prover "informação que os gestores precisam para identificar, selecionar, implementar e integrar as ferramentas certas para melhorar o desempenho da organização"

A Pesquisa Global Management Tools Survey de Rigby e Bilodeau entrevistou em 2007 gerentes seniores em setenta países para acompanhar a utilização de 25 das ferramentas de gestão mais disseminadas e pertinentes e tentar explicar como estão sendo usadas, assim como verificar a taxa de sucesso e analisar as circunstâncias em que cada uma produz os resultados desejados.

No Brasil, foram sessenta empresas e 101 gestores pesquisados. Rigby e Bilodeau (2007, p. 64), no relatório final da pesquisa, apresentam as seguintes sugestões para utilização das ferramentas.

1. Toda ferramenta reúne um conjunto de pontos fortes e fracos. O sucesso requer compreensão da eficácia de cada ferramenta.

2. Estratégias duradouras de gestão devem estar focada em resultados sustentáveis.

3. Escolha das melhores ferramentas: gestores precisam de um sistema racional para selecionar, implementar e integrar as soluções adequadas. Uma ferramenta de gestão só trará resultados se auxiliar a:

a. descobrir as necessidades não satisfeitas do cliente;

b. construir capacidades distintas;

c. explorar as vulnerabilidades do competidor;

d. desenvolver estratégias de inovação para efetivamente integrar essas aquisições.

4. Adaptar as ferramentas de gestão ao sistema empresarial. 
Rigby e Bilodeau (2007, p. 12) relatam a partir dos resultados obtidos nos estudos que:

- no conjunto, a satisfação com utilização de ferramentas é moderadamente positiva, mas as taxas de uso, facilidade de implementação, efetividade, pontos forres e fraco variam amplamente;

- ferramentas de gestão são muito mais eficientes quando fazem parte de um esforço organizacional abrangente;

- nenhuma ferramenta traz solução completa e definitiva.

Os autores perceberam também novas tendências em gestão:

- gestores estão despendendo mais tempo pensando na base de clientes - em como ampliá-la e mantê-la - buscando a satisfação no uso do produto ou serviço;

- há um consenso de que bens e serviços se estão tornando commodities, obrigando os gestores a procurar modos mais efetivos para inovar;

- a competição global demanda interesse crescente em ferramentas de gestão, na busca da eficiência operacional e econômica;

- ferramentas com fortes componentes tecnológicos estão sendo descartadas.

Ao avaliar como a utilização das ferramentas e a satisfação com elas têm mudado ao longo do tempo, identificaram-se quatro categorias de ferramentas:

- ferramentas incipientes - têm baixo nível de utilização e baixo nível satisfação;

- ferramentas brutas - têm alto nível de utilização, e baixo nível de satisfação;

- ferramentas especializadas - têm baixo nível de utilização, e alto nível de satisfação;

- ferramentas de impacto - têm alto nível de utilização e alto nível de satisfação.

Em geral, as ferramentas começam na categoria "incipiente", que na Pesquisa Global de 2007 incluiu RFID, Blogs Corporativos, Etnografia do Consumidor (Consumer Ethnography), Ferramentas de Fidelização e Centros de Serviços 
Compartilhados - todas relativamente novas no mundo corporativo e com avaliações abaixo da média em termos de utilização e satisfação.

Segundo o estudo, as ferramentas incipientes podem seguir quatro caminhos possíveis:

- continuarão a ter desempenho fraco e mostrarão ser modismo passageiro;

- serão melhoradas e funcionarão de forma mais efetiva, mas acabarão servindo algum nicho funcional, tornando-se "ferramenta especializada", como é o caso de Fusões e Aquisições;

- serão utilizadas de forma mais ampla, em virtude de necessidades reais, mas não conseguirão tornar-se efetivas, tornando-se "ferramenta bruta", continuadamente com baixos índices de satisfação, como é o caso de Gestão Conhecimento; ou

- acabarão adaptando-se, tornando-se eficientes, sendo amplamente utilizadas e se tornarão "ferramentas de impacto".

As ferramentas de gestão chegam ao ponto de se transformar em padrão para a maioria das empresas, como é o caso de Planejamento Estratégico, Gerenciamento do Relacionamento com Clientes (CRM) e Segmentação de Clientes.

A Figura 6 mostra como as prioridades ao longo do tempo.

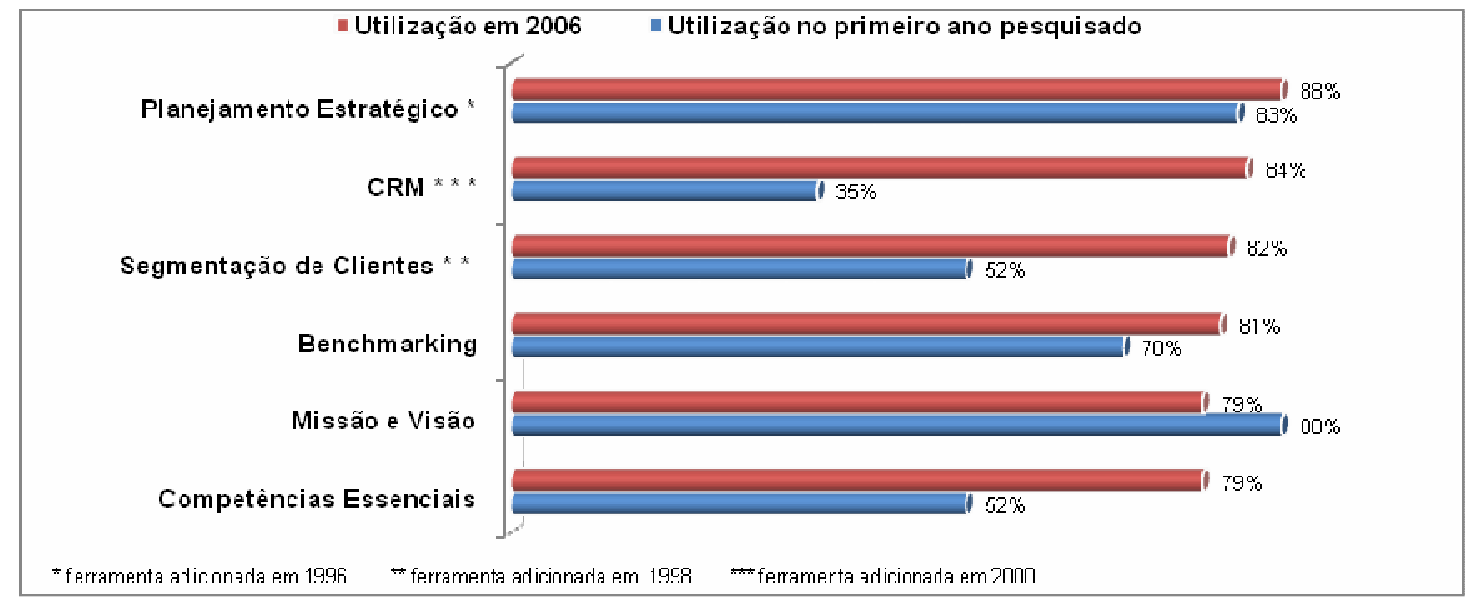

Figura 6 - A utilização das ferramentas mostra como objetivos e prioridades mudam ao longo do tempo.

Fonte: Rigby e Bilodeau (2007, p. 12) 


\subsubsection{As Dez FerRamentas Mais Usadas}

Do ponto de vista comparativo e a fim de entender melhor a utilização e importância das ferramentas de gestão, é interessante conhecer as mais utilizadas na Pesquisa Global. A Tabela 8 mostra as ferramentas mais usadas entre as 25 pesquisadas de acordo com Rigby e Bilodeau (2007, p. 5).

Tabela 8 - Planejamento estratégico é a ferramenta no 1 no mundo com exceção da região ÁsiaPacífico

\begin{tabular}{|c|c|c|c|c|c|}
\hline As 10 ferramentas mais usadas & Mundo & \begin{tabular}{|l|} 
América do \\
Norte
\end{tabular} & Europa & Ásia-Pacífico & América Latina \\
\hline Planejamento estratégico & 1 & 1 & 1 & 2 & 1 \\
\hline Relacionamento com clientes & 2 & 3 & 4 & 1 & 9 \\
\hline Segmentação de clientes & 3 & 6 & 2(il) & 3 & $3(\mathrm{il})$ \\
\hline Benchmarking & 4 & 2 & 2(il) & 9(il) & 2 \\
\hline Competências essenciais & 5 (il) & 5 & 5 (il) & 4 & 10 \\
\hline Missão e Visão & 5 (il) & 4 & 7 & $5(\mathrm{il})$ & 5 \\
\hline Terceirização & 7 & 8 & 5 (il) & $7(\mathrm{il})$ & 3(il) \\
\hline Reengenharia de processos & 8 (il) & 10 (il) & 10 (il) & 5(il) & 14(il) \\
\hline Gestão do conhecimento & 8 (il) & 12 & 10 (il) & $7(\mathrm{il})$ & 14(il) \\
\hline Planejamento especulativo/contingências & 8 (il) & 9 & 8 & 10 & 7 \\
\hline
\end{tabular}

Fonte: Rigby e Bilodeau, 2007b Nota: (il) = interligadas

A seguir são descritas, segundo Rigby, as 25 ferramentas mais utilizadas que fizeram parte da Pesquisa Global.

1. Planejamento Estratégico - é um abrangente e sistemático processo de perguntas e respostas sobre questões críticas com que se depara a equipe de gestores que procura definir o que o negócio deve tornar-se e o potencial da empresa e como alcançar esses objetivos.

2. Gerenciamento de Relação com Clientes - é o processo utilizado pelas empresas para conhecer e entender a carteira de clientes e responder rapidamente às mudanças das necessidades do cliente, com base na coleta de maior quantidade possível de dados do cliente e no planejamento de estratégias com base nessas informações.

3. Segmentação da Base de Clientes - é a subdivisão do mercado em grupos de clientes com características similares, o que auxilia a identificar 
necessidades não satisfeitas e desenvolver campanhas e estratégias de vendas para obter o máximo resultado.

4. Benchmarking - melhora os resultados ao identificar e aplicar práticas reconhecidamente vencedoras de operação e vendas em um esforço de comparação com o desempenho da concorrência.

5. Competências Essenciais - capacidade de passar ao cliente uma imagem diferenciada de valor, que envolve o aprendizado coletivo da organização de como coordenar diversas habilidades produtivas e integrar múltiplas tecnologias para diferenciar e unificar a empresa.

6. Missão e Visão - a Missão define o negócio da empresa, os objetivos e a maneira de alcançá-los. A Visão descreve a almejada posição futura da empresa. Ambos os elementos se combinam na declaração de propósitos, objetivos e valores.

7. Terceirização - a empresa utiliza a colaboração de terceiros para realizar serviços secundários, o que muitas vezes reduz custos e melhora a qualidade do produto terceirizado devido à produção em escala. Terceirizar permite à empresa manter o foco na competência principal do negócio.

8. Reengenharia - envolve a radical reestruturação dos processos essenciais para obter melhora em produtividade, no tempo de cada etapa de produção e na qualidade, normalmente com a adoção de um novo sistema de valores focado nas necessidades do cliente.

9. Gestão do Conhecimento - desenvolve sistemas e processos para adquirir e dividir valores intelectuais. Isso aumenta a produção de informações significantes e úteis e melhora o aprendizado individual e em equipe. $O$ capital intelectual é a chave que fornece vantagem competitiva em relação ao público-alvo.

10. Planejamento especulativo e de contingências - o planejamento especulativo permite aos gestores explorar e preparar-se para possibilidades futuras, calculando os resultados que se podem esperar a partir de variadas estratégias operacionais e condições econômicas. O 
planejamento de contingências avalia os efeitos de hipotéticas mudanças ou rupturas repentinas do mercado sobre a companhia.

11. Balanced Scorecard - define o que a gerência entende por desempenho e afere se os objetivos estão sendo alcançados. Traduz Missão e Visão em um compreensível conjunto de métricas de objetivo e desempenho que pode ser medido e quantificado.

12. Inovação Colaborativa - aplica o princípio de livre comércio de novas idéias no mercado, utilizando vantagens comparativas para destinar a eficiente alocação de recursos em P\&D. Permite ao negócio redirecionar os recursos de inovação onde eles são mais claramente competitivos.

13. Etnografia do Consumidor - um tipo especializado de pesquisa para estudar hábitos, atitudes e cultura e entender melhor as necessidades do consumidor e como este elabora as decisões de compra.

14. Blog Corporativo - site (webpage) onde comunidades de usuários criam conteúdo repassando informação entre si. É administrado por funcionários que divulgam informações sobre produtos e sobre a empresa para o público consumidor.

15. Ferramentas de Estratégia de Crescimento - orientam recursos para aproveitar oportunidades e gerar vantagens competitivas.

16. Otimização de Etapas - metodologia que procura eliminar o desperdício e reduzir o tempo entre o pedido do cliente e a entrega do produto. $\mathrm{O}$ objetivo é entregar o produto - no lugar, hora, e quantidade certa - com o mínimo desperdício.

17. Fidelidade - faz aumentar as vendas e crescer os lucros ao reter clientes, funcionários e fornecedores. O programa de fidelidade mede e monitora a lealdade desses grupos.

18. Fusões e Aquisições - estratégias financeiras corporativas para aumentar o valor das ações e criar vantagens competitivas.

19. Offshoring (mudança física em busca de vantagens) - transferência de operações da companhia para outras cidades, estados ou países. Normalmente, os novos locais oferecem incentivos como impostos mais baixos ou a vantagem da proximidade de pólos industriais. A ferramenta 
oferece risco em termos de relações públicas, pois elimina postos de trabalho no país de origem e cria empregos em outras partes.

20. Identificação por Radiofreqüência (RFID) - tecnologia que utiliza ondas de rádio para identificar objetos e ler dados. Usada em cartões de acesso e identificação (em substituição ao código de barras), monitora estoque e trabalhos em andamento.

21. Centro de Serviços - reduz custos consolidando em um único lugar serviços utilizados por múltiplas divisões da empresa.

22. Seis Sigma - "Sigma" é a variação estatística de uma grandeza. Seis Sigma se traduz por "quase perfeição": um rigoroso método dirigido à satisfação do cliente criando a cultura da excelência.

23. Alianças Estratégicas - são acordos entre empresas em que cada uma compromete recursos na busca de conjuntos de objetivos comuns e engloba uma série de atores: clientes, fornecedores, concorrentes, universidades e divisões do governo. Ajuda a melhorar a posição competitiva, ganhar entrada em novos mercados e divide o risco ou custo de grandes projetos de desenvolvimento.

24. Gestão da Cadeia de Fornecimento - sincroniza os esforços de todas as partes envolvidas (fornecedores, manufatura, distribuidores, varejo) no processo de satisfazer as necessidades dos clientes.

25. Gestão de Qualidade Total - abordagem sistemática de melhora da qualidade que alinha as especificações de produtos e serviços em busca da satisfação do cliente.

\subsubsection{A PESquisa no BRAsiL - Foco no CREscimento}

A Pesquisa Global de Rigby e Bilodeau entrevistou em 2007 sessenta empresas brasileiras e revelou aumento de $25 \%$ no uso de ferramentas de gestão, num provável reflexo destes tempos de crise, em que os gestores precisam responder a demandas cada vez maiores e até conflitantes entre si. Destacam-se as ferramentas que visam à expansão do negócio, como Planejamento Estratégico e Inovação (RIGBY, 2007, p. 8). 
De acordo com o estudo publicado, dois terços dos participantes da Pesquisa Global no Brasil disseram que se concentrariam no crescimento em 2007, não em cortes de custos. Os gestores se mostraram inclinados ao uso de ferramentas com foco nas áreas mais promissoras e produtivas dos negócios. Planejamento Estratégico, Benchmarking e Competências Essenciais alcançaram elevado índice de utilização, refletindo aumento de interesse em criar metas e identificar oportunidades para aperfeiçoamento.

A idéia de se concentrar no que as empresas fazem de melhor justifica os $72 \%$ dos participantes da pesquisa que afirmaram ter-se engajado na Terceirização - ainda que o posicionamento nos estágios iniciais da curva de experiência não permita grau de satisfação alto com esta utilização.

Inovação é elemento-chave para o sucesso empresarial: $84 \%$ afirmaram que ter capacidade de adaptação é uma grande vantagem competitiva; enquanto $78 \%$ acreditam que Inovação é mais importante do que preço no que diz respeito ao sucesso de longo prazo.

A ferramenta Estratégias de Crescimento teve maior utilização nos últimos dois anos, passando de uma aceitação de 55\% para 59\%. Mesmo assim, os dados também indicam que os gestores seniores apresentaram pouca propensão a investimentos arriscados.

Apesar do entusiasmo por Inovação, eles demonstraram aumento de interesse pelo conceito da open market innovation - abordagem que reúne ferramentas como licenciamentos, joint-ventures e alianças estratégicas para trazer os benefícios de livre mercado ao campo das idéias. A open market innovation pode reduzir o custo e aumentar a produtividade, abrindo as fronteiras das empresas para as idéias de fora, de fornecedores, clientes e até concorrentes.

Quase dois terços dos entrevistados concordaram que poderiam impulsionar a inovação utilizando parceria externa.

A Tabela 9 apresenta a visão de longo prazo dos gestores brasileiros participantes da pesquisa global. 
Tabela 9 - Como os gestores brasileiros enxergam o futuro

\begin{tabular}{|l|l|l|}
\hline Questão proposta & Concordo & Discordo \\
\hline $\begin{array}{l}\text { Tenho preocupações sobre como alcançaremos } \\
\text { nossos alvos de crescimento. }\end{array}$ & $71 \%$ & $21 \%$ \\
\hline $\begin{array}{l}\text { Nossa adaptação a mudanças é uma } \\
\text { vantagem corporativa significativa. }\end{array}$ & $84 \%$ & $1 \%$ \\
\hline $\begin{array}{l}\text { Inovação é mais importante que preço } \\
\text { para o sucesso de longo prazo em nosso setor. }\end{array}$ & $78 \%$ & $16 \%$ \\
\hline $\begin{array}{l}\text { Poderíamos estimular a inovação } \\
\text { significativamente se fizéssemos uma } \\
\text { parceria com outras empresas. }\end{array}$ & $67 \%$ & $19 \%$ \\
\hline
\end{tabular}

Fonte: Rigby (2007d, p.8)

Segundo Rigby (2007, p. 9), um sinal dos tempos verificado na pesquisa foi a elevada popularidade de Códigos de Ética Corporativa. Quase 60\% dos entrevistados disseram ter criado um código de ética na empresa no período pesquisado, e a ferramenta foi a terceira colocada no ranking de satisfação no Brasil (atrás apenas de Alianças Estratégicas e Planejamento Estratégico); e 88\% disseram estar orgulhosos da ética existente na corporação. Alguns entrevistados afirmaram que as empresas realmente se estão esforçando para manter normas comportamentais, acreditando que lapsos éticos podem prejudicar a valorização das empresas, produtividade e reputação.

O gestor brasileiro está mais confiante no futuro da economia do que seus pares ao redor do mundo. De acordo com os resultados da pesquisa, uma conseqüência disso é a concentração no uso de ferramentas que auxiliam e disciplinam o crescimento dos negócios, como Planejamento Estratégico e Benchmarking. As iniciativas em inovação ainda são mais tímidas no Brasil do que em outras regiões do globo.

Quando a pergunta era: "Você está preparado para uma desaceleração da economia nos próximos doze meses?", apenas $10 \%$ dos brasileiros responderam que sim, número que chega a impressionantes $37 \%$ na Pesquisa Global. Talvez por isso os brasileiros apostem menos na China e Índia para crescer do que americanos e europeus. Enquanto $54 \%$ dos americanos e europeus se preparam para trabalhar com os dois países nos próximos cinco anos, apenas $40 \%$ dos brasileiros têm planos similares. 
O amadurecimento no uso de ferramentas como Planejamento Estratégico, Benchmarking e Segmentação de Clientes reforça a concentração de esforços no crescimento dos negócios. As ferramentas que ganharão espaço nos próximos cinco anos também estão relacionadas a crescimento: Estratégias de Crescimento, Alianças Estratégicas e Balanced Scorecard.

Uma das grandes preocupações do executivo nacional é a comoditização de produtos. Para $70 \%$ deles, um número cada vez maior de produtos e serviços está se comportando como commodities - a média mundial é de 58\%. Apesar da constatação, os esforços em inovação ainda são limitados. Por exemplo, enquanto $58 \%$ dos americanos apostam em Inovação Colaborativa, apenas $41 \%$ dos brasileiros fazem uso dessa ferramenta. A mesma tendência pode ser verificada no uso de ferramentas mais inovadoras.

\subsubsection{Práticas de Gestão}

"O ambiente em que as organizações atuam hoje se caracteriza pela mudança cada vez mais veloz, descontínua e imprevisível.

Globalização: nas três últimas décadas do século $\mathrm{XX}, \mathrm{o}$ nacionalismo econômico entrou em declínio e as barreiras ao comércio e aos investimentos reduziram-se. A liberalização do comércio e dos investimentos levou a uma mudança na percepção e na ação das organizações quanto aos modelos de atuação global." (FNQ, 2006, p. 3)

Com a ascensão da globalização, as empresas vêm sendo submetidas a crescentes ondas de turbulências no ambiente competitivo, com mudanças de um mundo conhecido, em termos de produção e marketing, para outro, desconhecido, em que novas tecnologias, concorrentes, atitudes do consumidor, dimensões de controle social e, acima de tudo, questionamentos sobre papel social intensificam o grau de incerteza. Corporações e tradicionais escolas de administração do mundo todo procuram aprofundar o entendimento dos novos paradigmas em busca de êxito, perenidade e sustentabilidade dos negócios. Cliente, estratégia, auto-avaliação, aquisição de conhecimentos, redes de cooperação, liderança, gestão de pessoas, gestão de processos entre tantas outras devem estar na lista de prioridades dos gestores. 


\section{A Tabela 10 apresenta onze dimensões de negócios que exigiram mudança de} paradigma na era globalizada.

Tabela 10 - Mudança de paradigmas para a época da globalização

\begin{tabular}{|c|c|c|}
\hline DIMENSÕES & $\mathrm{De}$ & Para \\
\hline Ambiente externo & $\begin{array}{l}\text { Estabilidade, mudança progressiva e } \\
\text { linearidade }\end{array}$ & $\begin{array}{l}\text { Turbulência, descontinuidade e } \\
\text { mudança acelerada }\end{array}$ \\
\hline Organizações & $\begin{array}{l}\text { Máquina, como metáfora, sistema } \\
\text { isolado e independente }\end{array}$ & $\begin{array}{l}\text { Sistema vivo, ecossistema, } \\
\text { interdependência e adaptabilidade }\end{array}$ \\
\hline $\begin{array}{l}\text { Sociedade e meio } \\
\text { ambiente }\end{array}$ & $\begin{array}{l}\text { Restrições sujeitas a considerações } \\
\text { custo/benefício }\end{array}$ & $\begin{array}{l}\text { Partes integrantes do ecossistema da } \\
\text { organização }\end{array}$ \\
\hline Interação & $\begin{array}{l}\text { Competição, regionalidade e } \\
\text { relacionamento utilitário }\end{array}$ & $\begin{array}{l}\text { Competição, cooperação, globalização } \\
\text { e relacionamento de qualidade }\end{array}$ \\
\hline Estrutura & Pirâmide e integração vertical & Redes e integração horizontal \\
\hline Percepção de valor & Avaliação objetiva de ativos tangíveis & $\begin{array}{l}\text { Avaliação subjetiva de ativos } \\
\text { intangíveis }\end{array}$ \\
\hline Liderança & $\begin{array}{l}\text { Comando e controle, liderança } \\
\text { centralizadora e restrita à } \\
\text { organização com liderança distribuída } \\
\text { e abrangendo o ecossistema }\end{array}$ & $\begin{array}{l}\text { Líder como mentor, focalizador e } \\
\text { símbolo, com liderança distribuída e } \\
\text { abrangendo o ecossistema }\end{array}$ \\
\hline Inovação & Localizada, tarefa para especialistas & $\begin{array}{l}\text { Cultural, distribuída e abrangendo o } \\
\text { ecossistema }\end{array}$ \\
\hline Conhecimento & Crescimento linear e acesso restrito & $\begin{array}{l}\text { Crescimento exponencial e acesso } \\
\text { universal }\end{array}$ \\
\hline Aprendizado & $\begin{array}{l}\text { Função da escola. O que se aprende } \\
\text { uma vez para é para o resto da vida }\end{array}$ & $\begin{array}{l}\text { Função da escola e organização. } \\
\text { Aprendizado contínuo para toda a vida }\end{array}$ \\
\hline $\begin{array}{l}\text { Tecnologia da } \\
\text { Informação }\end{array}$ & $\begin{array}{l}\text { Automação } \\
\text { Mais tecnologia, menos pessoas }\end{array}$ & $\begin{array}{l}\text { Informatização. Mais conteúdo } \\
\text { intelectual e transformação do trabalho } \\
\text { em experiência desafiadora }\end{array}$ \\
\hline
\end{tabular}

Fonte: FNQ (2006, p. 7)

\subsubsection{Cliente}

"O conceito de cliente refere-se àquelas organizações e pessoas que recebem os produtos oferecidos pela organização. E somente este termo cliente - é usado nos Critérios de Excelência. Consumidor, usuário final, varejista, beneficiário e comprador são exemplos de clientes. Já o conceito relacionado a mercado é entendido como o ambiente socioeconômicoconcorrencial em que as atividades de uma organização são exercidas para suprir as necessidades e expectativas do conjunto de pessoas ou entidades envolvidas" (FNQ, 2007, p. 3).

A qualidade é inerente ao produto; não é a empresa que avalia a qualidade do que produz. Esta prerrogativa é do cliente. 
Atributos e características dos produtos - como garantia, assistência técnica, entrega e cortesia no atendimento - deixaram de ser diferenciais competitivos e já fazem parte dos requisitos explícitos dos clientes. Atualmente, o fundamento da excelência com relação ao cliente está estruturado em dois itens:

- aborda a forma como a organização identifica e entende as necessidades e expectativas dos clientes e do mercado. Também trata da divulgação dos produtos e marcas;

- trata do relacionamento com os clientes, abordando o atendimento das reclamações e a avaliação da satisfação, fidelidade e insatisfação dos clientes em relação a produtos e marcas (FNQ, 2007, p. 13).

O relacionamento é um recurso fundamental para o entendimento e a gestão das necessidades e expectativas dos clientes, bem como para o desenvolvimento de novos negócios.

\subsubsection{Classe Mundial}

A expressão Classe Mundial caracteriza empresas entre as melhores do mundo em gestão organizacional que se destacam por práticas e resultados, promovem interna e externamente a excelência de produtos e serviços, contribuem para a competitividade do mercado e para a melhoria da qualidade de vida das pessoas (FNQ, 2007). As empresas Classe Mundial possuem mecanismos para divulgar produtos, marcas e ações de melhoria com relação às práticas de gestão e produtos de forma que sejam conhecidas e reconhecidas pelos clientes e mercado, utilizando diversos meios, dentre os quais revistas, folhetos, catálogos; portais na internet, mensagens eletrônicas; patrocínio e participação em feiras, congressos, cursos; visitas aos clientes; e visita dos clientes às instalações da organização.

\subsubsection{Estratégias e planos}

A estratégia se torna o elemento-chave para a criação de diferenciais competitivos que contribuem para a criação de valor para as partes interessadas. A estratégia ocupa-se da definição de uma posição competitiva futura favorável ante os concorrentes. 
A formulação de estratégias está inserida no planejamento que define os passos para realizar a visão de futuro, e o caminho a percorrer é traduzido em objetivos estratégicos a ser perseguidos e monitorados a fim de viabilizar produtos competitivos e rentáveis no mercado e maximizar os resultados para as partes interessadas (FNQ, 2007, p.3).

Para Hayes (2008, p. 72), "projetar uma estratégia de produção eficaz é ainda uma forma de arte - restrita por possibilidades tecnológicas - assim como o projeto do produto". A implementação de estratégias apresenta-se como um dos aspectos críticos para o sucesso de longo prazo de uma organização, já que inclui o planejamento das ações, a alocação dos recursos e a definição das metas necessárias para sustentar as estratégias estabelecidas, assim como as sistemáticas para comunicação e o monitoramento de resultados.

O processo promove o encadeamento e o alinhamento dos objetivos dos diversos setores da organização às estratégias formuladas e compromete a cadeia de comando e os profissionais com objetivos comuns.

Tais objetivos, na forma de planos de ação, projetos que os compõem, prazos de conclusão e metas de desempenho, instrumentalizam o sistema de liderança com dois vetores essenciais à mobilização das pessoas - a promoção da motivação humana em torno de desafios; e a promoção da motivação humana em torno do incentivo das pessoas no tocante ao alcance de metas. Esses vetores são decorrentes do particionamento da Missão e Visão da organização em objetivos práticos e compreensíveis para os setores (FNQ, 2007, 19).

\subsubsection{Auto-avaliação e gestão de melhorias}

"A auto-avaliação tem por princípio realizar uma análise regular, sistemática e abrangente dos processos gerenciais e dos resultados de uma organização", e a empresa pode então identificar pontos fortes e oportunidades de melhoria. "Gera ações planejadas para melhorar as oportunidades identificadas e, quando procedente, incrementar seus pontos fortes, monitorando a implementação das ações e dos incrementos" (FNQ, 2007, p. 6). 
Entre os benefícios citados pela FNQ (idem) e alcançados com a aplicação do processo de auto-avaliação estão:

- aplicar abordagens bem estruturadas, baseadas em fatos, capazes de identificar os pontos fortes e as oportunidades para melhoria, com o progresso da implementação de ações monitorizado;

- subsidiar a análise dos cenários no processo de planejamento estratégico;

- tornar comum uma linguagem de gestão e um processo de aprendizado, com base em conceitos universalizados;

- formar pessoas nos conceitos fundamentais de excelência e proporcionarIhes os meios de compatibilizar-Ihes as responsabilidades com esses conceitos;

- desenvolver as competências das lideranças da organização;

- envolver no processo pessoas em todos os níveis e unidades da organização;

- avaliar a organização de forma coerente em nível macro (organização) ou micro (área);

- identificar as melhores práticas (pontos fortes) e disseminá-las pela organização;

- permitir o Benchmarking;

- subsidiar o reconhecimento interno pelo progresso alcançado, por meio de prêmios, baseado em critérios menos subjetivos.

As técnicas para proceder a uma auto-avaliação podem ser complementares ou evoluir na aplicação à medida que a organização desenvolve o sistema de gestão.

\subsubsection{Liderança}

A liderança se torna fundamental na medida em que é um caminho para levar para dentro das organizações a possibilidade de que todos os profissionais tenham acesso ao modelo da organização e possam, juntos, ir em busca da excelência.

Élcio Aníbal de Lucca (FNQ: Classe Mundial, 2004)

O exercício da liderança pressupõe que o gestor sirva de exemplo para todos, a partir de um comportamento ético e transparente, habilidades de planejamento, 
comunicação e análise. Isso é que estimula as pessoas a buscar a excelência e inclui a criação de um ambiente organizacional que leva as pessoas a realizar um propósito comum e duradouro, favorável à participação, autonomia, melhoria, inovação, proatividade e ao aprendizado organizacional (FNQ, 2007, p.3 e 4).

Para construir uma posição sustentável de liderança, uma das ferramentas mais adequadas é Gestão do Conhecimento, que requer que gerentes, além de catalogar e avaliar a base atual de conhecimento da empresa, determinem quais competências serão a chave de sucessos futuros e qual base de conhecimento é necessária (RIGBY, 2007, p.31).

O critério de liderança pode ser subdividido em três itens: a) o primeiro engloba os elementos necessários ao desenvolvimento e implementação de um sistema de liderança, incluindo a forma de exercício da liderança, a interação da direção com as partes interessadas, a implementação da governança, a gestão de riscos e o processo decisório, assim como práticas relacionadas à identificação, formação e desenvolvimento de líderes; b) o segundo envolve a cultura da excelência, representada por um conjunto de valores e princípios que são utilizados como guia e inspiração para toda a organização na implementação dos processos e práticas de gestão, definindo padrões de trabalho e assegurando o seu cumprimento por meio de mecanismos de controle estruturados; orienta o desenvolvimento de estratégias; destaca a gestão das mudanças culturais necessárias ao alinhamento organizacional e à concretização das estratégias; descreve o sistema de aprendizado da organização; e debate o desenvolvimento da inovação; c) o terceiro trata de como os líderes analisam o desempenho da organização, o que inclui a avaliação do atendimento das necessidades de todas as partes interessadas, em alinhamento com a estratégia organizacional (FNQ, 2007, p. 4 e 6).

Por outro ângulo, liderança de acordo com o Manual de Oslo (p. 32) está ligada ao Gerenciamento do Conhecimento, que compreende atividades relacionadas à apreensão, uso e compartilhamento do conhecimento pela organização. Diversas pesquisas sobre práticas de gerenciamento do conhecimento foram realizadas nos últimos anos abordando a questão da liderança, entre outros aspectos como políticas e estratégias, apreensão de conhecimento, treinamentos e comunicações, 
assim como as razões para o uso das práticas de gerenciamento do conhecimento e os motivos por trás do desenvolvimento dessas práticas.

\subsubsection{Pessoas}

De acordo com a FNQ (2007, p. 5), o critério "pessoas" relaciona o desempenho da organização com a capacitação, motivação e bem-estar da força de trabalho, bem como com um ambiente propício à participação e ao desenvolvimento e está estruturado em três itens:

- sistemas de trabalho - voltados a orientar a organização para a importância das relações entre as pessoas e do trabalho em equipe, com estímulo da cooperação mútua e comunicação eficaz. A empresa deve atentar para a importância das formas de avaliação de desempenho, recompensa e remuneração como alavancadores da busca do alto desempenho e da cultura da excelência;

- capacitação e desenvolvimento - aplica fundamentos de valorização das pessoas e aprendizado organizacional no sentido de assegurar a elas oportunidades para aprender e se desenvolver pessoal e profissionalmente.

- qualidade de vida - refere-se à manutenção do clima organizacional e da qualidade de vida, quesitos que abordam a integridade física, representada pela saúde ocupacional, segurança e ergonomia; assim como a busca do bem-estar, satisfação e motivação das pessoas, bem como a necessidade da avaliação de satisfação.

O atendimento a esses quesitos é condição fundamental para a retenção de talentos e para que a força de trabalho contribua para os resultados da organização, por meio da plena utilização da capacidade de cada um.

O critério "pessoas" está voltado a selecionar, integrar e organizar as pessoas e avaliar-Ihes o desempenho; capacitar e desenvolver; e manter o ambiente de trabalho, de forma a assegurar a utilização plena do potencial das pessoas que compõem a força de trabalho, em alinhamento com as estratégias organizacionais (FNQ, 2006d, p. 5). 


\subsubsection{Processos}

"Todo trabalho importante realizado nas empresas faz parte de algum processo (Graham e LeBaron, 1994). Não existe um produto ou um serviço oferecido por uma empresa sem um processo empresarial. Da mesma forma, não faz sentido existir um processo empresarial que não ofereça um produto ou um serviço. (...) $\mathrm{Na}$ concepção mais freqüente, processo é qualquer atividade ou conjunto de atividades que toma um input, adiciona valor a ele e fornece um output a um cliente específico" (GONÇALVES, 2000, p. 7).

Os processos são constituídos pelo conjunto das atividades inter-relacionadas ou interativas que transformam insumos (entradas) em produtos ou serviços (saídas). São um conjunto de atividades preestabelecidas que executadas numa seqüência determinada vão conduzir a um resultado esperado, assegurando o atendimento das necessidades e expectativas dos clientes e partes interessadas (FNQ, 2007, p. 3).

Gonçalves (2000, p. 10) divide os processos empresariais em três categorias:

- processos de negócio são aqueles que caracterizam a atuação da empresa e que são suportados por outros processos internos, resultando no produto ou serviço que é recebido por um cliente externo;

- processos organizacionais são centralizados na organização e viabilizam o funcionamento coordenado dos vários subsistemas da organização em busca do desempenho geral, garantindo o suporte adequado aos processos de negócio;

- processos gerenciais são focalizados nos gerentes e nas suas relações (Garvin, 1998) e incluem as ações de medição e ajuste do desempenho da organização.

A identificação e o mapeamento dos processos definem as necessidades e expectativas dos clientes e partes interessadas (acionistas, proprietários, funcionários, fornecedores e sociedade), permitindo planejamento de atividades, definição das responsabilidades e uso adequado dos recursos disponíveis (FNQ, 2007, p. 3 e 6$)$. 
O interesse em gerenciamento de processos nas empresas se dá pelas características que o tornam similar a uma ferramenta de gestão. Processo é um grupo de atividades realizadas numa seqüência lógica com o objetivo de produzir um bem ou um serviço que tem valor para um grupo específico de clientes (GONÇALVES, 2000, p. 6 apud HAMMER e CHAMPY, 1994).

De maneira geral, os processos nas empresas podem ser internos (quando se iniciam, são executados e terminam dentro da empresa) ou externos (se envolvem diversas empresas). Também podem ser horizontais e verticais, dependendo da orientação básica com relação à estrutura organizacional da empresa.

Uma das mais importantes aplicações da idéia de processos é a simulação do funcionamento de novas formas operacionais de obtenção dos resultados da empresa, sejam produtos, sejam conquistas de qualquer tipo. Outra aplicação importante ocorre na implementação das mudanças previstas para a operacionalização de um novo processo (GONÇALVES, 2000, p. 18).

\subsubsection{7.a Tecnologia e processos}

A tecnologia tem papel fundamental no estudo de processos empresariais, pois influencia tanto a forma de realizar o trabalho como a maneira de gerenciá-lo. Muitas vezes, o processo obedece a uma seqüência estrita de atividades, ditada pela tecnologia característica ou pela própria lógica do trabalho. O impacto da tecnologia abrange desde alterações na forma de realização do trabalho individual até a maneira pela qual as empresas trabalham colaborativamente em processos interorganizacionais (GONÇALVES, 2000).

A tecnologia empregada induz algumas dessas modificações e facilita a ocorrência de outras. O emprego de sistemas integrados de gestão empresarial, por exemplo, exige que as pessoas passem a executar tarefas de acordo com rotinas e procedimentos determinados pela tecnologia, por maior que seja a diferença com relação aos padrões anteriores. Por outro lado, a utilização de ferramentas de comunicação modernas, como correio eletrônico e teleconferência, viabiliza a montagem e o funcionamento de novos modelos de trabalho em redes. 
A falta de entendimento claro sobre o conceito de processo e a aplicação apenas pontual do conceito na gestão do negócio pode impactar os resultados e o desempenho da empresa.

A importância do emprego do conceito de processo aumenta à medida que as empresas trabalham com conteúdo cada vez mais intelectual, oferecendo produtos mais ricos em valores intangíveis. É maior ainda nas empresas de conteúdo puramente intelectual. As técnicas e práticas de gestão empresarial deverão se adequar às organizações que se estão estruturando por processos (GONÇALVES, 2000, p.18).

\subsubsection{Informação e conhecimento}

Informação e conhecimento compõem um instrumento orientado a determinar a tomada de decisões na empresa com base em prospecção do desempenho, fatos e dados do ambiente interno e externo. A organização necessita lançar mão de sistemas de informação adequados para tal finalidade e utilizar regularmente informações comparativas. Os diferenciais favoráveis, identificados em relação às informações, expressam o potencial de ativos intangíveis em agregar valor ao negócio e gerar diferencial competitivo (FNQ, 2008, p. 5).

Um desafio adicional para o uso de fontes de informação é localizá-las, já que as empresas podem ter acesso limitado a fontes potenciais de informação, e os importantes dados sobre fontes de informação podem auxiliar a montar um croqui de iniciativas de políticas para treinamento, melhoria nas potencialidades em TIC e estabelecimento de redes e de serviços de suporte (MANUAL DE OSLO, p. 91).

Enormes quantidades de dados são processados pelas empresas, gerando informações que são armazenadas e disponibilizadas a usuários internos e externos por meio de sistemas de informação. Parte dessas informações é utilizada para dar suporte a operações diárias, acompanhar o desenvolvimento de planos de ação, que implementam estratégias, e ainda subsidiar a tomada de decisões em toda a organização. 
Há alguns processos gerenciais importantes utilizados na gestão de informações (FNQ, 2008, p. 7):

- identificação da necessidade da informação;

- implementação de sistemas de informação que a atenda;

- atualização tecnológica dos sistemas desenvolvidos;

- disponibilização das informações aos usuários; e

- segurança das informações.

Fato relevante é que as atividades de inovação de uma empresa dependem parcialmente da variedade e da estrutura das relações que mantém com as fontes de informação e conhecimento, além de tecnologias, recursos humanos e financeiros (MANUAL de FRASCATI, p. 289). Um dos cinco princípios que orientaram inicialmente o trabalho da OECD é tirar o melhor resultado possível das fontes de informação existentes.

Os sistemas de informação via de regra são implantados por meio de softwares aplicativos. Há, contudo, dentro das empresas importantes sistemas de informação para apoiar as operações, acompanhar os planos de ação ou tomar decisões que não utilizam necessariamente soluções informatizadas em decorrência do perfil da organização, do baixo nível de complexidade para geração e tratamento dos dados e da simplicidade da disponibilização e acesso às informações (FNQ, 2008, p. 7).

\subsubsection{Cidadania e sustentabilidade}

O relacionamento ético e transparente com todas as partes interessadas, visando ao desenvolvimento sustentável, não pode estar fora da visão do gestor. Para a preservação dos recursos ambientais e culturais para gerações futuras, o exercício da cidadania deve pressupor apoio a ações de interesse social, podendo incluir educação e assistência comunitária, promoção de cultura, esporte e lazer e participação no desenvolvimento nacional, regional ou setorial. A liderança na cidadania requer incluir outras organizações, públicas ou privadas, nesses propósitos e, também, estimular os quadros internos a se engajar em atividades sociais. 
Na Palavra do Presidente, do que ficou conhecido como Relatório Brundtland, a exprimeira-ministra da Noruega Gro Harlem Brundtland, que presidiu a Comissão Mundial de Meio Ambiente e Desenvolvimento em 1987, lembra que "o 'meio ambiente' é onde todos nós vivemos; e 'desenvolvimento' é o que todos nós fazemos tentando melhorar nosso pedaço de terra dentro daquele condomínio. Os dois são inseparáveis" (...) "muitos dos caminhos de desenvolvimento das nações industrializadas são claramente insustentáveis. E as decisões de desenvolvimento desses países, por causa do grande poder econômico e político, terão efeito profundo na habilidade de todas os povos para sustentar o progresso humano das gerações vindouras". Trata-se assim de buscar o desenvolvimento amplo da sociedade com garantia de saúde, conforto e conhecimento, sem exaurir os recursos naturais do planeta. Para isso, todas as formas de relação do homem com a natureza devem ocorrer com o menor dano possível ao ambiente. As políticas, os sistemas de produção, a transformação, o comércio, os serviços - agricultura, indústria, turismo, mineração - e o consumo têm de coexistir preservando a biodiversidade.

Desde então, a expressão "desenvolvimento sustentável" passou a ser usada, evoluindo para "sustentabilidade", um meio de configurar a atividade humana de forma que a sociedade possa satisfazer as necessidades e expressar o potencial, preservando a biodiversidade e os ecossistemas naturais. Para um empreendimento ser sustentável, tem de ter em vista quatro requisitos básicos: ser ecologicamente correcto; economicamente viável; socialmente justo; e culturalmente aceito.

Um relatório sobre o encontro de 2008 do Fórum Econômico Mundial, que reúne indústrias de bens de consumo e governos, tratou do tema Crescimento com Sustentabilidade. O autor afirma que "metade dos cinqüenta maiores varejistas e $70 \%$ das cinqüenta maiores indústrias de bens de consumo publicam relatórios sobre sustentabilidade" (RIGBY, 2007, p. 3). Pergunta-se no texto se executivos responsáveis por sustentabilidade e crescimento acelerado, em meio à competição global por mercado, investiriam milhões de dólares em projetos sustentáveis? A locomotiva híbrida, díesel-elétrica, de 207 toneladas da General Eletric mostra que sim. 
De acordo com Rigby (2007, p.3), os incentivos fiscais vão facilitar a rápida transição para a máquina nova da GE. Se todos os motores de antes de 2001 forem substituídos pela nova locomotiva, as estradas de ferro não só economizariam 425 milhões de dólares anualmente em combustível, mas a mudança cortaria em um terço as emissões de óxido de nitrogênio, o que seria como retirar um terço de todos os carros das estradas norte-americanas.

Em termos de desenvolvimento sustentável, organizações que buscam a excelência devem contribuir de forma proativa para a preservação dos ecossistemas e a conservação dos recursos. Conseqüentemente, devem identificar e maximizar ações em que teria contribuição mais relevante. A alta direção deve estar comprometida com o tema e alinhar tais ações com a estratégia e os valores organizacionais ( $F N Q$, 2006, p. 10).

Há um entendimento cada vez maior de que sustentabilidade pode ser "condição prévia" para o crescimento lucrativo, e as empresas devem estar atentas às estatísticas. RIGBY (2007, p.3) lembra que um estudo ambiental de 2004 mostrou que pelo menos dois terços de 25.000 consumidores pesquisados nos EUA, Canadá e Europa Ocidental formam a opinião baseados parcialmente na ética, impacto ambiental e responsabilidade social das empresas.

Nos EUA, $60 \%$ dos adultos entrevistados disseram que saber que uma empresa se preocupa com o impacto ambiental e social os torna mais suscetíveis a adquirir produtos e serviços dessa empresa; enquanto $40 \%$ disseram que evitariam comprar produtos se soubessem que a disposição das embalagens causaria ameaça potencial à vida selvagem (RIGBY, 2007, p. 3).

Como forma de obter feedback das ações apoiadas, as empresas podem estabelecer processos para avaliar a satisfação da sociedade em relação à própria atuação cidadã contemplando essencialmente os seguintes aspectos:

- satisfação com relação aos impactos dos processos e operações; e

- satisfação com relação aos esforços para o fortalecimento da sociedade (FNQ, 2006, p. 18). 


\subsubsection{MicROS E PEQUENAS EMPRESAS}

Para Santos e Cunha apud Ferro e Torkomian (2004, p. 20), "a definição de empresa de base tecnológica ou de alta tecnologia não é tarefa fácil, pois há dificuldade em estabelecer os critérios para caracterizar uma pequena empresa". Para Sbragia e Pereira (2006, p. 4), "a legislação pode determinar o que é pequena empresa a partir de várias maneiras, como, por exemplo, o número de funcionários, e o faturamento. (...) A classificação mais utilizada no Brasil é a por número de empregados, utilizada pelo SEBRAE e pelo IBGE apud Miranda (1998)":

- microempresas - têm até dezenove empregados na indústria e até nove empregados no setor de comércio e serviços;

- pequenas empresas - empregam de vinte a 99 empregados na indústria e de dez a 49 empregados no setor de comércio e serviços;

- médias empresas - empregam de 100 a 499 empregados na indústria e de cinqüenta a 99 empregados no setor de comércio e serviços;

- grandes empresas - empregam acima de 500 empregados na indústria e acima de 100 empregados no setor de comércio e serviços.

As pequenas empresas são de fundamental importância para a economia de um país e estão presentes em todos os segmentos. Além de mais rapidez de entrega de produtos e mais flexibilidade, geram um número substancial de empregos (SBRAGIA E PEREIRA, p. 5).

Médias e Pequenas Empresas (MPEs) de base tecnológica que atuam em mercados competitivos necessitam conciliar os propósitos essenciais com uma gestão eficiente e profissionalizada. Por isso, é necessário analisar experiências que permitam identificar quais fatores, de origem interna ou externa, têm impactado o êxito dessas empresas e, a partir daí, desenvolver critérios e modelos sistematizados de avaliação desses empreendimentos. Os principais problemas das empresas residentes são a falta de experiência empresarial, dificuldades técnicas, dificuldades na gestão de projetos de inovação e o desafio em competir no mercado globalizado. 
Num estudo de casos múltiplos no Centro Incubador de Empresas Tecnológicas (CIETEC) com quatro empresas de origem universitária com pelo menos 2,5 anos de vida, Sbragia e Pereira (s/p., 2003) verificaram que, "não obstante serem de base tecnológica, tais empresas parecem apresentar, enquanto trajetória histórica, características inerentes a qualquer MPEs", entre as quais estão:

- dificuldade para lidar com sócios;

- falta de formação gerencial;

- dificuldades no desenvolvimento rápido de produtos;

- desinteresse/dificuldades em registrar patentes.

Com relação aos aspectos facilitadores de origem interna que têm contribuído para o êxito dessas empresas, estão os seguintes:

- conhecimento técnico, especialmente no início;

- criatividade da equipe de trabalho;

- produtos inovadores;

- capacidade das pessoas de atuar em redes de cooperação;

- necessidade de elaboração de planos de negócio, contendo estimativas de demanda, orçamentos e metas futuras de crescimento;

Com relação aos aspectos facilitadores de origem externa que têm contribuído para o êxito das empresas estudadas, estão:

- a universidade como ambiente facilitador;

- facilidade para usar os laboratórios da universidade;

- apoio da incubadora para busca de financiamentos;

- infra-estrutura oferecida pela incubadora; e

- possibilidade de atuar em redes com as outras incubadas; 
Os dados levantados apontaram que as incubadoras desempenham papel importante para o êxito dessas empresas. Assim, as seguintes recomendações podem ser feitas enquanto ações a serem desencadeadas por esse tipo de instituição:

- auxílio às incubadas na obtenção de recursos financeiros nas agências de fomento, especialmente para as empresas start up;

- constituir-se numa fonte permanente de networking para as incubadas, aspecto este importante para seu desenvolvimento;

- auxiliar no planejamento estratégico das empresas e na definição clara do mercado-alvo, especialmente em âmbito internacional;

- colaborar na formação gerencial dos incubados. Tendo em vista que os dados apontaram que as empresas estudadas eram mais fortes na área técnica do que na gerencial, esse desequilíbrio é apontado pelos autores como gerador de dificuldades futuras para as incubadas.

A partir desses resultados, que devem ser vistos como meramente indicativos e bastante limitados quanto à representatividade dado o pequeno universo analisado, sugere-se a condução de estudos complementares que visem identificar com maior grau de precisão como cada um desses fatores pode afetar iniciativas futuras de criação de novas empresas de base tecnológica. Estar-se-ia assim caminhando para a criação de um modelo de avaliação técnico-econômica e de gestão de novas empresas.

\subsubsection{Gestão de pequenas empresas}

A escolha correta de ferramentas de gestão pode conferir muito mais do que aumento na receita às empresas de pequeno porte, permitindo crescimento sustentável e consolidação dos negócios. A busca pela excelência envolve não delegar, por exemplo, tarefas "menores" como o controle fiscal e financeiro para o contador e tocar o negócio sem preocupar-se com isso. 
A formação em gestão ajuda a entender como a empresa pode melhorar, conquistar mercado e ser mais competitiva, sem descuidar do aspecto empreendedorismo para ampliar a visão estratégica. Melhor preparo do empreendedor significa maior taxa de sobrevida das empresas.

A Figura 7 mostra a taxa de sobrevida das empresas no Estado de São Paulo.

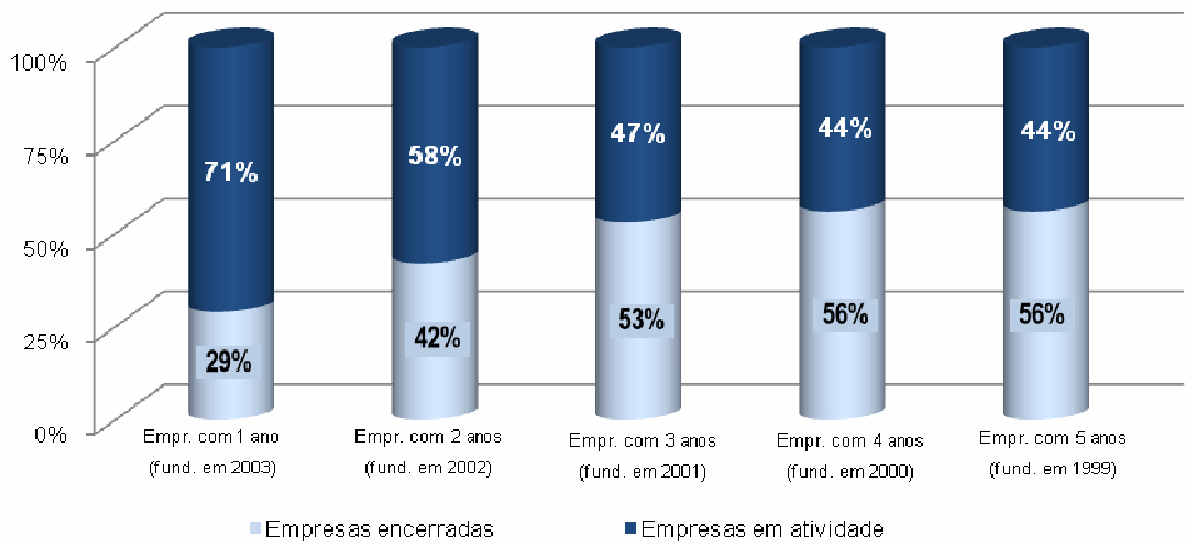

Figura 7 - Taxa de mortalidade das empresas no Estado de São Paulo (rastreamento out/dez 2004).

Fonte: SEBRAE-SP

Segundo o SEBRAE-SP (2008), no Brasil existem 5,1 milhões de empresas, dos quais $98 \%$ são micro e pequenas empresas (MPEs). Os pequenos negócios (formais e informais) respondem por mais de dois terços das ocupações do setor privado.

De acordo com dados de pesquisa do SEBRAE, 56\% das empresas fecham antes de completar o quinto ano de atividade, tendo como principais causas:

- comportamento empreendedor pouco desenvolvido;

- falta de planejamento prévio;

- gestão deficiente;

- insuficiência de políticas de apoio;

- conjuntura econômica deprimida;

- problemas pessoais dos proprietários. 
Corrobora as conclusões do SEBRAE um estudo da FIPE/USP (1998) com 3.000 pequenas empresas paulistas, ao verificar o conjunto de fatores que geram sucesso ou limitações para o desenvolvimento de pequenos empreendimentos. Entre os fatores de êxito foram citados:

- empresários com experiência prévia e dedicação exclusiva;

- uso de assessorias externas e planejamento cuidadoso do novo negócio antes de iniciá-lo;

- preocupação com maior grau de escolaridade;

- disciplina para planejar e executar o planejamento.

Como principais fatores da desistência ou falência dos empreendimentos, foram citados:

- falta de crédito e de capital de giro (25\%);

- falta de demanda pelo produto $(30 \%)$;

- problemas pessoais (16\%);

- inadimplência dos clientes (7\%);

- carga tributária (7\%); e

- problemas com sócios (9\%).

A pesquisa realizada com empresas de base tecnológica apoiadas por incubadoras revela que o porte da empresa (pequena) não é necessariamente fator limitante para o sucesso. Os fatores mais citados foram: ausência de planejamento e de gestão; pouco conhecimento sobre as potencialidades tecnológicas e mercadológicas das empresas; desencontros da política econômica e social e de Ciência e Tecnologia do país.

Há ainda problemas de ordem técnica, como distribuição e comercialização, decorrentes, às vezes, dos poucos recursos existentes para investimento em publicidade e marketing, como falta de experiência na empresa para elaborar estratégias adequadas. 
E, ainda, por incertezas quanto à qualidade dos produtos e a capacidade da empresa de cumprir prazos e escalas de produção (SBRAGIA \& STAL, 2002, p. 191).

Há estreita relação entre tempo investido em formação e longevidade das empresas. A contratação de serviços de consultoria também é uma boa receita para melhorar a gestão dos negócios e as técnicas de produção, assim como aprender a delegar poder - é preciso dar chances para os funcionários e capacitá-los, pois passam a enxergar um plano de carreira.

Com maior domínio da gestão, a rotina de planejamento também entrou para a agenda das empresas de pequeno porte, como observar todos os aspectos do negócio, avaliar conquistas e admitir deficiências, buscando meios de superá-las.

Muitos gestores mantêm o foco no produto e investem em processos mas não podem deixar de focar na administração do modelo de vendas. A falta de pensamento sistêmico é uma das deficiências mais comuns nas empresas de pequeno porte. $\mathrm{O}$ inter-relacionamento entre os diferentes departamentos é um conceito difícil de incutir em uma pequena empresa, podendo ser item determinante para o sucesso.

O conhecimento sobre o mercado é um fator que diferencia concorrentes e que impulsiona o crescimento, somando novas preocupações para gestores que precisam cuidar do resultado financeiro, da produção e das equipes internas: é necessário olhar para fora, ir ao mercado, conhecer o cliente.

A busca pela excelência em empresas de pequeno porte é uma corrida que já ganhou lugar nas estatísticas, pois, para competir, é preciso avaliar o desempenho e as práticas de gestão.

\subsection{TECNOLOGIA DA INFORMAÇÃO E COMUNICAÇÃO (TIC)}

A partir da Cúpula Mundial da Sociedade da Informação (WSIS) realizada em Genebra em 2003, países e regiões foram convocados a desenvolver ferramentas para medir e monitorar o progresso em direção à "sociedade da informação", incluindo indicadores básicos de tecnologia da informação e comunicação (TIC). 
A cúpula marca o início de um processo geopolítico conduzido pela Organização das Nações Unidas e pela União Internacional de Telecomunicações. Portanto, um período decisivo do ponto de vista das negociações multilaterais que eventualmente conduzirão a um novo patamar de governança global das redes digitais, pautado, em boa medida, pela qualidade dos indicadores de inclusão, acesso digital ou conectibilidade (FAPESP, 2004, p. 7).

"A convergência digital entre telefonia, internet e telecomunicações (rádio e TV) prenuncia modificações de grande amplitude e profundidade não apenas nos comportamentos e relações humanas e institucionais, mas também nos padrões de conexão entre as infra-estruturas de todos os setores da vida econômica e social. Essas mudanças têm como fator determinante $\mathrm{o}$ desenvolvimento de tecnologias de informação e comunicação operadas por meio de redes digitais interativas" (FAPESP, 2004, p. 5).

Na pesquisa de mensuração realizada pela Organização das Nações Unidas (ONU) em 2004, 179 países receberam o questionário. Na região da América Latina e Caribe, mais da metade dos vinte países pesquisados não têm definição formal para TIC; seis países aplicaram algum tipo de definição e três estão desenvolvendo uma (UN, 2005a, p. 128).

Segundo o relatório, Tecnologia da Informação (TI) pode ser resumida como um conjunto de todas as atividades e soluções providas por recursos de computação e, com aplicações ligadas às mais diversas áreas. Tecnologia da Informação também é comumente utilizada para designar o conjunto de recursos não humanos dedicados ao armazenamento, processamento e comunicação da informação, bem como o modo de como esses recursos estão organizados num sistema capaz de executar um conjunto de tarefas. A TI não se restringe a equipamentos (hardware), programas (software) e comunicação de dados. Existem tecnologias relativas ao planejamento de Informática, ao desenvolvimento de sistemas, ao suporte ao software, aos processos de produção e operação e ao suporte de hardware. A sigla TI abrange todas as atividades desenvolvidas na sociedade pelos recursos da informática. 
É a difusão social da informação em larga escala de transmissão a partir de sistemas tecnológicos inteligentes. A aplicação, obtenção, processamento, armazenamento e transmissão de dados também são objeto de estudo na TI.

Convivem no cenário de pesquisa e desenvolvimento das novas TICs a percepção do caráter revolucionário e um conjunto inédito de dificuldades no campo da mensuração, interpretação e, portanto, tomada de decisões (FAPESP, 2004, p. 5). Estatísticas comparativas sobre acesso e uso de TIC são críticas para a formulação de políticas e estratégias relativas ao crescimento de TIC visando a inclusão social e a coesão e para monitorar e avaliar o impacto da TIC no desenvolvimento econômico e social (UN, 2005b, Foreword).

\subsubsection{INDICADORES DE TIC}

Emergindo da crise de 2000, a indústria das telecomunicações vem se transformando. A voz continua a ser o principal impulsionador dos mercados de telecomunicações dos países-membros da OECD, que alcancaram rendimentos de milhões dólares com ela e não param de evoluir. Os serviços móveis perfazem $40 \%$ de todos os rendimentos de telecomunicações da região da OECD, e os assinantes de serviços móveis ultrapassam os da rede fixa numa razão de três para um (3:1). Ao mesmo tempo, tecnologias como Voz sobre o Protocolo Internet (VolP) exercem forte pressão nos preços dos serviços de voz. A banda larga está-se tornando a tecnologia dominante para acesso à internet na região da OECD; 60\% dos 256 milhões de assinantes de internet possuem ligação em banda larga. Os fornecedores de serviços por cabo oferecem freqüentemente dados e voz, enquanto as empresas de serviços móveis complementam as ofertas com pacotes de dados e vídeo, e os fornecedores tradicionais de telecomunicações disponibilizam produtos múltiplos similares sobre as redes (OECD, 2007a, p. 3).

De acordo com a OECD, o crescimento e desenvolvimento dos mercados de comunicações também se refletem no comércio de equipamentos. $O$ aumento das importações de países como a China estão tendo impacto substancial no equilíbrio do mercado. As exportações para países não-membros cresceram 66\% desde 1996, enquanto as importações cresceram $112 \%$. 
A China é um dos cinco países emergentes no grupo conhecido por BRIC (Brasil, Rússia, Índia, China), que está entre os mercados mundiais de TIC de mais rápido crescimento; e o desenvolvimento no bloco tem efeitos colaterais na região da OECD.

Entre 2000 e 2005, as despesas com TIC nas economias BRIC aumentou de 114 bilhões de dólares para 277 bilhões (140\%), enquanto mundialmente as despesas com TIC aumentaram apenas 5,6\% ao ano e na região da OECD em 4,2\% ao ano (OCDE, 2007a, p. 3).

Segundo a Sociedade para Promoção da Excelência do Software Brasileiro (Softex), o setor de tecnologia da informação no Brasil (inclusive a indústria eletroeletrônica) apresentou em 2001 faturamento de 42,3 bilhões de reais. Entre os principais segmentos responsáveis por esse montante está o setor de software, com 18 bilhões de reais, e de hardware, com 19,92 bilhões de reais (FAPESP, 2004, p. 7).

\subsubsection{INTERNET E COMÉRCIO ELETRÔNICO}

Uma forma elementar e prática de se referir a comércio eletrônico é a utilizada pelo Comitê Gestor da Internet no Brasil (CGI, 2007, p. 348): "compra ou venda de mercadorias ou serviços por meio de redes de computadores baseadas em protocolos da internet ou outras redes mediadas por computadores".

A definição não leva em conta as vantagens competitivas resultantes da associação dos participantes das cadeias de abastecimento e de valor (as pessoas envolvidas no fluxo de mercadorias, serviços, dinheiro e informações necessários para levar os produtos da matéria-prima até as mãos do consumidor).

Nesse sentido, comércio eletrônico inclui qualquer atividade comercial que ocorra diretamente entre empresa, parceiros ou clientes por meio de uma combinação de tecnologia de computação e comunicação (LUCIANO, 2003 apud TREPPER, 2000, p. 4). 
O comércio eletrônico está provocando mudanças intensas na organização das empresas e na relação das empresas com clientes, parceiros e fornecedores, inaugurando uma nova era no mundo dos negócios.

Por trás da aparentemente simples mudança na forma de comprar, há modificações na economia, organização da indústria, legislação, empregos, formas de consumo, de relacionamento e de criação de valor (LUCIANO, 2003, p. 2).

De acordo com Viotti e Macedo (2003, p. 553-554). No Brasil, em 1999, o segmento B2B ("business to business", ou transações comerciais entre empresas) apresentou faturamento de 50,4 bilhões de dólares; contra 30,1 bilhões do segmento B2C ("business to consumer", ou empresa com o consumidor final).

Quase metade das pessoas que já utilizaram a Internet declarou ter realizado pesquisas de preço de produtos ou serviços pela rede (45\%) em 2007; enquanto apenas $16 \%$ informaram ter finalizado uma compra via web.

O dado demonstra que a internet já se consolidou como ferramenta para comparação de custos e levantamento da disponibilidade de bens e serviços, mesmo que a finalização do processo de aquisição do produto não ocorra por meio dela (CGI, 2007, p. 95).

De acordo com a Câmara Brasileira de Comércio Eletrônico (2005), o faturamento do comércio eletrônico no Brasil teve crescimento nominal de $400 \%$ nos últimos cinco anos. Além disso, um levantamento encomendado pela Camara-e.net aponta que, entre 2003 e 2004, o valor movimentado pelo comércio eletrônico entre as empresas e os consumidores brasileiros representou 4,22\% do total de negociações efetuadas no Brasil.

A Figura 8, com dados de comércio eletrônico do Brasil (2001-2005), e a Figura 9, com dados do comércio eletrônico mundial (1999-2004), permitem comparar a posição do Brasil em relação aos demais países pesquisados. O setor no Brasil deve atingir a marca dos 2,8 bilhões de reais em 2010 de acordo com estudo desenvolvido pela Forrester Consulting (CBCE, 2005, p. 2-3). 
Confrontando os gráficos, é possível ter uma noção das quantias envolvidas e da posição do comércio eletrônico brasileiro no mundo.

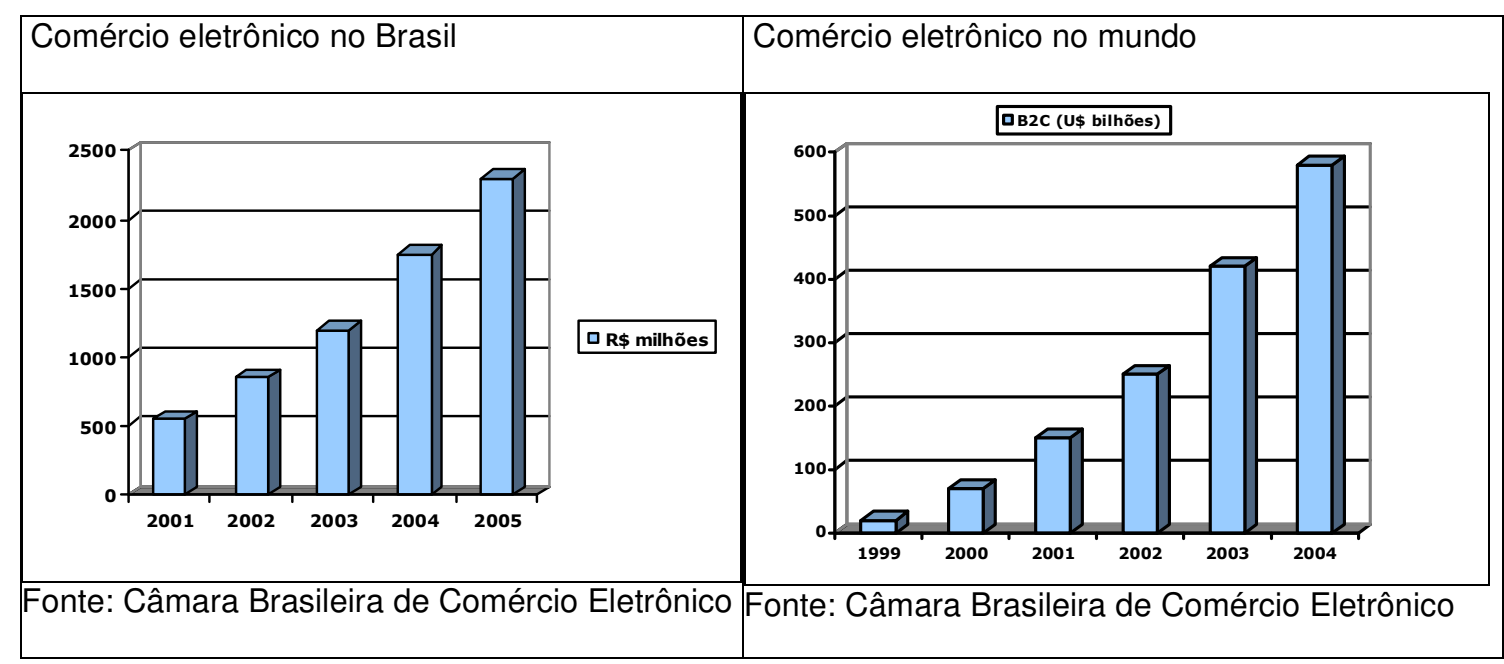

Figura 8 - Comércio eletrônico no Brasil

Figura 9 - Comércio eletrônico no mundo

\subsubsection{INTERNET E TIC NO BRASIL E NA OECD}

O setor de TIC está entre os mais dinâmicos no comércio de produtos e serviços em investimentos estrangeiros diretos orientados à exportação, fusões e aquisições, particularmente em telecomunicações. Em 2003, mais de 14,4 milhões de pessoas estavam empregadas na área de TIC nos países da OECD, ou $5,5 \%$ da força de trabalho: 5 milhões na manufatura e 9,5 milhões em serviços (OECD, 2006, p. 63).

O comércio de produtos de TIC expandiu-se rapidamente nos anos 1990, crescendo mais de 20\% em 2000. Em 2001 houve desaceleração, e o declínio na demanda foi acentuado, com forte recuperação em 2003 e 2004 . O crescimento manteve-se firme nos mesmo valores em 2005, e para 2006 era esperada a manutenção das mesmas taxas na produção, com crescimento maior em alguns segmentos e especialmente no comércio com países em desenvolvimento como a China (OECD, 2006, p. 64).

No Brasil, no início de 1990, quando a Lei de Reserva de Informática é substituída pela Lei no 8.248 , de 23/out./1991, havia 105.000 postos de trabalho; e, no final da década, já com a importação franqueada e o advento da internet para o público, o número caiu para 100.000 (VIOTTI \& MACEDO, 2003, p. 555). 
Csillag e Graeml (2005) buscaram avaliar a intensidade de uso da internet e outras ferramentas de TI; o impacto destas sobre os processos e atividades das empresas entre 2001 e 2004; e a intenção de adotar as ferramentas nos próximos três anos. A amostra foi composta de 665 empresas da base de dados da Federação das Indústrias do Estado de São Paulo (FIESP), já que o Estado responde por 36,6\% dos postos de trabalho do setor industrial brasileiro e $49,1 \%$ do valor de transformação industrial (ITV) nacional.

Os resultados mostram que muitas ferramentas adotadas no exterior são subutilizadas no Brasil. Apesar de a maioria das empresas possuir site próprio, o uso é basicamente como uma vitrine de produtos, sem geração de receita. $\mathrm{O}$ comércio eletrônico, por exemplo, é muito pouco explorado, e conferências pela rede e "chats" estão praticamente ausentes do ambiente organizacional, embora sejam ferramentas promissoras para a comunicação entre profissionais da empresa, fornecedores e clientes.

Pelo menos $20 \%$ das empresas participantes da pesquisa de Csillag e Graeml acreditam que a internet e outras tecnologias de informação foram responsáveis por mudança considerável na maioria de seus processos e atividades nos últimos três anos. Também se constatou que quase três quartos das grandes empresas já buscam obter respostas dos clientes por meio dos sites, e metade os usam para serviço pós-venda. Segundo Csillag e Graeml, isso sugere que a indústria está descobrindo que proporcionar o melhor serviço para os clientes pode representar um argumento poderoso para diferenciar o produto da concorrência e obter vantagem competitiva.

Outro ponto positivo é o aumento do interesse pelo e-procurement, ferramenta utilizada para compras corporativas na internet. Além disso, a literatura citada pelos autores mostra que o predomínio dos sites institucionais não é, em si, um retrocesso para o comércio eletrônico, como poderia parecer. Segundo eles, sites institucionais costumam ser um ensaio para sites comercialmente agressivos, assim como a compra de materiais não-produtivos pela internet tende a ser um ensaio para a compra de materiais produtivos, o que é mais central ao negócio. 
A internet e a rápida expansão da telefonia celular transformaram o segmento de equipamentos de comunicação no de mais rápido crescimento em TIC desde 1996, com as exportações dos países da OECD tendo dobrado entre 1996 e 2000. Os maiores exportadores foram Coréia, Alemanha e Estados Unidos. Equipamentos de informática formam o maior mercado de TIC, com um terço do total negociado; e Coréia e Irlanda permanecem sendo os maiores produtores (OECD, 2006, p. 65).

No Brasil, a liberalização do mercado das TIC no início dos anos 1990 teve maior impacto no setor de informática; as transformações nas telecomunicações foram ocorrer mais tarde, com a Lei Geral de Telecomunicações (VIOTTI \& MACEDO, 2003, p. 549). A Tabela 11 mostra, por meio de "hosts", o crescimento da internet no Brasil, cujo índice é elevado mesmo comparado a países desenvolvidos.

Tabela 11 - Expansão da internet no Brasil e no mundo (jan./1998 e jan./2008)

\begin{tabular}{|c|c|c|c|c|c|}
\hline & \multicolumn{5}{|c|}{ Posição dos países por número de hosts (provedores de internet) } \\
\hline & \multicolumn{3}{|c|}{ jan./1998 } & \multicolumn{2}{|c|}{ jan./2008 } \\
\hline $1^{\circ} \underline{0}$ & Estados Unidos* & 20.623 .995 & 10 & Estados Unidos* & 302.884 .146 \\
\hline $2^{0}$ & Japão (.jp) & 1.168 .956 & $2^{\circ}$ & Japão (.jp) & 36.803 .719 \\
\hline $3^{\circ}$ & Reino Unido (.uk) & 987.733 & $3^{\circ}$ & Alemanha (.de) & 20.659 .105 \\
\hline $4^{0}$ & Alemanha (.de) & 994.926 & $4^{\circ}$ & Itália (.it) & 16.730 .591 \\
\hline $5^{\circ}$ & Canadá (.ca) & 839.141 & $5^{\circ}$ & França (.fr) & 14.356 .747 \\
\hline $6^{0}$ & Austrália (.au) & 665.403 & $6^{0}$ & China (.cn) & 13.113 .985 \\
\hline $7^{0}$ & Holanda (.nl) & 381.172 & $7^{0}$ & Austrália (.au) & 10.707 .139 \\
\hline $8^{\circ}$ & Finlândia (.fi) & 450.044 & $8^{\circ}$ & Holanda (.nl) & 10.540 .083 \\
\hline $9^{\circ}$ & França (.fr) & 333.306 & 90 & Brasil (.br) & 10.151 .592 \\
\hline $10^{\circ}$ & Suécia (.se) & 319.065 & $10^{\circ}$ & México (.mx) & 10.071 .370 \\
\hline $11^{\circ}$ & Itália (.it) & 243.250 & $11^{\circ}$ & Reino Unido (.uk) & 7.727 .550 \\
\hline $12^{\circ}$ & Noruega (.no) & 286.338 & $12^{\circ}$ & Polônia (pl) & 7.134 .976 \\
\hline $13^{0}$ & Espanha (.es) & 168.913 & $13^{\circ}$ & Taiwan (.tw) & 5.121 .607 \\
\hline $14^{\circ}$ & Suíça (.ch) & 114.816 & $14^{\circ}$ & Canadá (.ca) & 4.717.308 \\
\hline $15^{0}$ & Dinamarca (.dk) & 159.358 & $15^{\circ}$ & Finlândia (.fi) & 3.728 .551 \\
\hline $16^{0}$ & Nova Zelândia & 169.264 & $16^{\circ}$ & Bélgica (.be) & 3.618 .495 \\
\hline $17^{0}$ & Coréia (.kr) & 121.932 & $17^{\circ}$ & Rússia (.ru) & 3.577 .635 \\
\hline $18^{\circ}$ & Brasil (.br) & 117.200 & $18^{\circ}$ & Suécia (.se) & 3.513 .170 \\
\hline $19^{\circ}$ & Bélgica (.be) & 87.938 & $19^{\circ}$ & Suíça (.ch) & 3.308 .684 \\
\hline $20^{\circ}$ & África do Sul (.za) & 122.025 & $20^{\circ}$ & Dinamarca (.dk) & 3.256 .134 \\
\hline
\end{tabular}

Fonte: Comitê Gestor da Internet no Brasil (excertos e fusão de tabelas de 1998 e 2008) 
Em 2007, a Internet atingiu 17\% do total de domicílios brasileiros, o que representa crescimento de 3 pontos percentuais em relação ao ano anterior. Conexões em banda larga já estão presentes em $50 \%$ dos domicílios brasileiros que possuem acesso à internet, mas $42 \%$ ainda se conectam à rede principalmente por modem tradicional via acesso discado. Em 2006, o acesso discado era predominante, com $49 \%$, enquanto as conexões em banda larga representavam $40 \%$ dos tipos de acesso domiciliar. $O$ crescimento da banda larga no período foi, portanto, de 10 pontos percentuais (CGI, 2007, p. 79).

\subsubsection{RisCOS E BENEFíCIOS DO INVESTIMENTO EM TI}

Quando acontece, o colapso em projetos de $\mathrm{Tl}$ assume duas formas. O primeiro padrão de fracasso é marcado por falta de consenso em objetivos e falta de confiança nos negócios de TI da empresa. Os executivos hesitam em investir em grandes projetos de $\mathrm{TI}$, o que resulta em orçamento menor para a área. No outro padrão, a TI e os negócios da empresa alinham-se, e o gasto em TI permanece estável, mas os gestores resistem em investir em qualquer coisa que não esteja intimamente conectada com as necessidades imediatas para aplicação no negócio a infra-estrutura torna-se obsoleta, a base comum de dados não cresce e o sistema se torna complexo e frágil. Uma vez que o colapso em TI tenha sido evitado e a confiança restaurada, as empresas devem permanecer vigilantes. O alinhamento entre $\mathrm{TI}$ e o fundamento dos negócios é importante e requer constante ajustamento para manter a TI na direção correta. (WESTERMAN, 2008)

A performance das maiores empresas de TIC nos últimos anos mostra ampla recuperação desde o agudo declínio e recessão que começou em 2000 e foi até 2002. Software, serviços e equipamento de TI têm crescido consistentemente, mas as condições foram muito mais desafiadoras para empresa de equipamentos de comunicações.

As corporações precisam encontrar o equilíbrio entre o extremo de não inovar em nada - e perder oportunidades - e só inovar - e aumentar as despesa e o risco (FUJITSU, 2002). 
As 250 maiores empresas de TIC tiveram receita de 3 trilhões de dólares, cerca de 570 bilhões a mais que em 2000, com crescimento médio de $4 \%$ ao ano desde então. As 250 maiores firmas empregam 10 milhões de pessoas no mundo todo, com gasto em P\&D da ordem de 135 bilhões (6,3\%) em 2005 (OCDE, 2006, p. $27-$ 28). A Figura 10 mostra a fatia de mercado de cada setor de TIC em 2005.

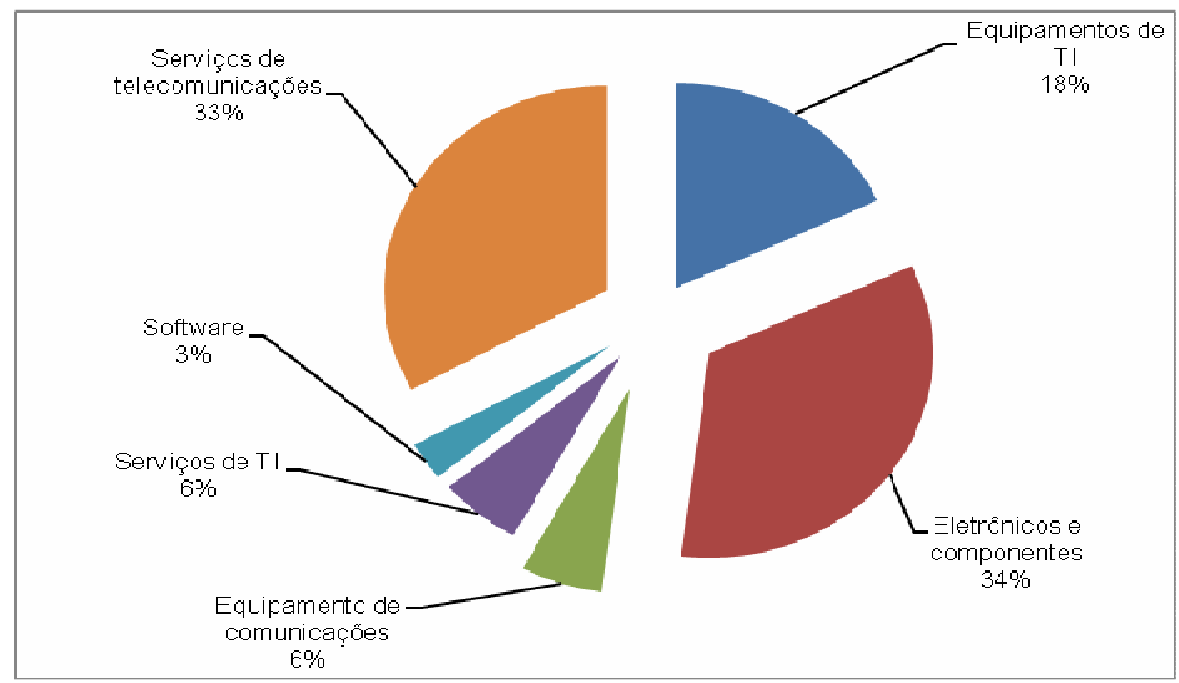

Figura 10 - Fatias de receita por setor das 250 maiores empresas de TIC (2005).

Fonte: OECD, 2006, p. 31 (dados compilados de relatórios anuais, SEC filings - Comissão de Valores Mobiliários e Câmbio dos EUA - e mercado financeiro)

Uma pesquisa de 2003 da IBM Business Consulting Services com 150 empresas sediadas no Brasil e com os clientes internos revela, entre outras, a necessidade de maior equilíbrio entre objetivos de curto e longo prazo em projetos de $\mathrm{TI}$.

A seguir, as conclusões do estudo da IBM, reunidas em seis aspectos abrangentes.

- Planejamento estratégico: a área deve contribuir com questionamentos sobre a viabilidade das estratégias corporativas e propor novas soluções e alternativas; não é possível fazer planejamento estratégico sem algum apoio da TI.

- Equilíbrio entre curto e longo prazo: a pressão por redução de custos no curto prazo não pode eliminar $\mathrm{P} \& D$, sob risco de a empresa não conseguir enfrentar os desafios impostos pelo ambiente competitivo, cabendo à TI potencializar as competências e habilidades individuais de cada elemento da 
cadeia de valor, sem necessariamente arcar com todos os custos e riscos dessas atividades.

- Governança: é necessário profissionalizar e sistematizar os processos de decisão e proporcionar o comprometimento, a definição de prioridades para os investimentos, o acompanhamento da contribuição da $\mathrm{TI}$ ao negócio e a correta captura e atribuição dos custos do departamento às áreas usuárias.

- Aferição de valor: a área de TI tem de demonstrar resultados que possam ser entendidos pelos gestores, o que exige sistemas de avaliação estruturados em métricas financeiras e não-financeiras, internas e externas, que avaliem o passado e as perspectivas para o futuro, quantificando os benefícios - não só os custos da atividade de $\mathrm{TI}$.

- Relacionamento da TI com os usuários: a TI deve buscar uma nova forma de interagir com os clientes internos, capturando expectativas e superando-as.

- Sourcing: aspectos como fortalecimento do relacionamento com um número reduzido de fornecedores, padronização de itens de material, renegociação de contratos de fornecimento e análise dos processos de gestão dos ativos raramente são tratadas de modo adequado em relação a TI. Não são problemas de gestão de TI, mas de gestão em TI. Por mais que se escreva e se fale de governança e gestão de portfólio de investimentos de TI, não houve adaptações tão significativas nessas técnicas que justificassem imaginar problemas distintos daqueles abordados originalmente por elas. As pessoas, o relacionamento, a comunicação, o planejamento e o controle devem estar sempre em primeiro plano.

\subsubsection{CENÁRIOS DA TIC}

Conteúdo digital é hoje um importante motor da indústria de TIC. A inovação tecnológica e a nova demanda dos consumidores estão levando a novas e diretas formas de suprir a criatividade, novos métodos de distribuição e melhoria no acesso. Os resultados das pesquisas, por exemplo, estão se tornando mais acessíveis, e o conteúdo digital está invadindo vários setores, em aplicações que podem mostrar-se mais significativas que as demais para o entretenimento (OECD, 2006, p. 17). 
Melhoramentos contínuos em tecnologia de redes, software e hardware, incluindo serviço celular e sem fio e proteção de conteúdo e prestação de serviços, têm tornado possível o desenvolvimento de conteúdo digital avançado. Maior cooperação é um grande desafio, já que a produção de conteúdo digital requer acordos entre desenvolvedores de conteúdo, fabricantes de equipamentos e distribuidores.

Essa implementação bem-sucedida necessita de serviços eficientes e de baixo custo em infra-estrutura e tecnologias de proteção de conteúdo. Questões de compatibilidade e interoperacionalidade também devem ser resolvidas (OECD, 2006, p. 17).

Expressivo número de empresas pretende fornecer meios para que os clientes possam acompanhar o andamento dos pedidos por meio da internet $(49,8 \%)$ nos próximos três anos. Essa foi uma das tendências reveladas quando o estudo de Csillag e Graeml (2005) investigou a intenção futura de uso de tecnologias. O eprocurement $(41,8 \%)$, as extranets para fornecedores $(41,1 \%)$ e para clientes $(44,4 \%)$, o CRM $(45,8 \%)$ e a cobrança eletrônica $(41,2 \%)$ são áreas em que se esperam grandes mudanças.

Na pesquisa de Day e Hubbard (2005) com 352 executivos sobre o impacto da Internet na capacidade de gerenciar o relacionamento com clientes, redução de custos de aquisição de novos clientes foi a variável mais importante para os gestores. No entanto, o fato de os clientes poderem ampliar o campo de ação, comparar preços com rapidez e eliminar custos de transação usando a internet não significa que venham a abandonar o fornecedor atual.

Apenas $3 \%$ das empresas consideravam esse fator uma grande ameaça, enquanto $14 \%$ o viam como oportunidade importante. A possibilidade de reduzir custos de atendimento ao cliente (já que ocorre o auto-atendimento) foi o segundo fator mais importante na opinião dos entrevistados, o que reflete mudança nas metas de projetos de CRM, que deixam de visar aumento de receita para conter custos.

As repostas ao questionário de 2005 da $\operatorname{OECD~(2006,~p.~285-286)~sobre~Política~de~}$ Tecnologia da Informação indicam que as políticas governamentais visam principalmente: 
- à coordenação e ao ajuste prioritário e de direção geral da política de TI e sua contribuição para objetivos mais amplos de política econômica;

- ao fomento de inovações na área de TI (com especial ênfase em P\&D e em inovações de redes);

- à difusão e utilização (com ênfase em governo eletrônico - eGov);

- ao emprego e a especialização em TIC

- ao conteúdo digital;

- ao ambiente de negócios de TIC (com ênfase em direitos de propriedade intelectual);

- ao reforço da infra-estrutura (especialmente banda larga).

O termo "banda larga" normalmente está associado a conexões de internet de alta velocidade via cabo. Contudo, nos últimos anos, as empresas de celular começaram a oferecer serviços de banda-larga na rede móvel. Um estudo da OCDE de 2006 detectou quase $30 \%$ de operadoras de celular oferecendo conexão de dados $3 \mathrm{G}$, de terceira geração (OECD, 2007c, p. 19).

A habilidade de alavancar o potencial da tecnologia está se tornando cada vez mais crítica para o sucesso das organizações. O principal instrumento para adquirir essa habilidade é desenvolver uma organização de TI eficaz, focando três aspectos fundamentais:

- definição de uma estrutura organizacional adequada ao ambientes de serviços e tecnológico da empresa;

- desenvolvimento de processos e competências para centralizar funções críticas;

- modelo de governança estruturado que facilite 0 alinhamento dos responsáveis pelo serviço com a equipe de TI. 


\section{METODOLOGIA}

Entendo por razão não a faculdade de raciocinar, que pode ser bem ou mal utilizada, mas o encadeamento das verdades, que só pode produzir verdades - e uma verdade não pode ser contrária a outra.

(Gottfried Leibniz)

Neste capítulo são apresentados os aspectos relacionados à metodologia utilizada, estratégia de coleta, tratamento e análise dos dados. Esta prospecção não tem caráter experimental, mas exploratório.

\subsection{MÉTODO DA PESQUISA}

O método científico é o conjunto de processos ou operações mentais que se devem empregar na investigação. É a linha de raciocínio adotada no processo de pesquisa. Os métodos que fornecem as bases lógicas à investigação são: dedutivo, indutivo, hipotético-dedutivo, dialético e fenomenológico (GIL,1991; LAKATOS; MARCONI, 1991). Partindo dessas concepções, a metodologia utilizada neste estudo é do tipo fenomenológico.

\subsection{O INSTRUMENTO DE PESQUISA}

A pesquisa estabeleceu a partir de referenciais teóricos e uma Pesquisa Global, um conjunto de ferramentas de gestão mais utilizadas aliado à elaboração de perguntas para empreendedores a partir das quais foi possível, com base no paradigma teórico oriundo da revisão da literatura, estruturar o método de coleta de dados que verificou na prática as proposições referenciais.

A população ou universo da pesquisa incluiu os indivíduos (gestores e empresas) que possuem as mesmas características definidas para este estudo: empresas incubadas de base tecnológica. A amostra, a parte da população ou do universo selecionada de acordo com o plano preestabelecido, ateve-se ao âmbito das empresas incubadas no CIETEC, agrupadas em áreas de atuação; Biotecnologia, Eletroeletrônico, Medicina e Saúde, Meio Ambiente e Tecnologia da Informação. 
Foram utilizados dois questionário, exclusivamente digitais, que se encontram em ANEXOS, para investigar os vários aspectos concernentes à proposta deste estudo. A Pesquisa de Campo Fase 1 ateve-se à exploração da utilização de Ferramentas de Gestão por empresas de base tecnológica incubadas no CIETEC. Um segundo questionário ofereceu ao gestor a possibilidade de autodiagnóstico e teve o objetivo de avaliar quão inovadora é a empresa e o grau de maturidade na adoção de melhores práticas de governança e de $\mathrm{TI}$.

A Pesquisa Global pergunta a gestores em todo o mundo quais ferramentas de gestão eles utilizam e quais resultados elas têm gerado. A pesquisa de 2007 concentra-se em 25 ferramentas. Para fazer parte da pesquisa global, as ferramentas precisam ser consideradas importantes pelos gestores seniores, ter aplicação específica e ser mensuráveis. Ao monitorar quais ferramentas as empresas utilizam, em quais circunstâncias e com qual nível de sofisticação, podemse orientar os gestores a melhor selecionar, implementar e integrar as ferramentas, maximizando assim o desempenho de cada uma.

Após catorze anos de pesquisa, e com um banco de dados de mais de 8.500 pesquisados, torna-se possível mapear de forma sistemática a efetividade das ferramentas de gestão ao longo dos anos. Parte da pesquisa foca nas opiniões dos gestores com relação a uma série de temas relevantes ligados aos empreendimentos. Dessa maneira, podemos também acompanhar como as prioridades em termos de gestão evoluem ao longo do tempo.

Como elemento fundamental da metodologia utilizada, os resultados dos dados obtidos no que aqui denominamos Estudo no CIETEC serão aferidos e comparados com os dados do Estudo Global de 2007.

\subsubsection{Pesquisa de CAMpo FASe 1}

Os critérios de escolha e a estratégia de coleta e análise dos dados convergem para o instrumento de pesquisa, desenvolvido a partir do equacionamento das dimensões e fronteiras investigadas na pesquisa de campo e que foram particionadas em três enfoques primordiais, subdivididos de acordo com a conveniência e importância do assunto: 
1. técnicas de gestão utilizadas no negócio - como a empresa se vale das ferramentas de gestão para alavancar os negócios interna e externamente;

2. análise da eficácia das técnicas de gestão utilizadas - qual o grau de satisfação experimentado nos últimos cinco anos a partir de técnicas e ferramentas de gestão adotadas pela empresa;

3. tendências em gestão - necessidades e prioridades com relação à manutenção ou implementação de novas técnicas e ferramentas de gestão.

Também fizeram parte do questionário dados cadastrais (opcionais) e a indicação do perfil da empresa, com informações estatísticas básicas do negócio, como receita, área de atuação, rede de cooperação e estágio de desenvolvimento.

Com base na ótica definida para esquadrinhar o problema da pesquisa, desenvolvemos o questionário cuja cópia impressa se encontra em ANEXOS, visto que foi elaborado por meio digital e enviado aos empreendedores. Abaixo, o link para a visualização via internet - Questionário "Pesquisa de Campo Fase 1: Ferramentas de Gestão" disponível em: < http://paletta.cmsxpert.com.br/ >

O questionário utilizado como principal instrumento de coleta de dados para a pesquisa foi elaborado e posteriormente aperfeiçoado com a colaboração de empreendedores do CIETEC.

Figura 11 - Dimensões consideradas na pesquisa de campo

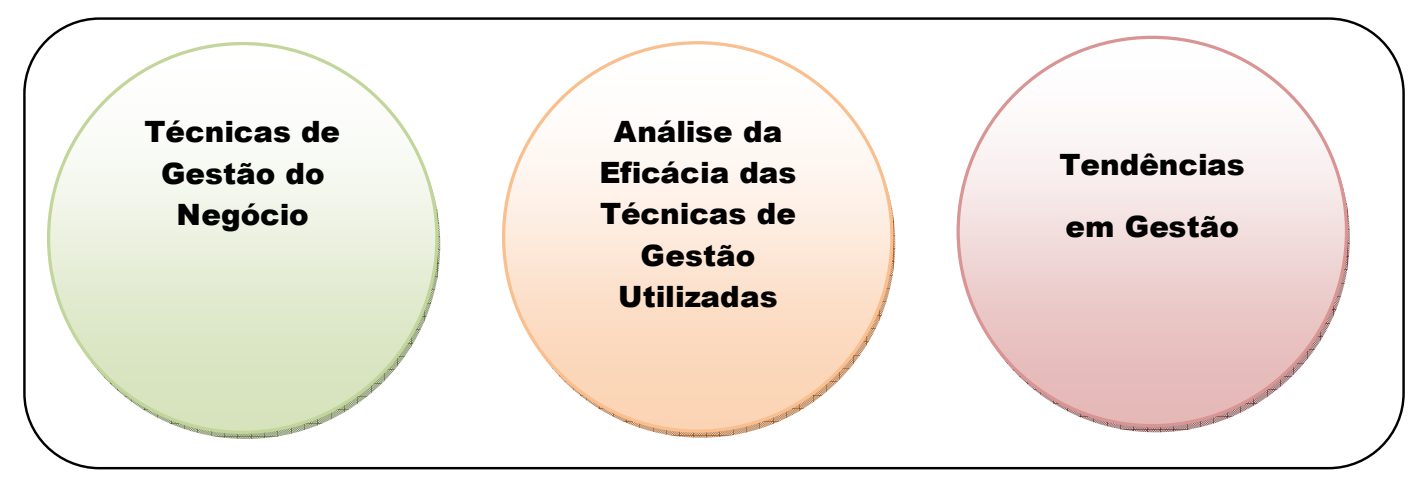




\subsection{AMOSTRA E ESTRATÉGIA DE COLETA}

Dentre um universo de 127 empresas incubadas no CIETEC, que juntas, registram receita de 33,41 milhões de reais e empregam 780 profissionais especializados, foi feita uma seleção para identificar aquelas que se qualificavam para atender aos parâmetros do estudo. Os questionários foram enviados e preenchidos pelas empresas de base tecnológica incubadas representadas pelos empreendedores, ou executivos em cargo de gestão.

A pergunta que esta pesquisa se propõe a estudar e responder é: "Quais os fatores críticos de sucesso no uso de ferramentas de gestão em empresas incubadas de base tecnológica a partir do referencial da tecnologia da informação, inovação e empreendedorismo?"

O estudo tem por escopo confrontar a utilização das ferramentas de gestão nas práticas administrativas e/ou gerenciais em empresas brasileiras de base tecnológica incubadas com os resultados da Pesquisa Global para conhecer e entender as formas de utilização, as razões do sucesso e as perspectivas de manutenção ou incorporação dessas práticas num centro incubador reconhecido como maior núcleo de incubação de empresas de base tecnológica da América Latina. 


\section{ANÁLISE E DISCUSSÃO DE RESULTADOS}

Os resultados aferidos a partir do tratamento dado aos questionários, aqui compilados no que chamamos de Estudo no CIETEC, permitiu traduzir as respostas em gráficos, que analisaremos a seguir juntamente com a comparação e balizamento com o que foi denominado Estudo Global, realizada pela Bain \& Company em 23 países em 2007.

\subsection{PERFIL DAS EMPRESAS}

A Figura 12 mostra o estágio de desenvolvimento explicitado pelo próprio gestor da EBT incubada no CIETEC; observa-se que 2/3 (dois terços) das empresas entrevistadas se posicionam em estágio avançado de desenvolvimento.

\section{Perfil das Empresas por Estágio de Desenvolvimento}

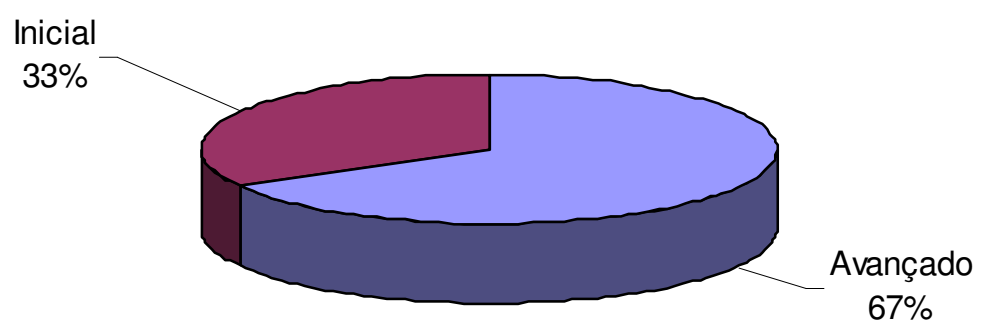

Figura 12 - Perfil das empresas por estágio de desenvolvimento 
A Figura 13 mostra que, das empresas envolvidas no Estudo no CIETEC, 75\% apresentaram receita inferior a 500.000,00 reais em 2007, o que caracteriza bem o perfil de empresas incubadas.

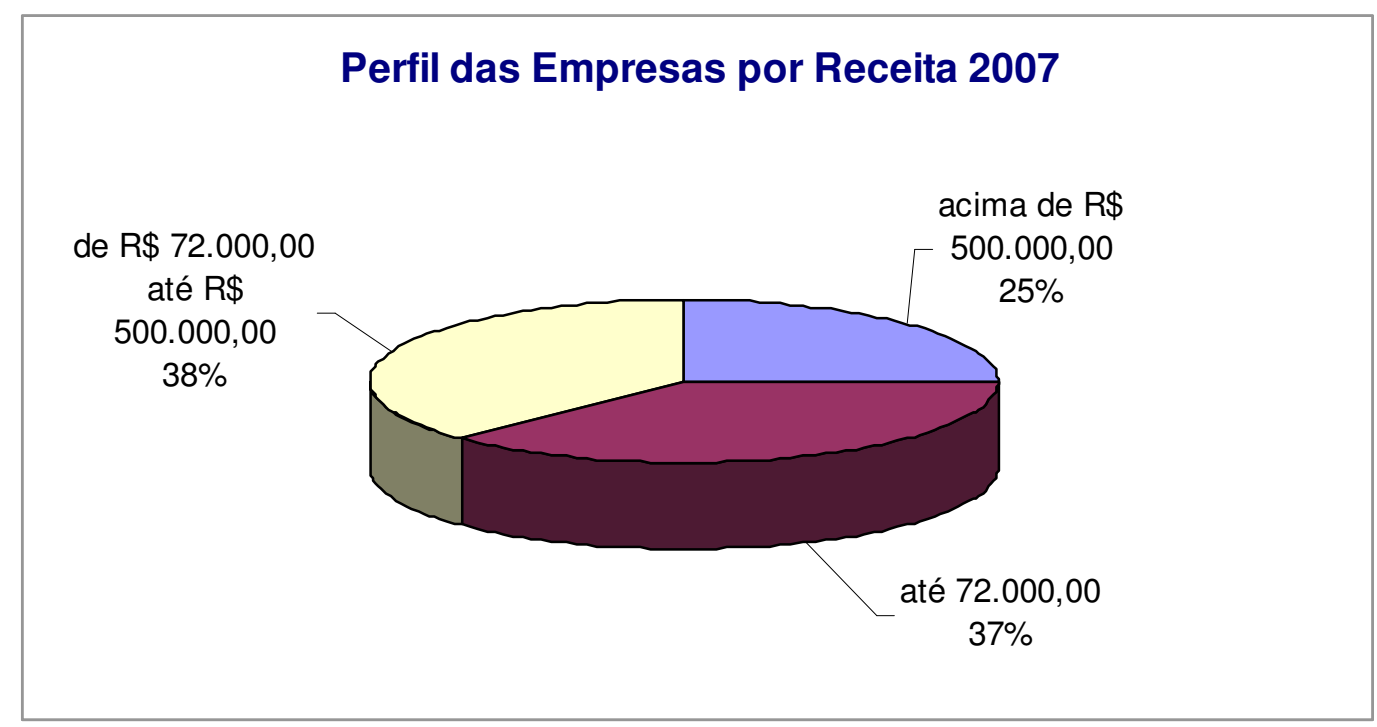

Figura 13 - Perfil das empresas por receita auferida em 2007

Na Figura 14 e Figura 15, vê-se que o perfil das EBTs é diversificado, concentrandose em áreas definidas pela incubadora como estratégicas. Observamos que Tecnologia da Informação é a área que concentra mais da metade das empresas que compõem a amostra do Estudo no CIETEC, tanto com relação ao setor de atuação quanto à rede de cooperação da qual participam. 


\section{Perfil das Empresas por Rede de Cooperação}

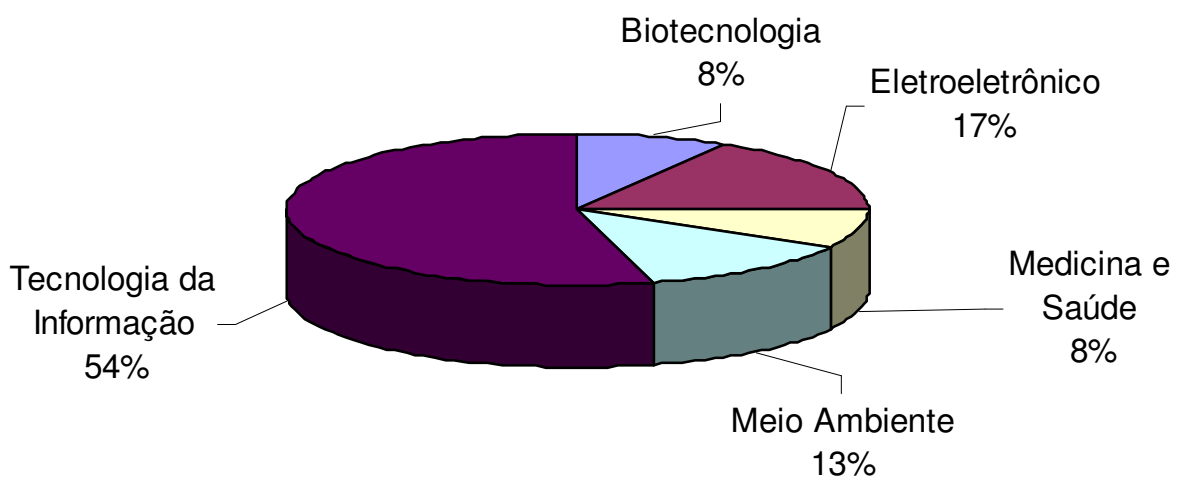

Figura 14 - Perfil das empresas por inserção em redes de cooperação

\section{Perfil das Empresas por Setor Empresarial}

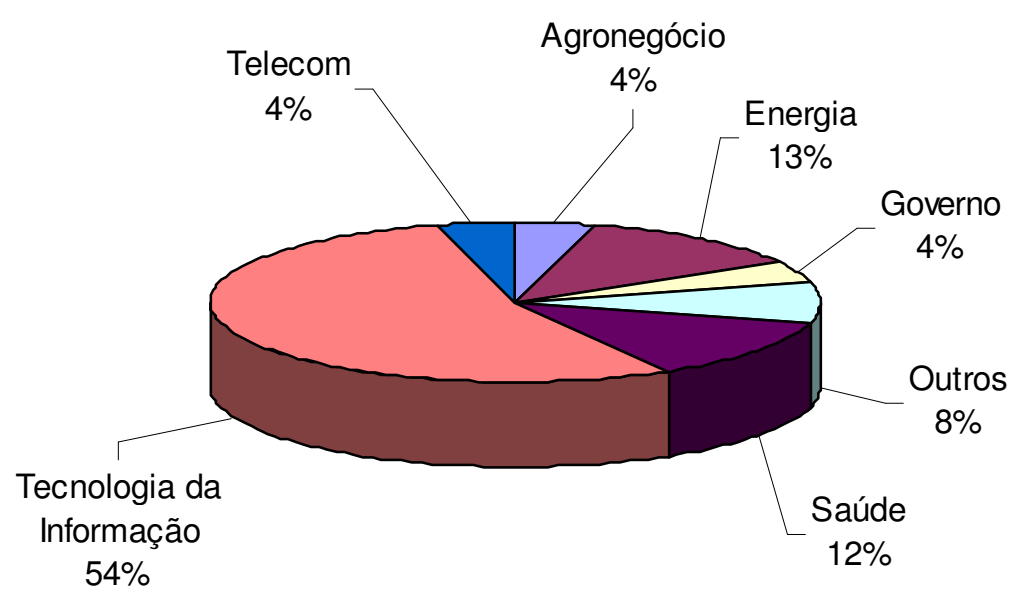

Figura 15 - Perfil das empresas por setor de atuação empresarial

Outros aspectos de caráter geral foram analisados, tais como o recebimento de recursos externos para o desenvolvimento da EBT (suporte de capital) e habilitação para recebimento de investimentos externos. Estes quesitos visam avaliar se a empresa está apta ou se está se preparando para a abertura de capital. Este fato demanda das empresas incubadas controle dos ativos (Governança). 
Na Figura 16 e Figura 17 observamos que 58\% das empresas receberam suporte de capital. Das empresas estudadas, 83\% estão se preparando para receber investidores, das quais apenas 40\% utilizam a ferramenta Governança. Das empresas que não se estão preparando para receber investidores, 25\% utilizam Governança.

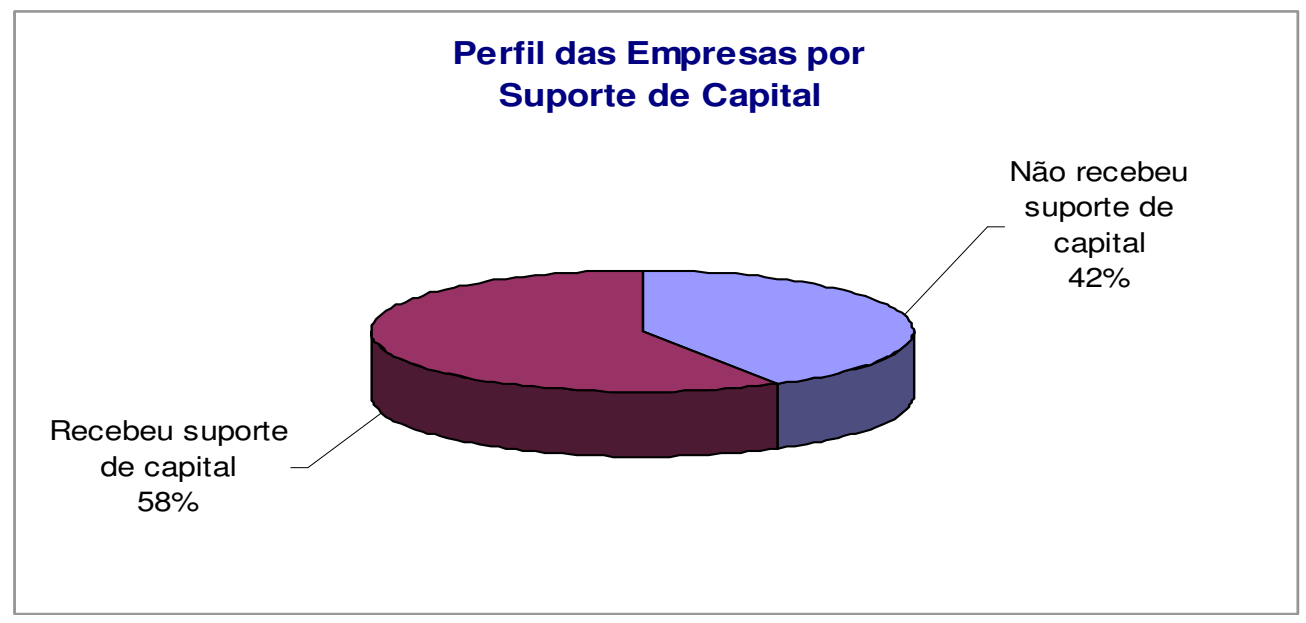

Figura 16 - Perfil das empresas por estar aberta ou não a receber suporte empresarial

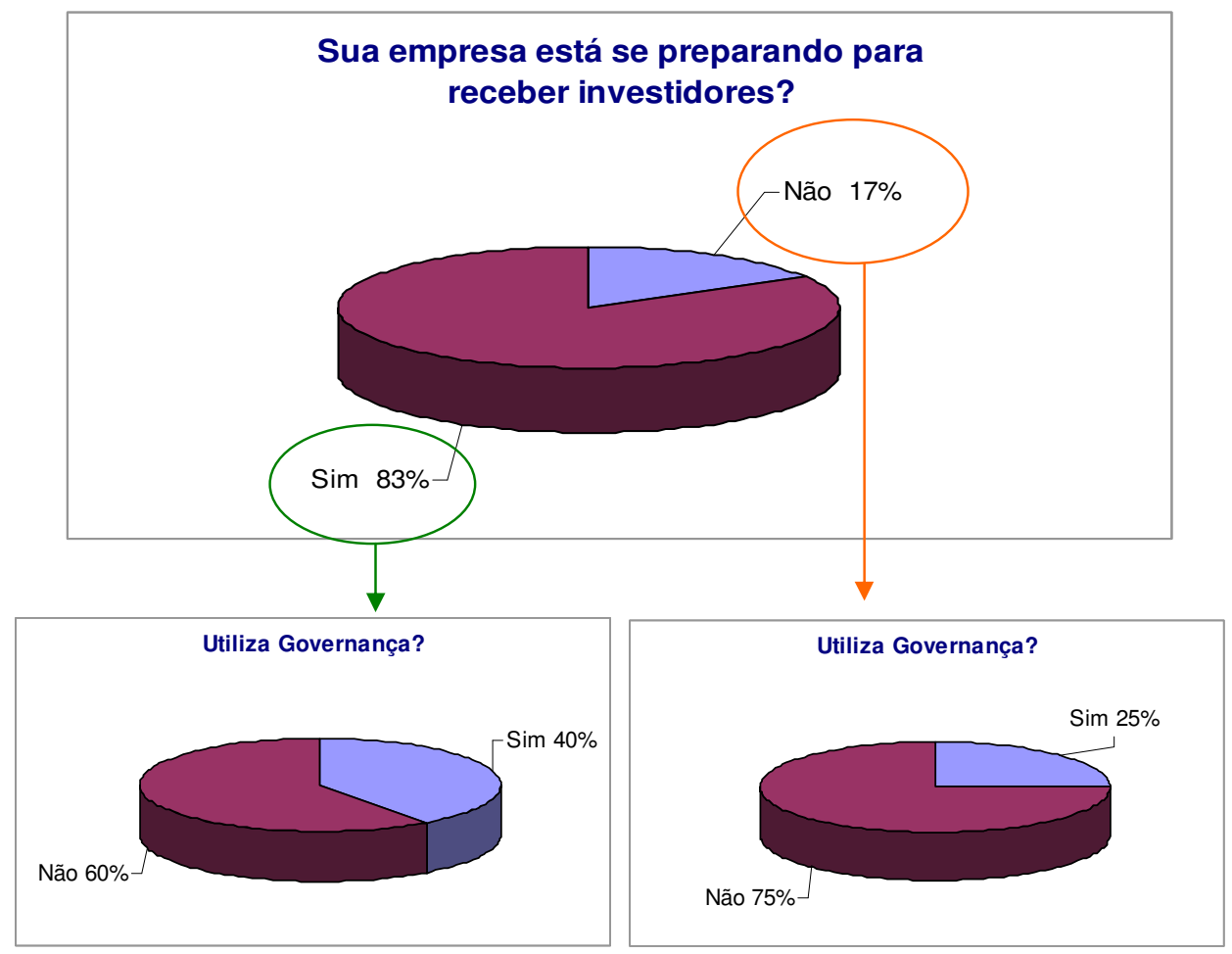

Figura 17 - Perfil das empresas em relação à preparação para admitir investidores 


\subsection{UTILIZAÇÃO DE FERRAMENTAS NAS EMPRESAS DO CIETEC}

Considerando o total de empresas estudadas, quase $55 \%$ utilizaram de seis a quinze ferramentas entre 2003 e 2007. Ou seja, a média de ferramentas utilizadas no período é de 15,4\% conforme apresentado na Figura 18.

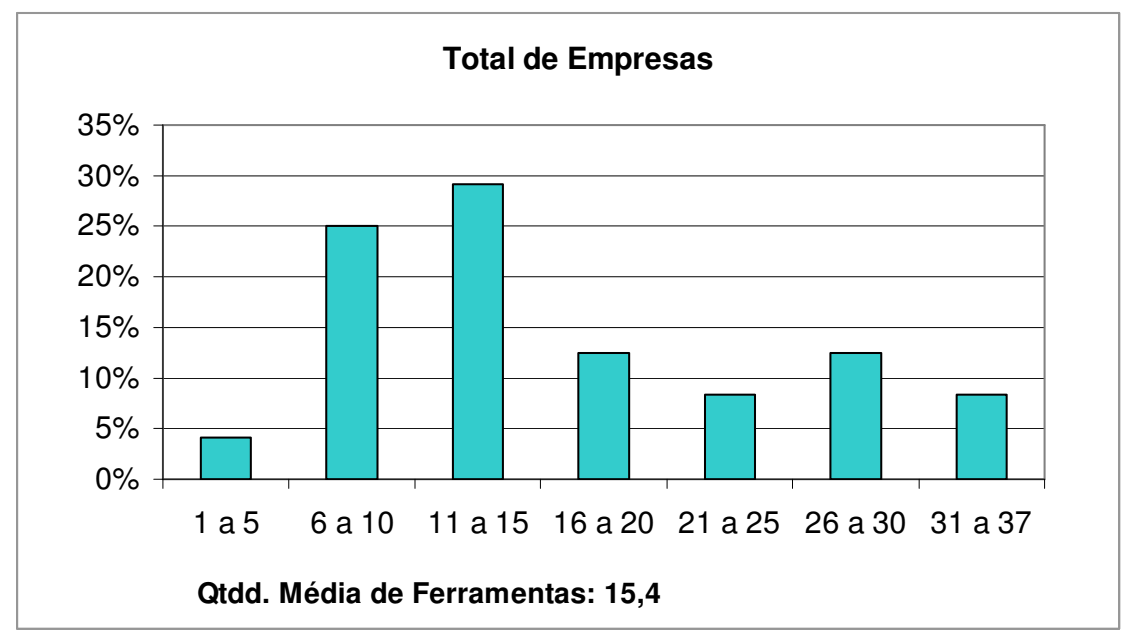

Figura 18 - Utilização de ferramentas de gestão pelo total de empresas pesquisadas

$\mathrm{Na}$ Figura 19, considerando o estágio de desenvolvimento, encontramos média de dez ferramentas utilizadas por empresas em estágio inicial de desenvolvimento; e, em contrapartida, média de vinte ferramentas utilizadas por empresas em estágio avançado, o que vai ao encontro do esperado.

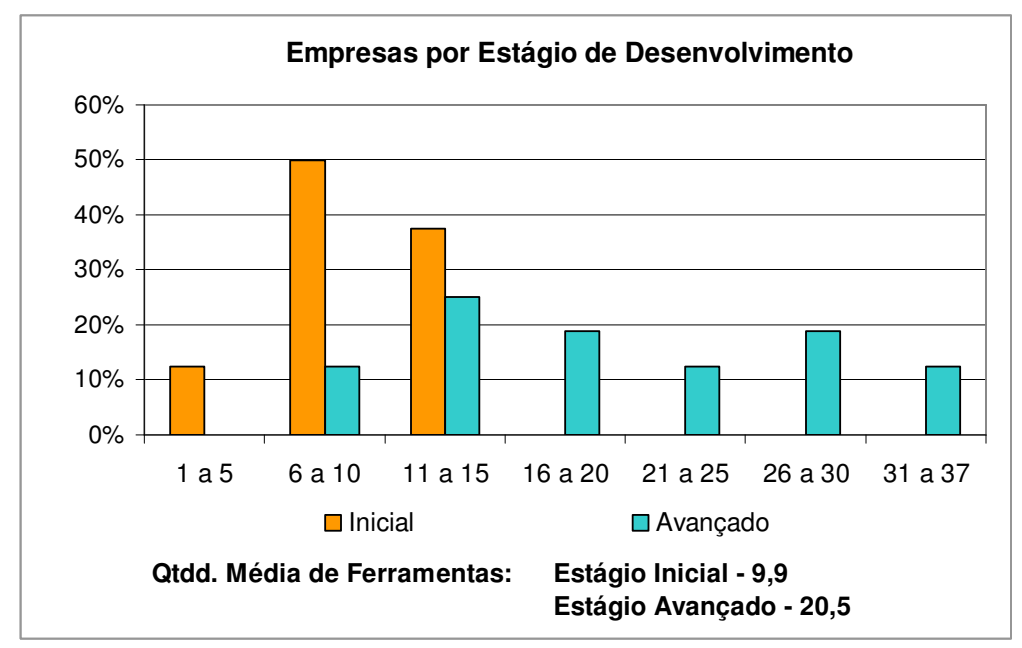

Figura 19 - Porcentagem de empresas em relação ao estágio de desenvolvimento 
$\mathrm{Na}$ Figura 20, selecionando as empresas por receita em 2007, observamos que o grupo de empresas com menor receita apresenta média de dezesseis ferramentas utilizadas; enquanto o grupo de empresas com receita acima de 500.000,00 reais (25\% da amostra) utiliza média de vinte ferramentas.

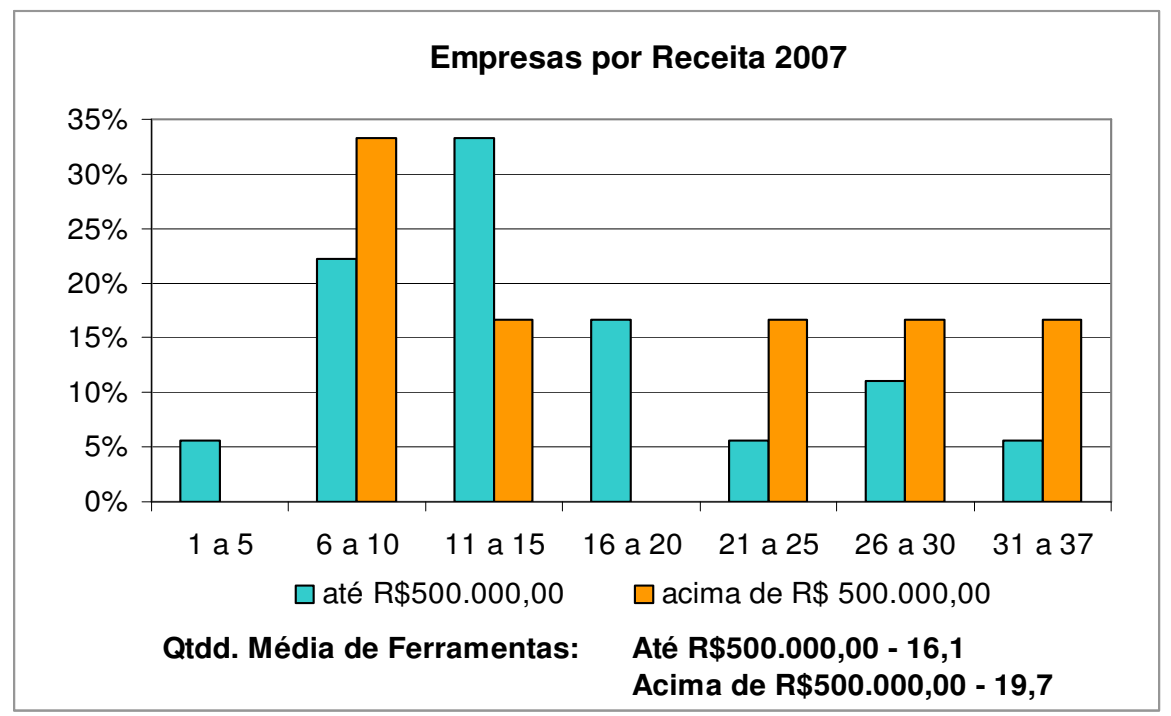

Figura 20 - Utilização de ferramentas por faixa de receita das empresas em 2007

Empresas do setor de TI e de EBT (demais empresas) tendem a utilizar, em média, quantidade equivalente de ferramentas de gestão conforme resultado apresentado na Figura 21.

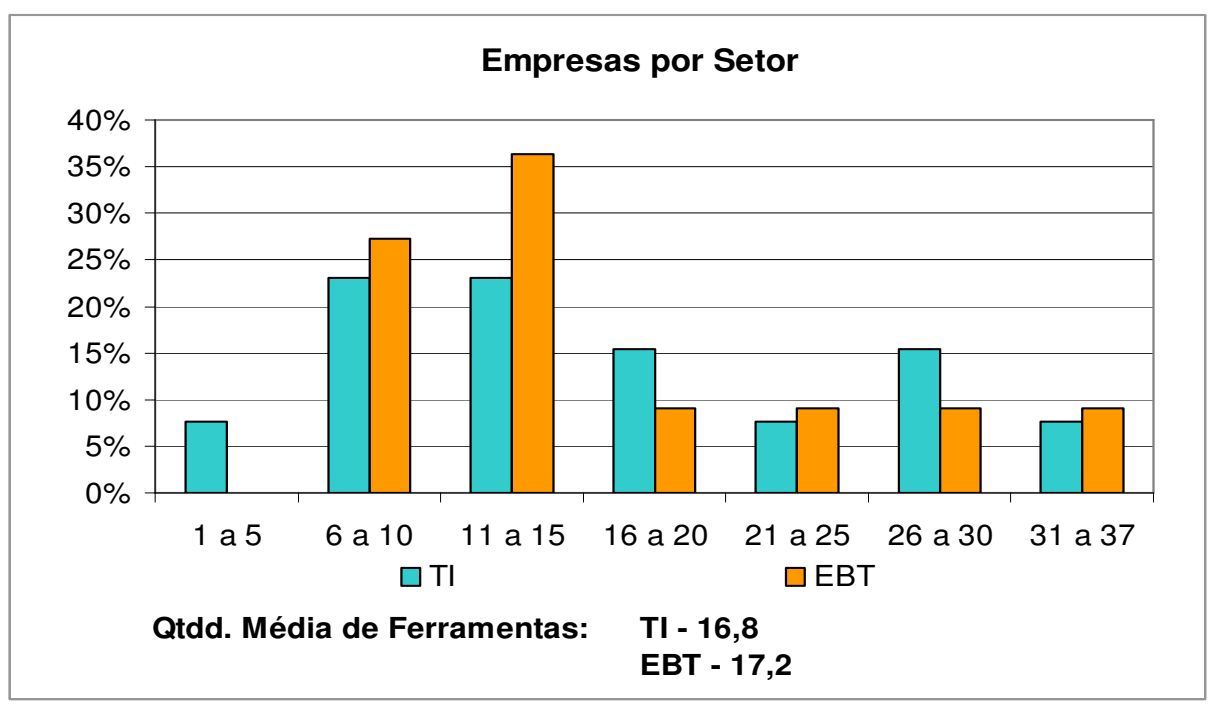

Figura 21 - Quantidade de ferramentas utilizadas por empresas de TI e EBT 
Na Figura 22, do Estudo no CIETEC, em média, as ferramentas de gestão são utilizadas por $50,8 \%$ das empresas. Das cinco ferramentas mais utilizadas, três não foram consideradas no Estudo Global: Desenvolvimento de Plano de Negócio, Gestão de Processos e Tecnologia da Informação.

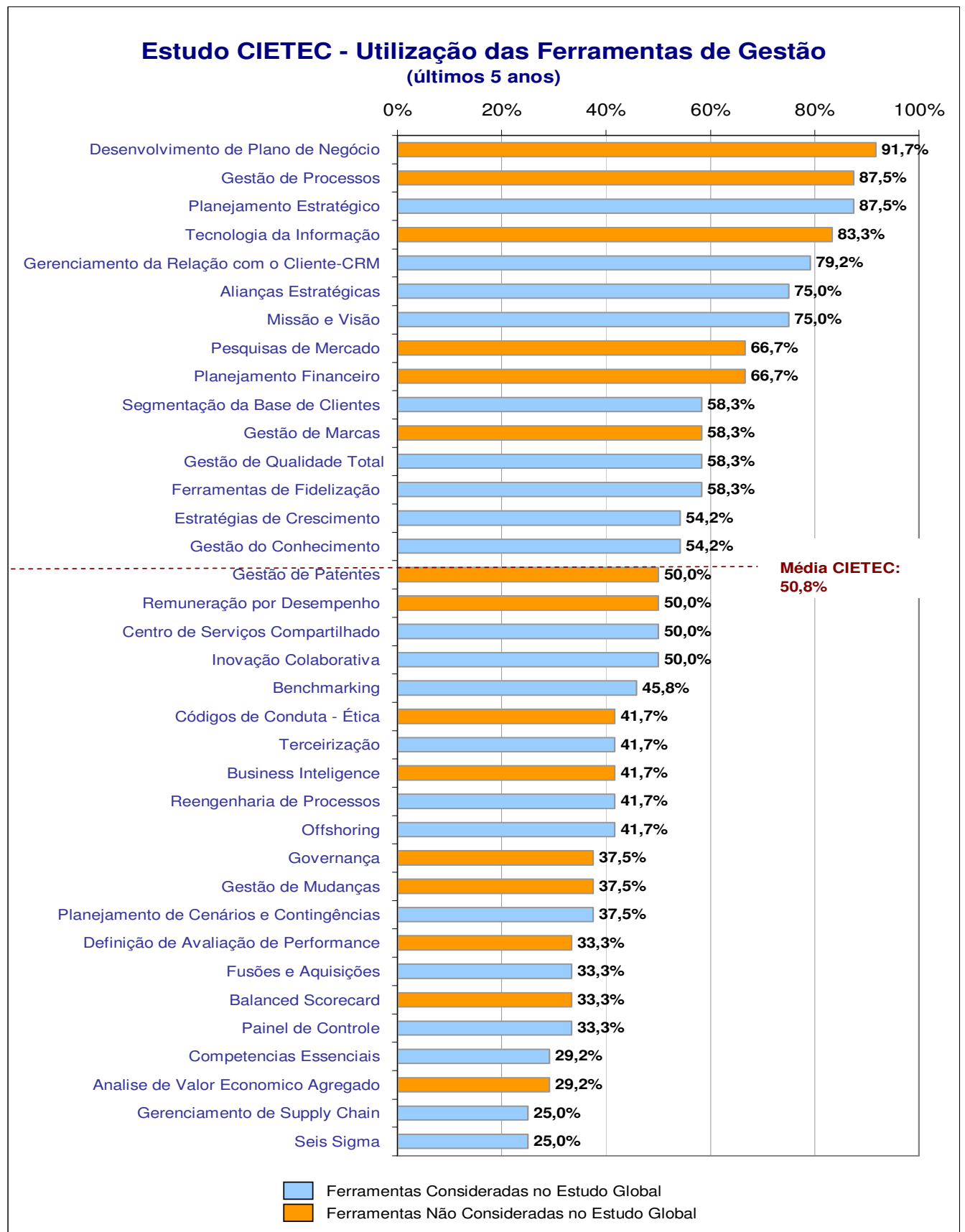

Figura 22 - Distribuição de utilização de ferramentas do Estudo no CIETEC de 2003 a 2007 
No Estudo Global, em média, as ferramentas de gestão são utilizadas por $62 \%$ das empresas, valor superior ao das empresas incubadas do Estudo CIETEC conforme apresentado na Figura 23 e Figura 24.

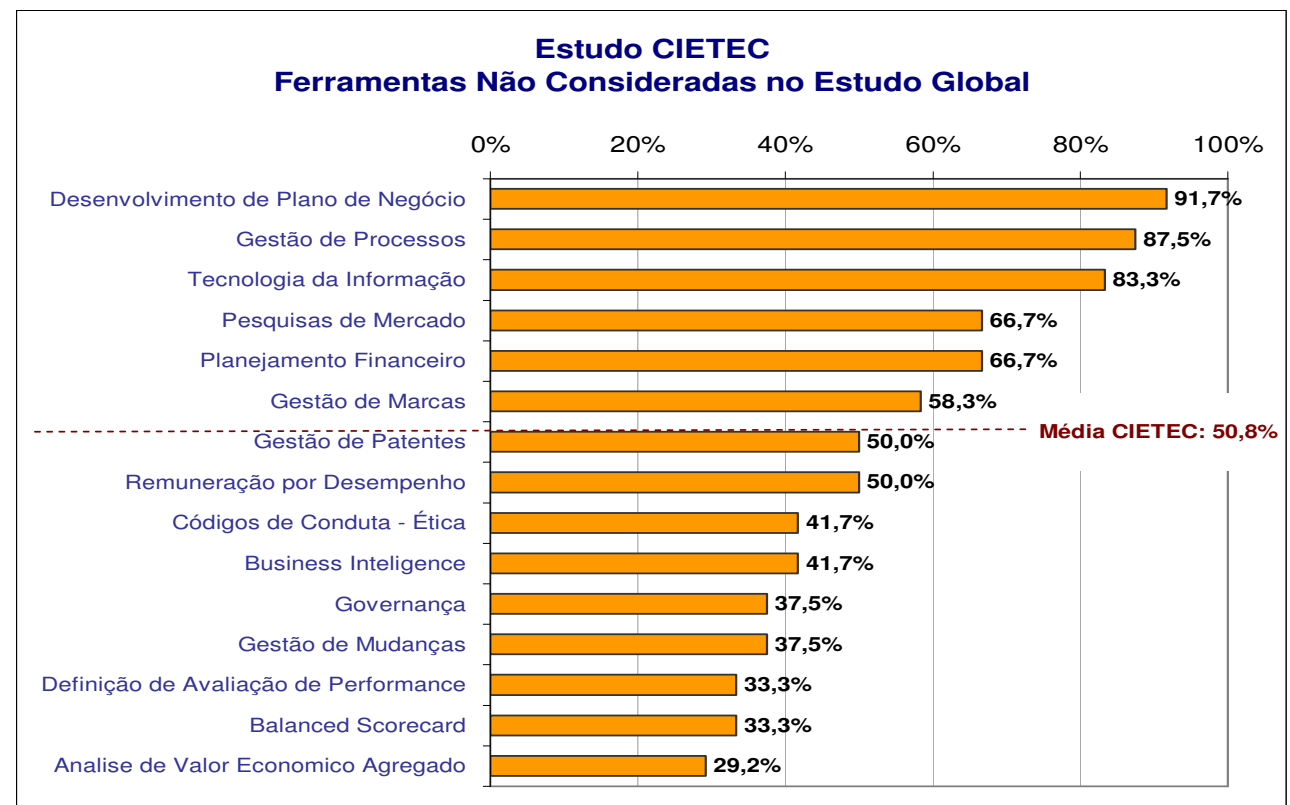

Figura 23 - Ferramentas de gestão consideradas somente no Estudo no CIETEC

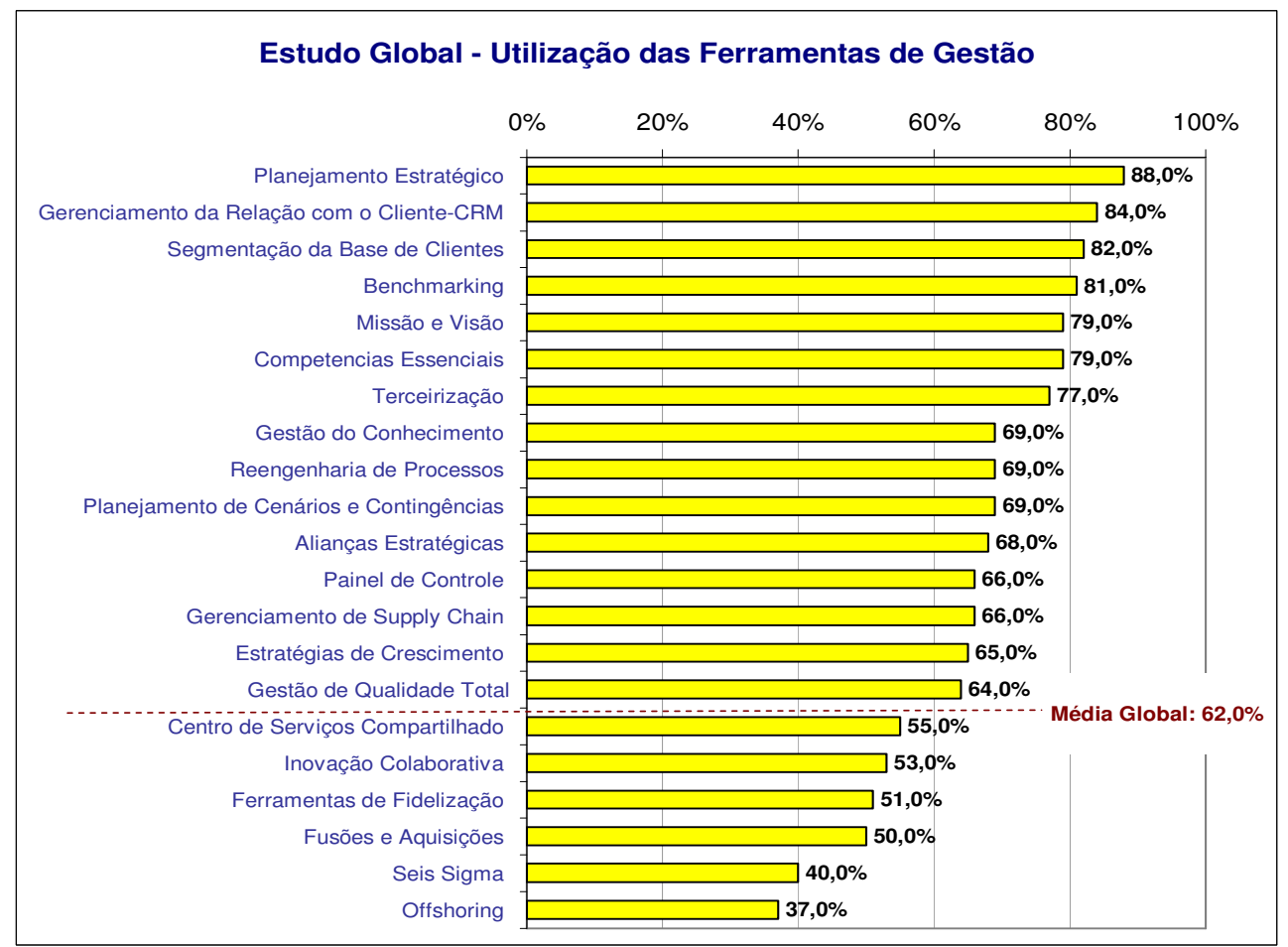

Figura 24 - Distribuição de utilização de ferramentas na Pesquisa Global 
$\mathrm{Na}$ Figura 25 observamos que a maioria das ferramentas de gestão estudadas apresenta utilização maior no Estudo Global do que no Estudo CIETEC. As ferramentas cuja utilização é notadamente superior no Estudo Global são: Benchmarking; Competências Essenciais; Terceirização; Reengenharia de Processos; Planejamento de Cenários e Contingências; Painel de Controle; Gerenciamento de Supply Chain. As ferramentas cuja utilização é superior no Estudo CIETEC são: Alianças Estratégicas e Ferramentas de Fidelização.

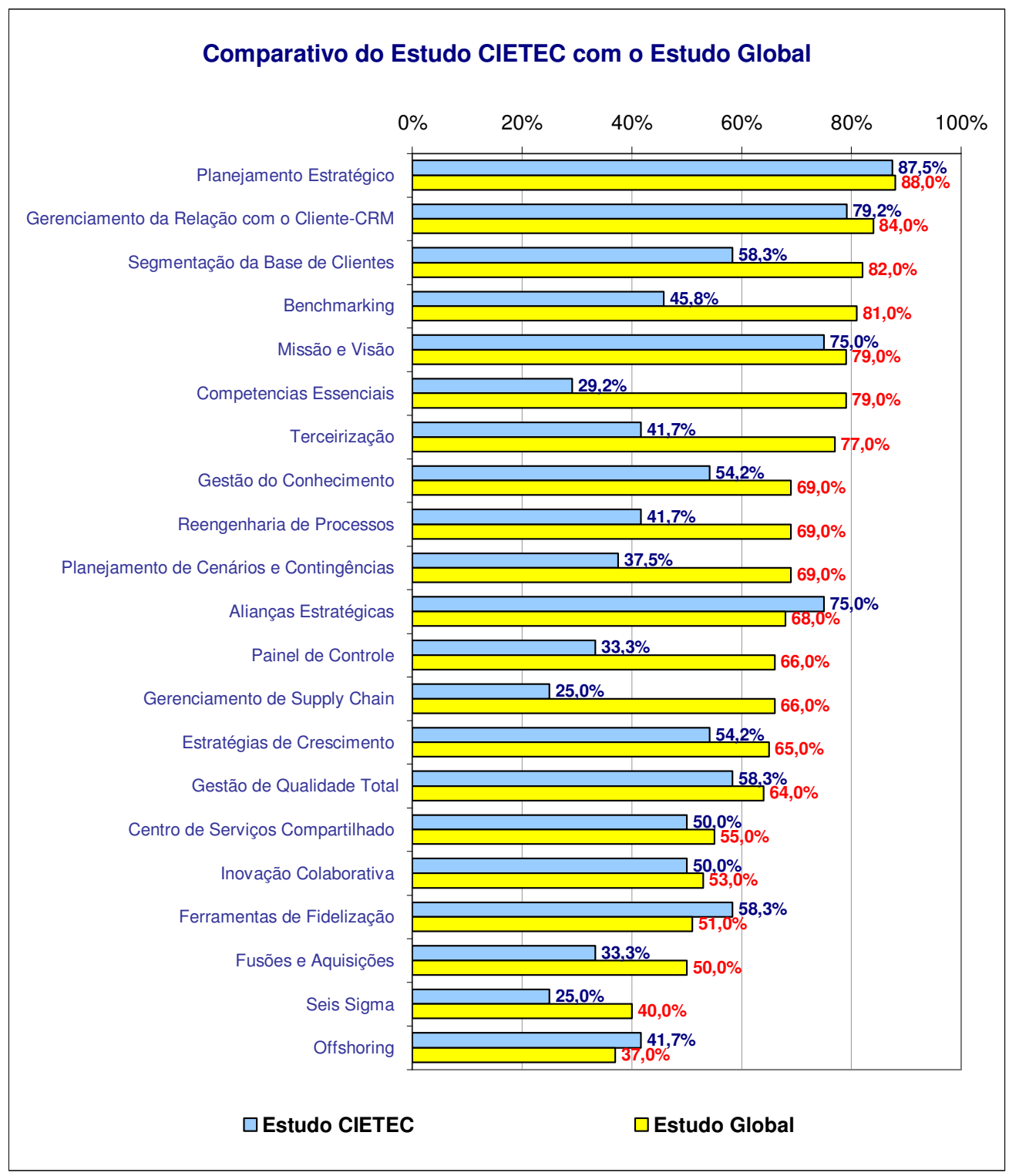

Figura 25 - Comparativo de utilização de ferramentas na Pesquisa no CIETEC e na Pesquisa Global 
Na Figura 26 e Figura 27 observamos que Empresas em estágio avançado de desenvolvimento apresentam maior utilização das ferramentas de gestão do que empresas em estágio inicial de desenvolvimento, como esperado.

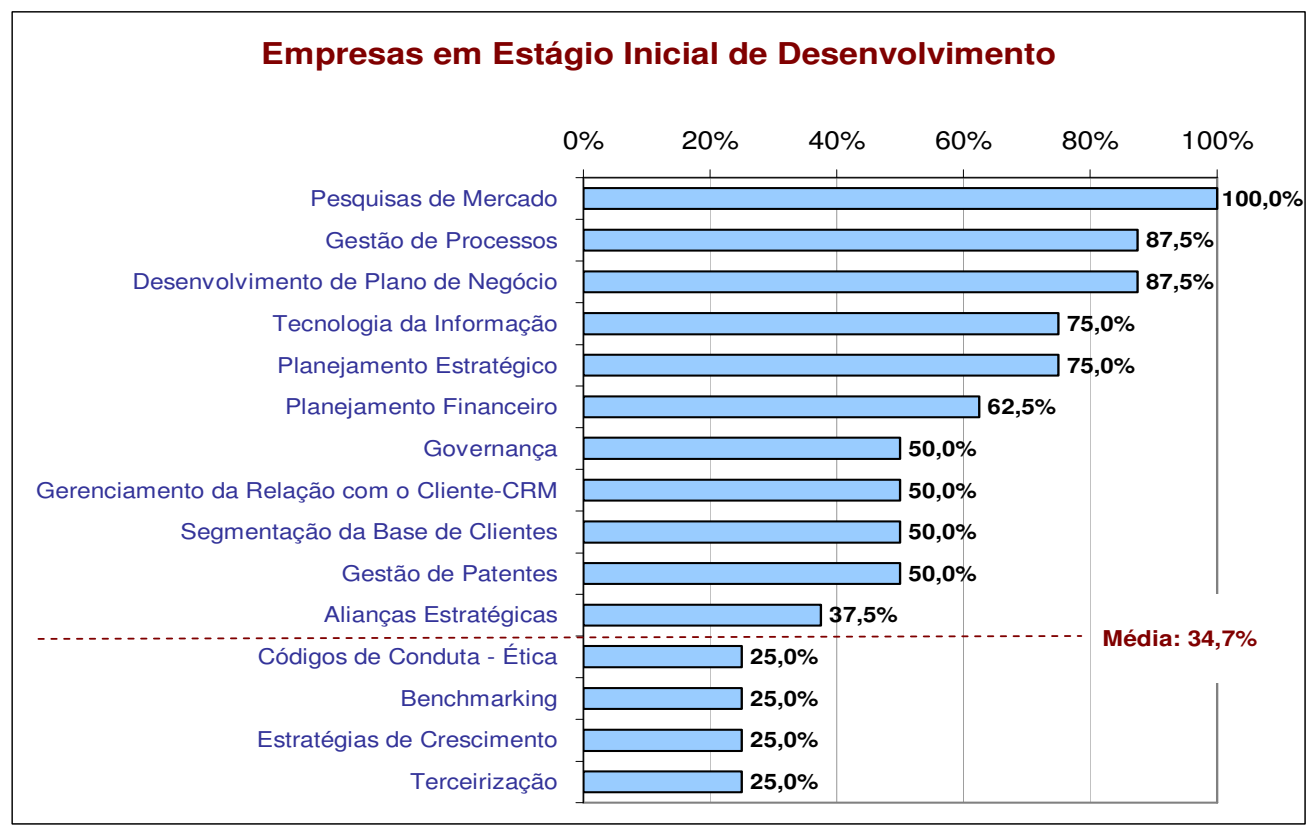

Figura 26 - Utilização de ferramentas nas empresas em estágio inicial de desenvolvimento

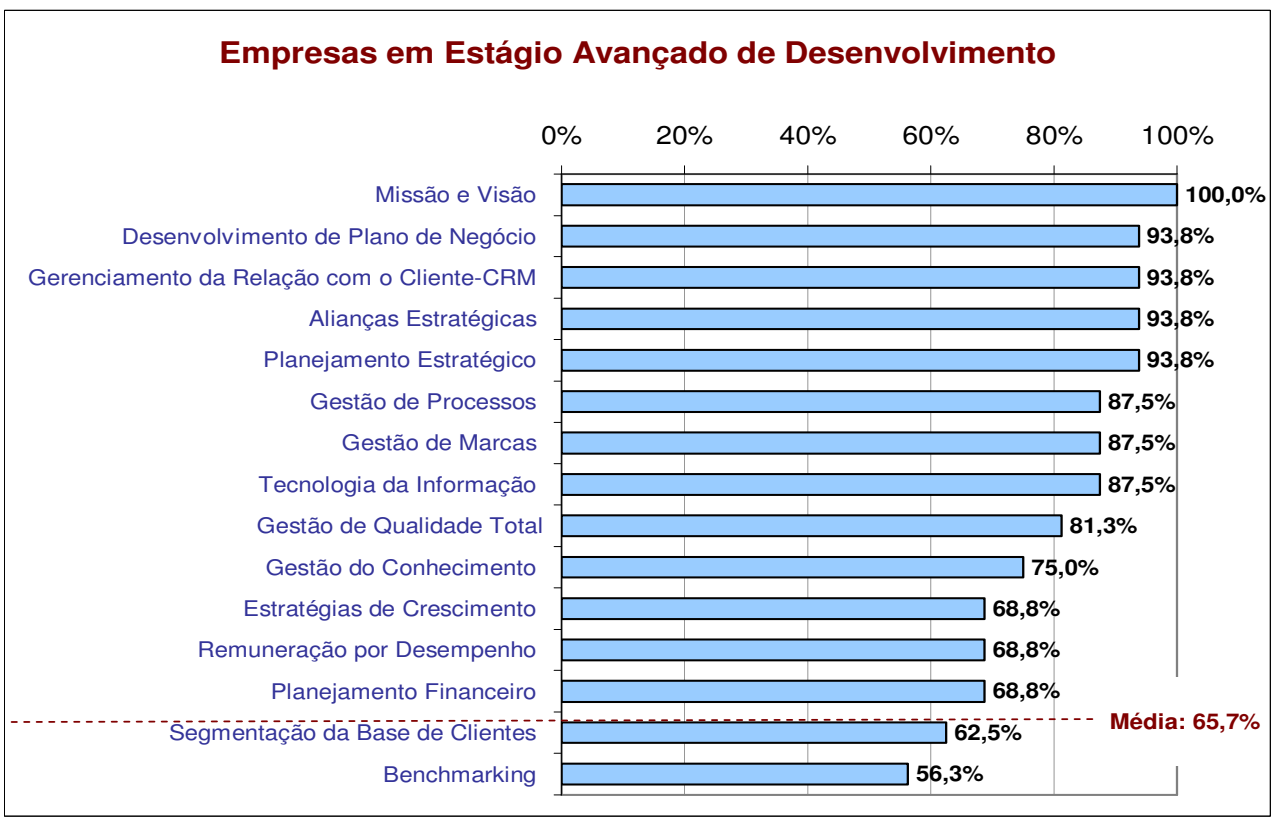

Figura 27 - Utilização de ferramentas nas empresas em estágio avançado de desenvolvimento 
$\mathrm{Na}$ Figura 28, vemos que quase todas as ferramentas são mais utilizadas por empresas em estágio avançado de desenvolvimento; das quais podemos destacar: Gestão de Mudanças; Planejamento de Cenários e Contingências; Competências Essenciais; Benchmarking; Estratégias de Crescimento; Gestão do Conhecimento; Gestão de Marcas; Definição de Avaliação de Performance; Remuneração por Desempenho; Business Intelligence; Alianças Estratégicas; Gerenciamento de Supply Chain; Gestão de Qualidade Total; Missão e Visão. Já nas por empresas em estágio inicial temos: Gestão de Processos; Desenvolvimento de Plano de Negócio; Pesquisa de Mercado; Tecnologia da Informação; Planejamento Estratégico e Financeiro.

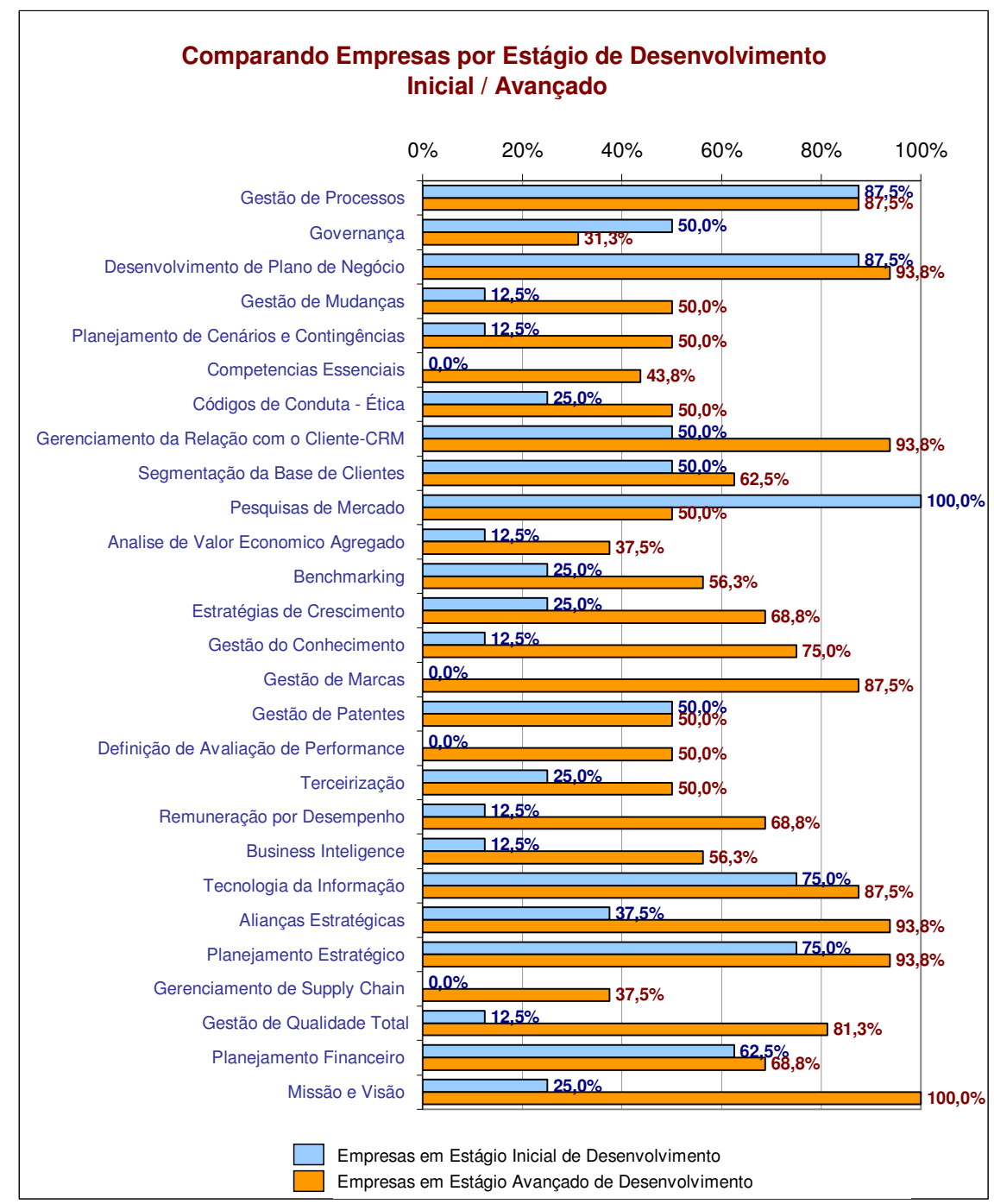

Figura 28 - Comparativo de utilização de ferramentas por empresas em estágio inicial e avançado de desenvolvimento 


\section{Empresas do Setor TI e de Base Tecnológica apresentam, em média, percentual de} utilização equivalente de ferramentas de gestão conforme apresentado na Figura 29 e Figura 30.

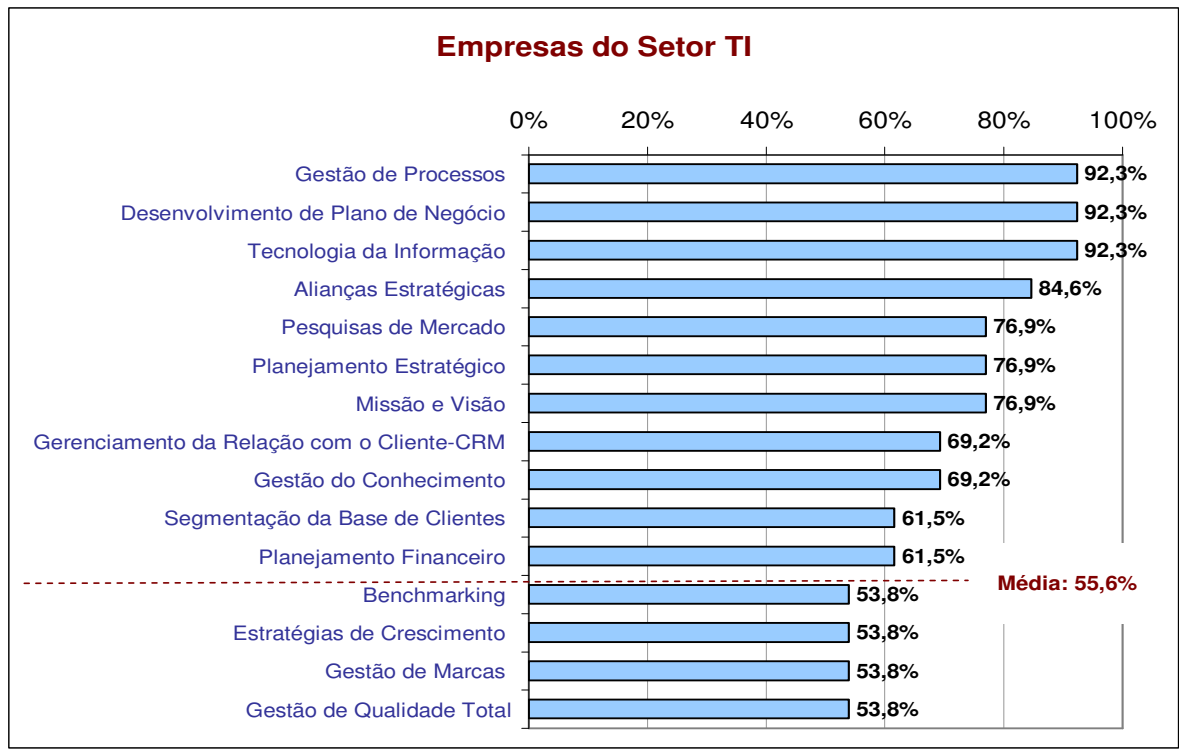

Figura 29 - Utilização de ferramentas por empresas do setor de TI no CIETEC (2003/2007)

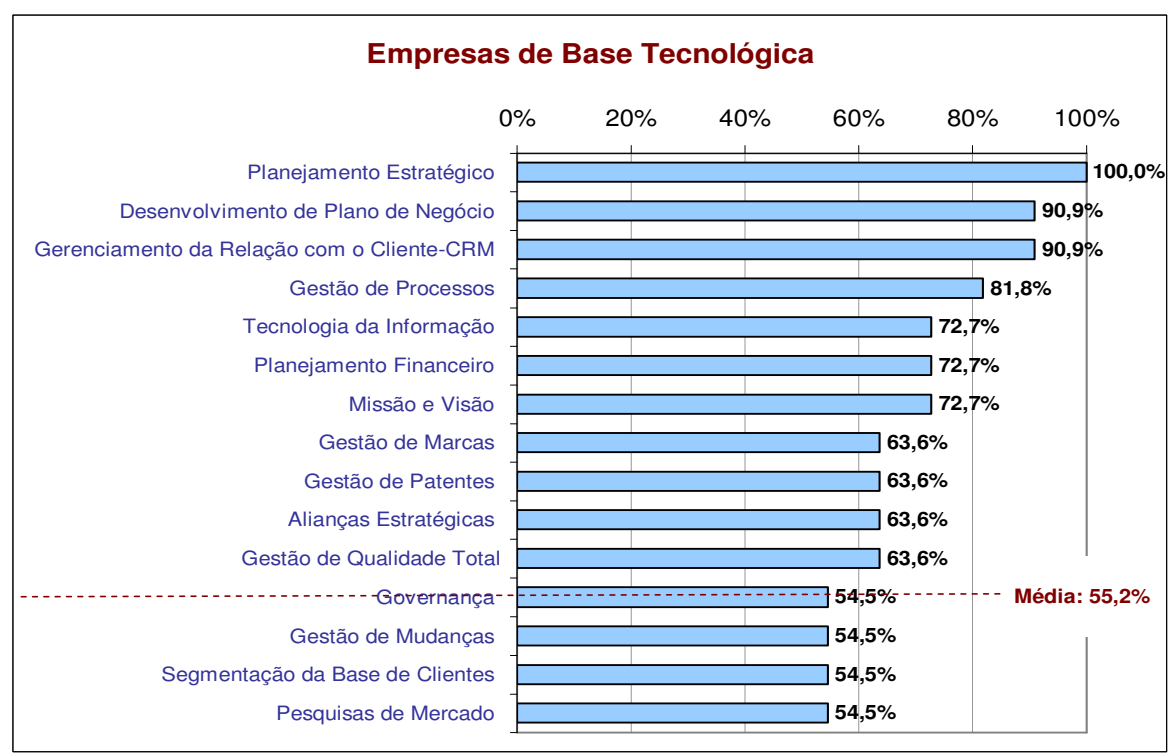

Figura 30 - Utilização de ferramentas por EBT na Pesquisa CIETEC (2003/2007) 
Na Figura 31, observa-se que as ferramentas mais utilizadas por Empresas do Setor TI são: Pesquisa de Mercado; Análise de Valor Econômico Agregado; Benchmarking; Gestão de Conhecimento; Tecnologia da Informação; Alianças Estratégicas; Missão e Visão. Já as ferramentas mais utilizadas por EBT: Governança; Gestão de Mudanças; CRM; Gestão de Patentes; Planejamento Estratégico; Gerenciamento de Supply Chain.

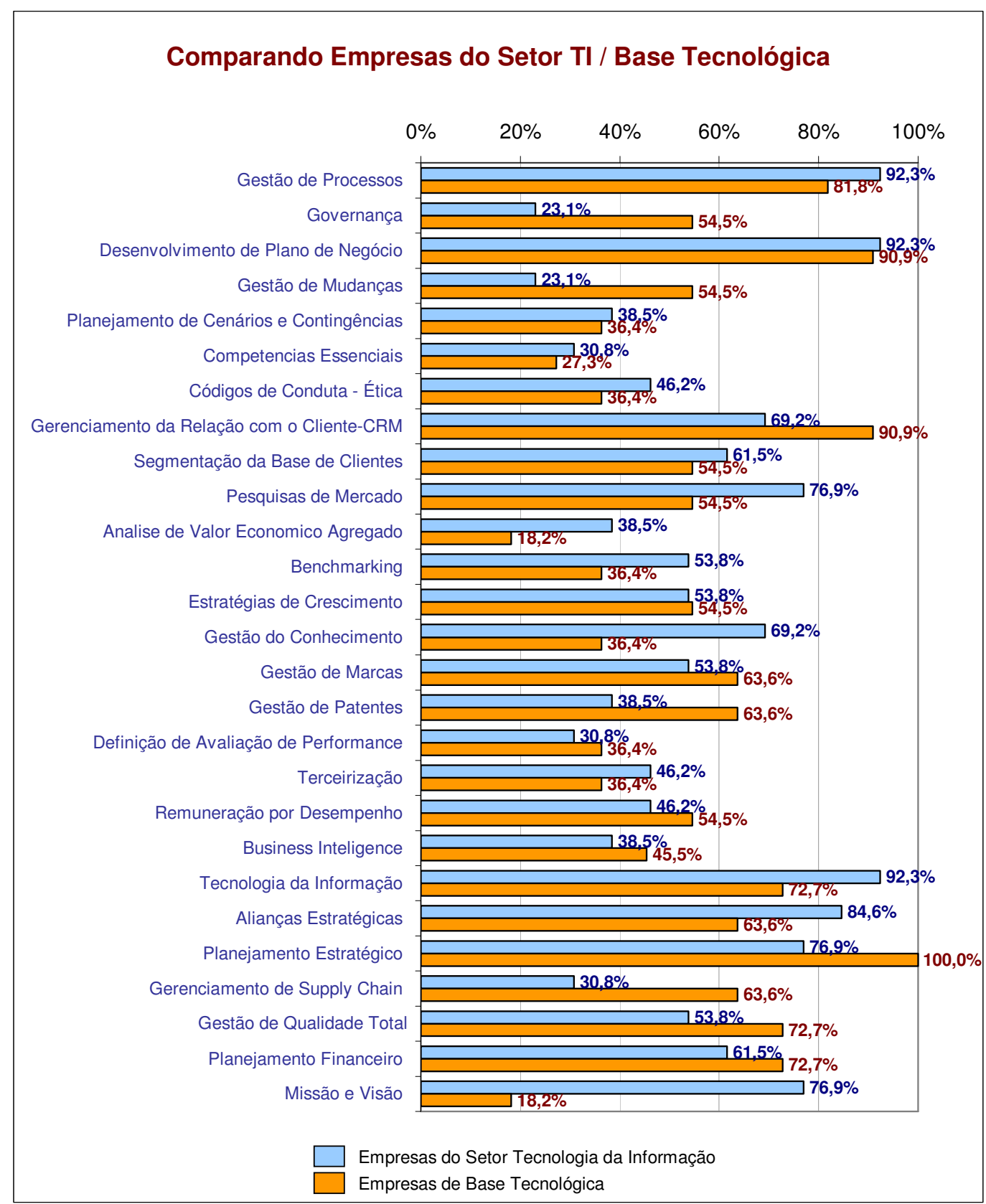

Figura 31 - Comparativo de utilização de ferramentas por empresas de TI e EBT (2003/2007) 
A Figura 32 e a Figura 33 apresentam a utilização de ferramentas de gestão associada à receita anual da EBT. Constata-se que as ferramentas de gestão são mais utilizadas por empresas que tiveram receita em 2007 superior a 500.000,00 reais.

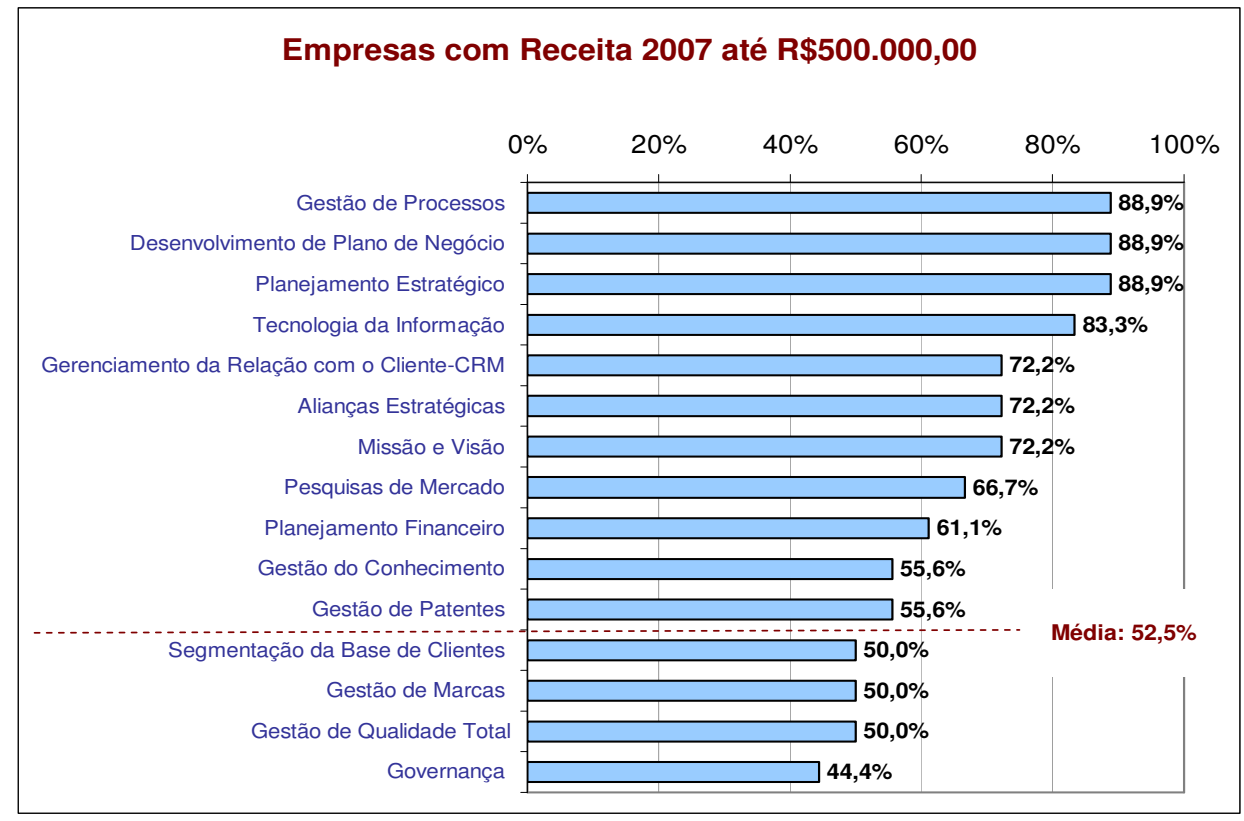

Figura 32 - Utilização de ferramentas por empresas com receita em 2007 até $\mathrm{R} \$ 500.000,00$

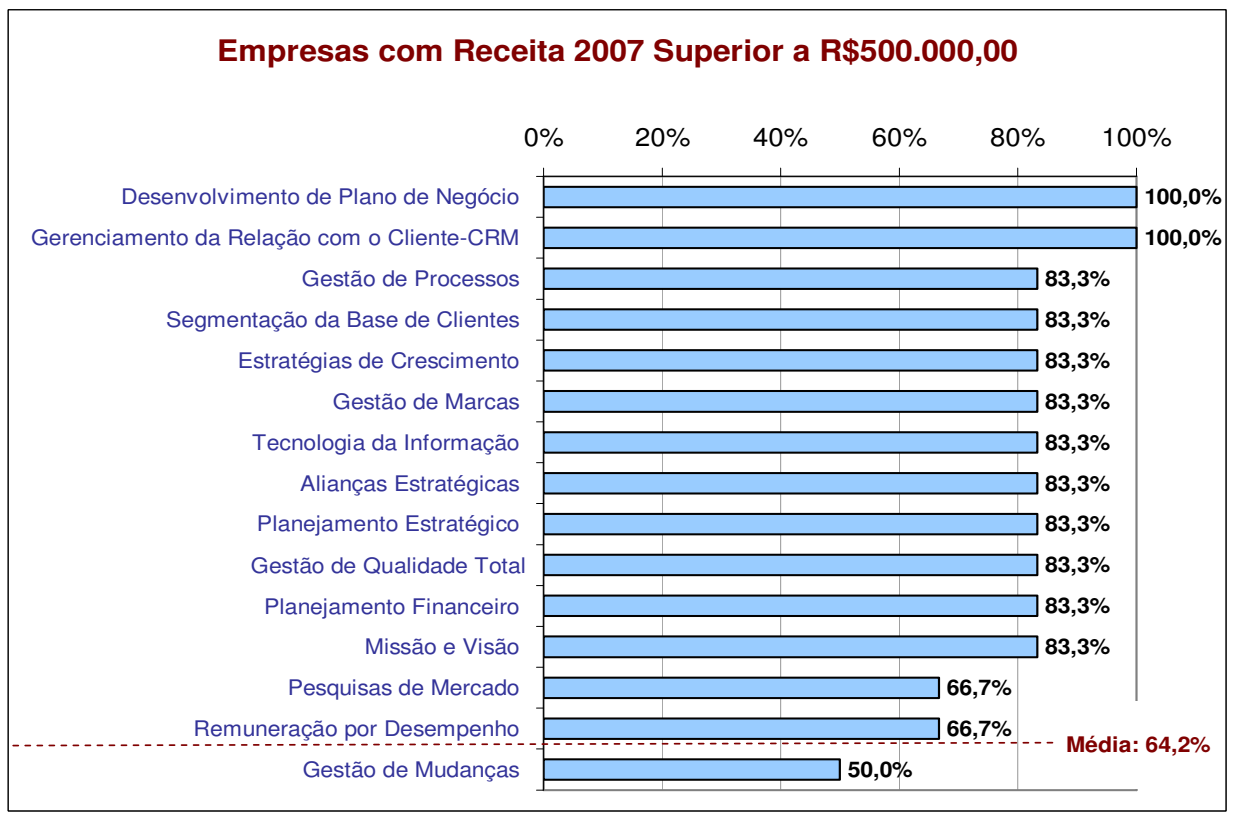

Figura 33 - Utilização de ferramentas por empresas com receita em 2007 acima de $\mathrm{R} \$ 500.000,00$ 
A Figura 34 mostra o comparativo de utilização de ferramentas de gestão por faixa de receita no Estudo no CIETEC. Observa-se que há algumas ferramentas que se destacam por mais utilização por empresas com maior receita em 2007. São elas: CRM; Segmentação da Base de Clientes; Estratégias de Crescimento; Gestão de Marcas; Remuneração por Desempenho; Gestão de Qualidade Total; Planejamento Financeiro.

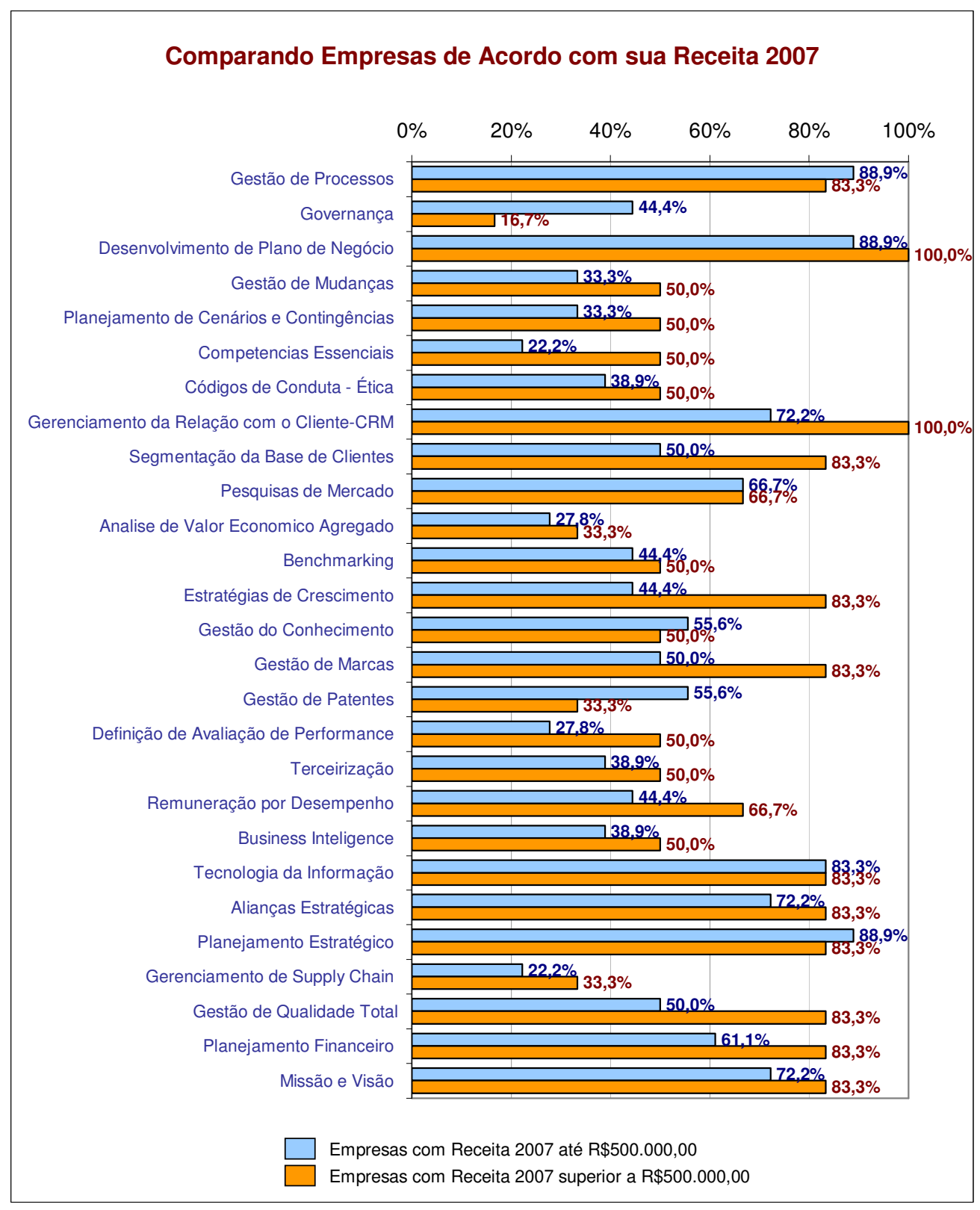

Figura 34 - Comparativo de utilização de ferramentas por faixa de receita no Estudo no CIETEC 
Na Figura 35 temos o resultado do nível de satisfação das Empresas do Estudo no CIETEC com a utilização das ferramentas de Gestão. Observa-se que a nota média obtida para a satisfação com o desempenho das ferramentas de gestão - variando de 1 (extremamente insatisfeito) a 5 (extremamente satisfeito) - é de 3,7. As ferramentas com as quais as empresas estão mais satisfeitas são: Competências Essenciais; Tecnologia da Informação; Planejamento de Cenários e Contingências.

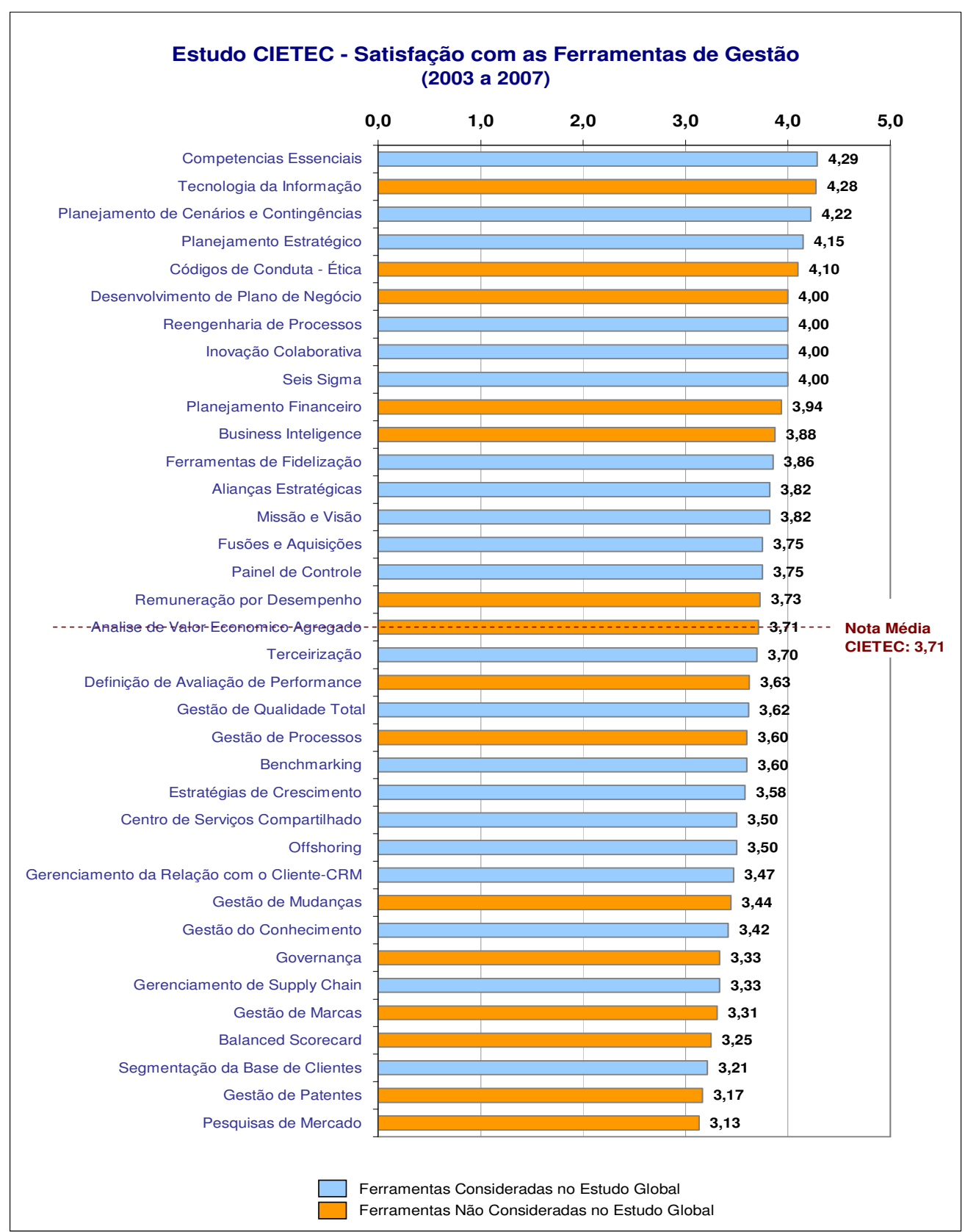

Figura 35 - Satisfação com a utilização de ferramentas (Estudo no CIETEC 2003 a 2007) 
Comparando aos resultados obtidos no Estudo Global, a nota média de satisfação é praticamente igual. Entretanto, o conjunto de notas do Estudo Global apresenta variabilidade bastante inferior ao conjunto de notas do Estudo CIETEC - o Estudo Global varia de 3,59 a 3,93; enquanto o Estudo CIETEC varia de 3,13 a 4,29; conforme mostrado na Figura 36.

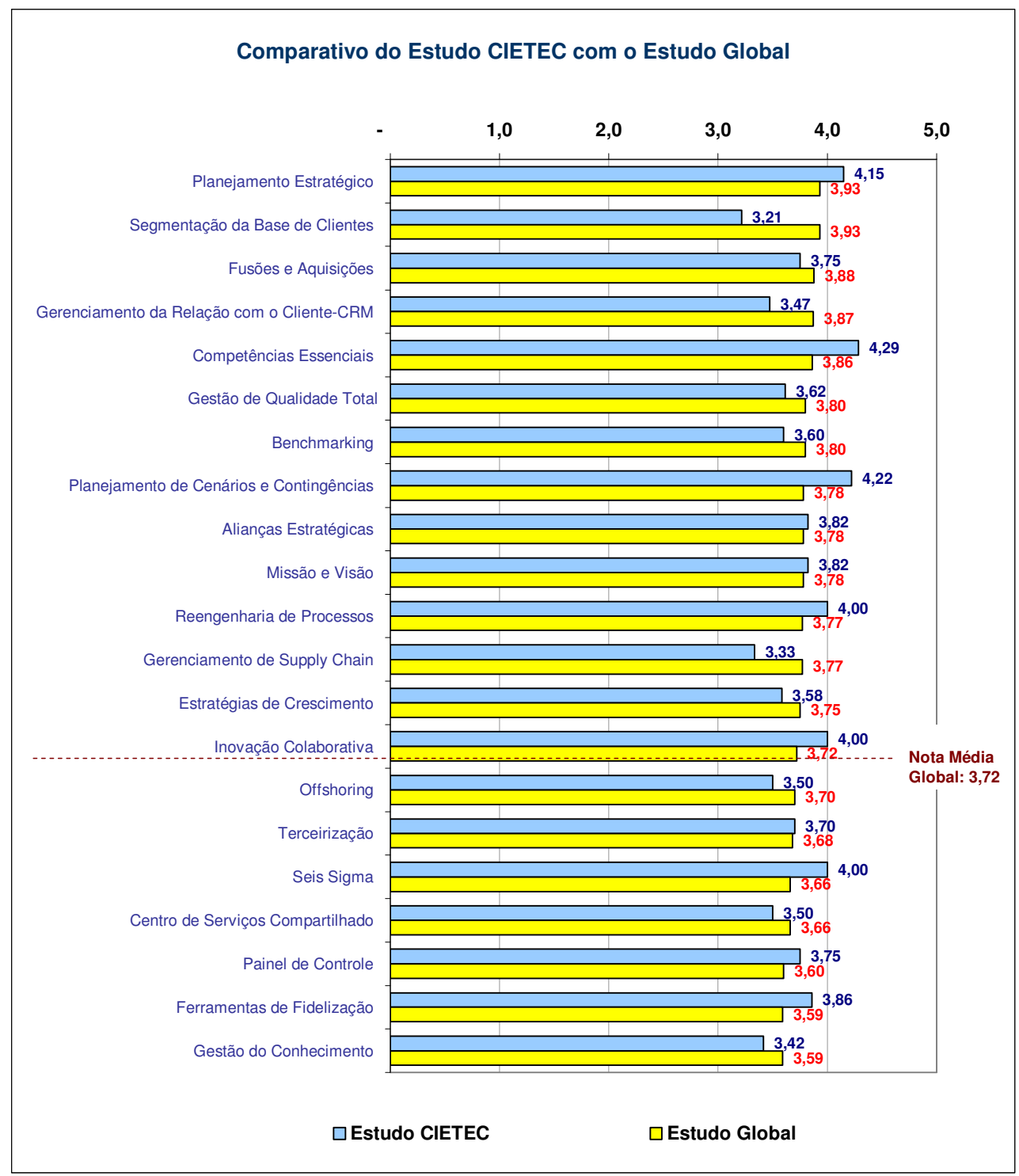

Figura 36 - Comparativo de satisfação de uso das ferramentas entre o Estudo no CIETEC e o Estudo Global 
A Figura 37 apresenta comparativo da utilização de ferramentas de gestão com a satisfação na utilização. Podemos apontar aqui quatro grupos de ferramentas que se destacam pelo percentual de utilização e nota média de satisfação:

- Alta utilização e baixa satisfação: Pesquisa de Mercado; Segmentação da Base de Clientes; Gestão de Marcas; CRM.

- Alta utilização e alta satisfação: Desenvolvimento de Plano de Negócio; Planejamento Estratégico; Tecnologia da Informação.

- Baixa utilização e alta satisfação: Planejamento de Cenários e Contingência; Competências Essenciais; Seis Sigma.

- Baixa utilização e baixa satisfação: Gerenciamento de Supply Chain; Balanced Scorecard; Governança.

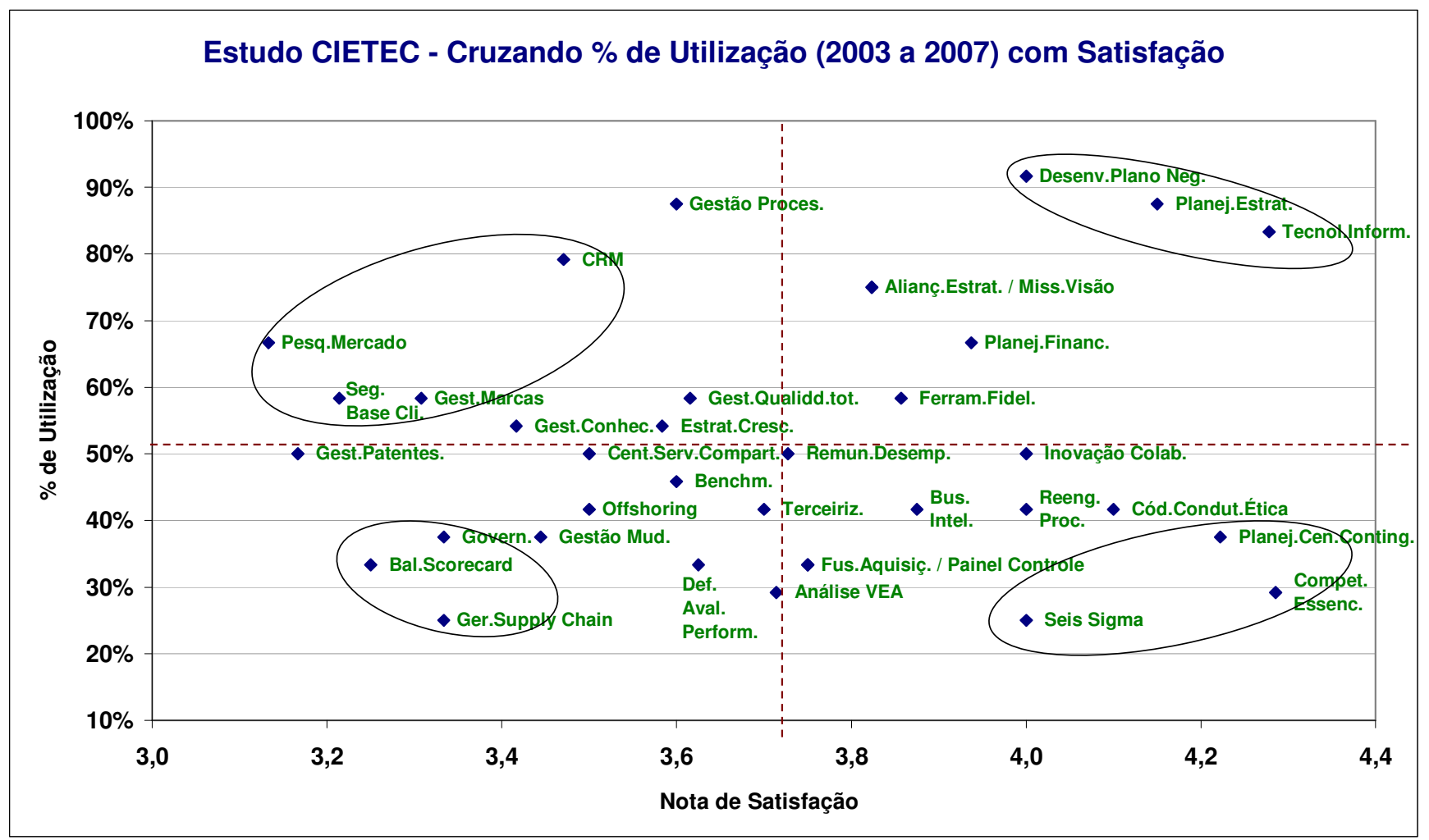

Figura 37 - Comparativo de utilização de ferramentas com satisfação (2003 a 2007) 
A Figura 38 mostra o comparativo de utilização de ferramentas de gestão no período estudado (2003 a 2007) com a expectativa de utilização em 2008. Podemos constatar que, de forma geral, as empresas não possuem expectativa de mudanças para 2008 no que diz respeito à utilização das ferramentas de gestão. Ou seja, as ferramentas que têm sido pouco utilizadas tendem a continuar a sê-lo em 2008 (mesmo aquelas que apresentam alta nota de satisfação), enquanto as ferramentas com alta utilização até 2007 continuarão a ser as mais utilizadas em 2008.

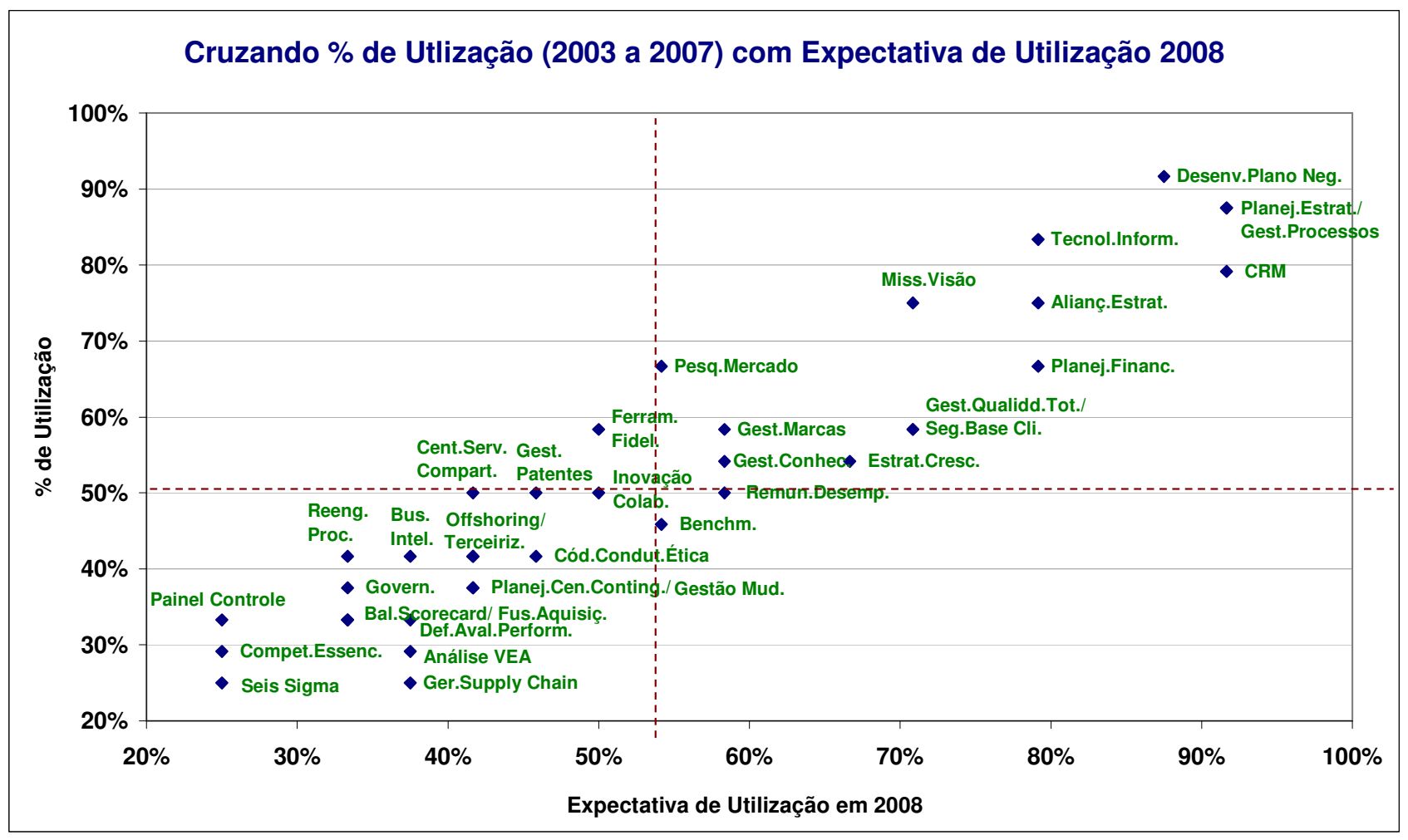

Figura 38 - Comparativo de utilização de ferramentas (de 2003 a 2007) com expectativa de utilização em 2008 
A Figura 39 apresenta comparativo de expectativa de utilização da ferramenta de gestão em 2008 e a satisfação com a utilização. Constata-se que as ferramentas CRM e Segmentação da Base de Clientes destacam-se pelo fato de ter recebido nota baixa e mesmo assim apresentar alta expectativa de utilização em 2008. Por outro lado, Seis Sigma; Reengenharia de Processos; Planejamento de Cenários; e Contingência e Competências Essenciais são ferramentas que receberam nota alta de satisfação pelas empresas, que, entretanto, possuem baixa expectativa de utilizá-las em 2008.

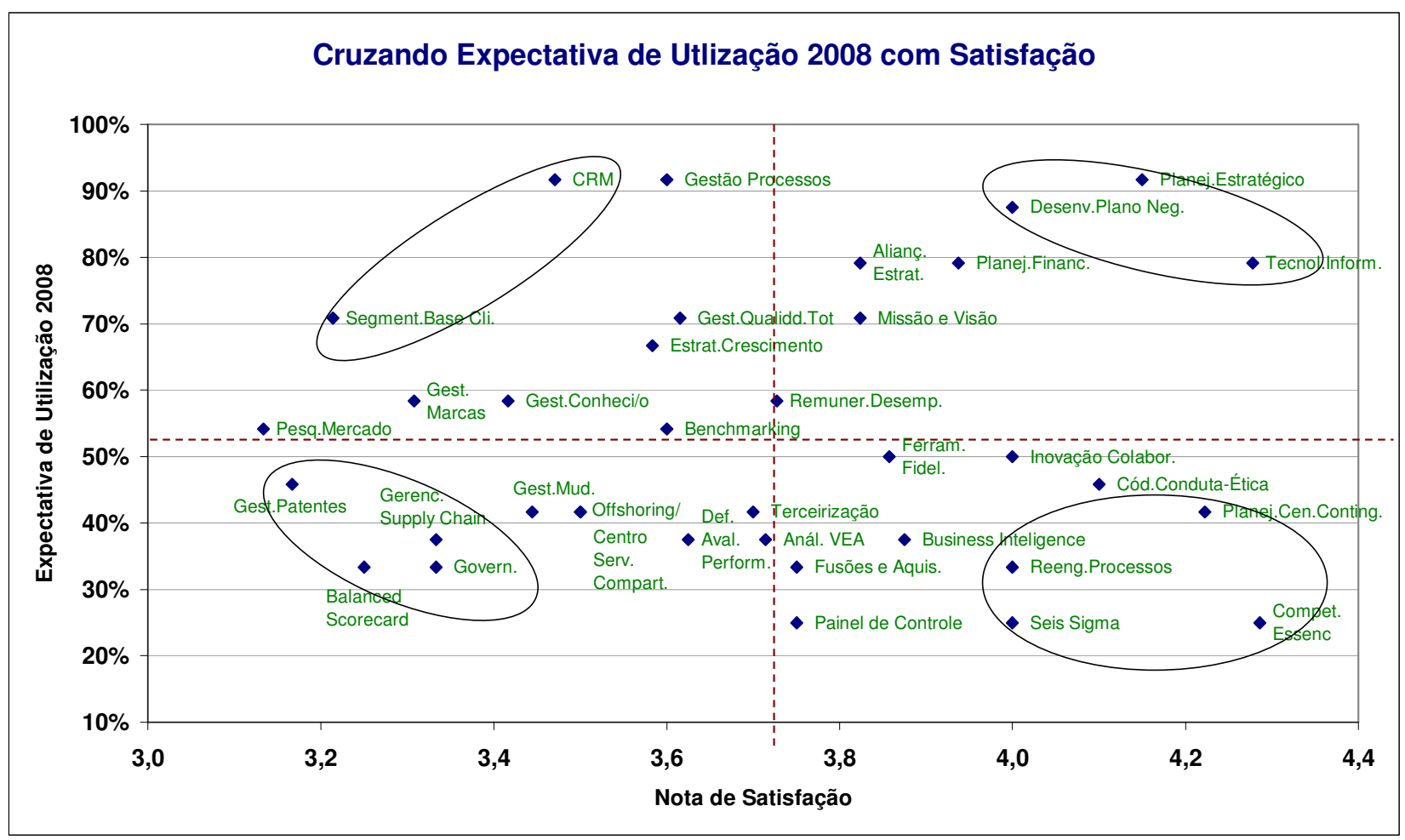

Figura 39 - Comparativo de expectativa de utilização em 2008 com satisfação na utilização de ferramentas 
A Figura 40 apresenta as tendências de gestão das EBTs participantes do Estudo no CIETEC. Observa-se que os gestores possuem forte compromisso com Missão valores, e ética empresarial. O investimento em $\mathrm{TI}$ aparece como elemento estratégico para atingir metas de crescimento. Constata-se que inovação e P\&D estão entre as seis principais prioridades dos gestores das EBTs estudadas.

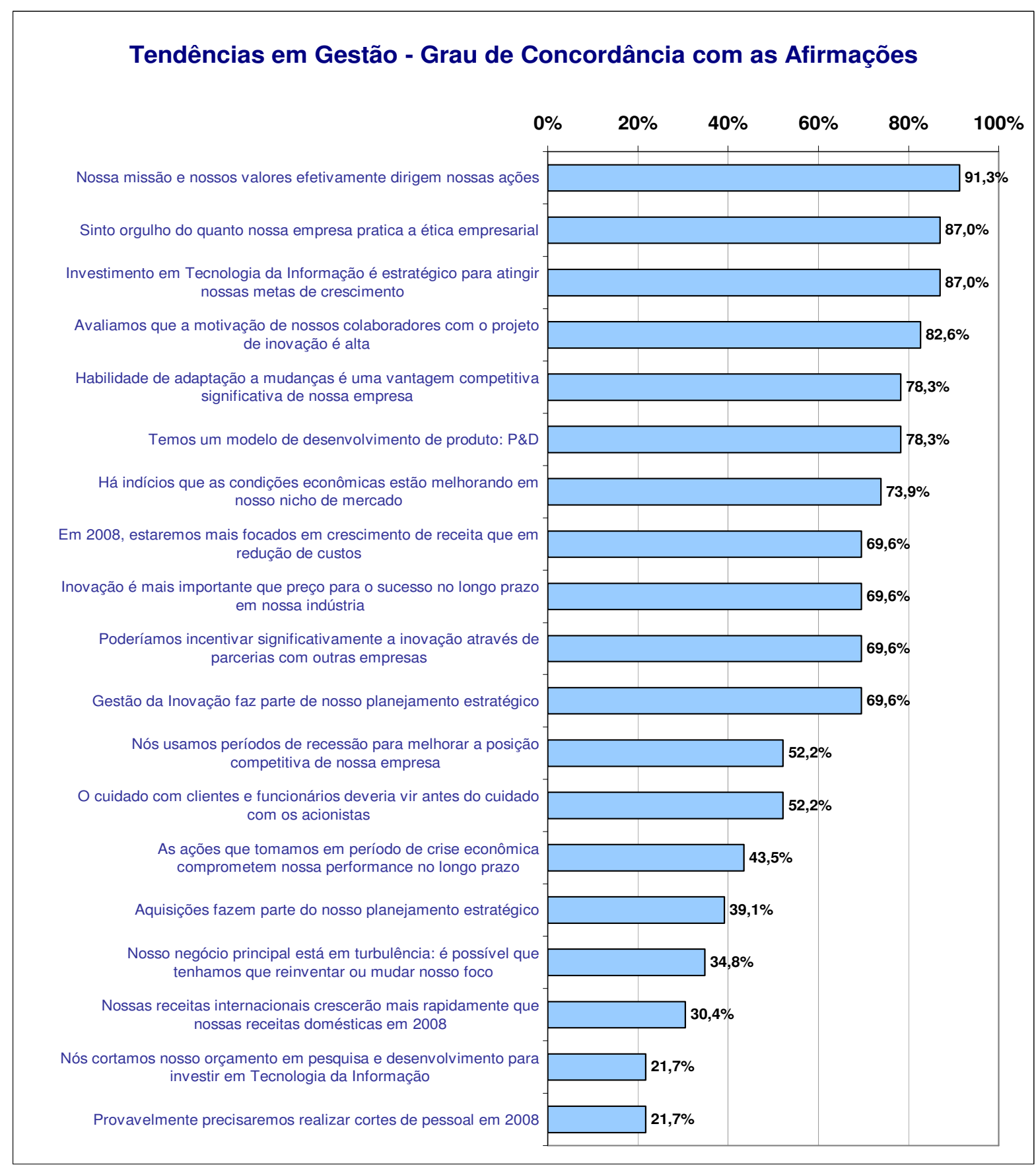

Figura 40 - Tendências em gestão nas EBTs do Estudo no CIETEC (grau de concordâncias com as afirmações) 


\subsection{INOVAÇÃO E MELHORES PRÁTICAS DE TI}

A Figura 41 apresenta o nível de percepção de práticas de inovação das EBTs com relação à concorrência e na Figura 42 a expectativa de implementação de práticas inovadoras em relação à condição atual. Constata-se que as empresas pesquisadas no Estudo CIETEC se consideram mais inovadoras do que os competidores no mercado, e mais de $80 \%$ delas acreditam que deveriam inovar ainda mais.

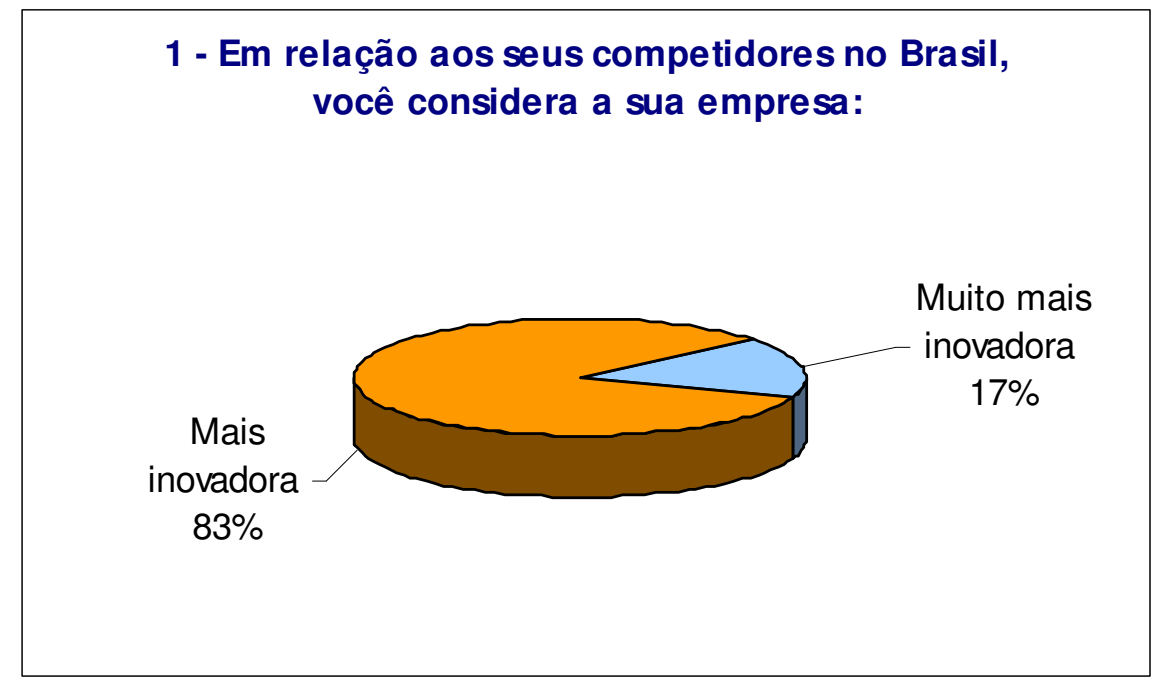

Figura 41 - Nível de percepção de práticas de inovação em relação à concorrência

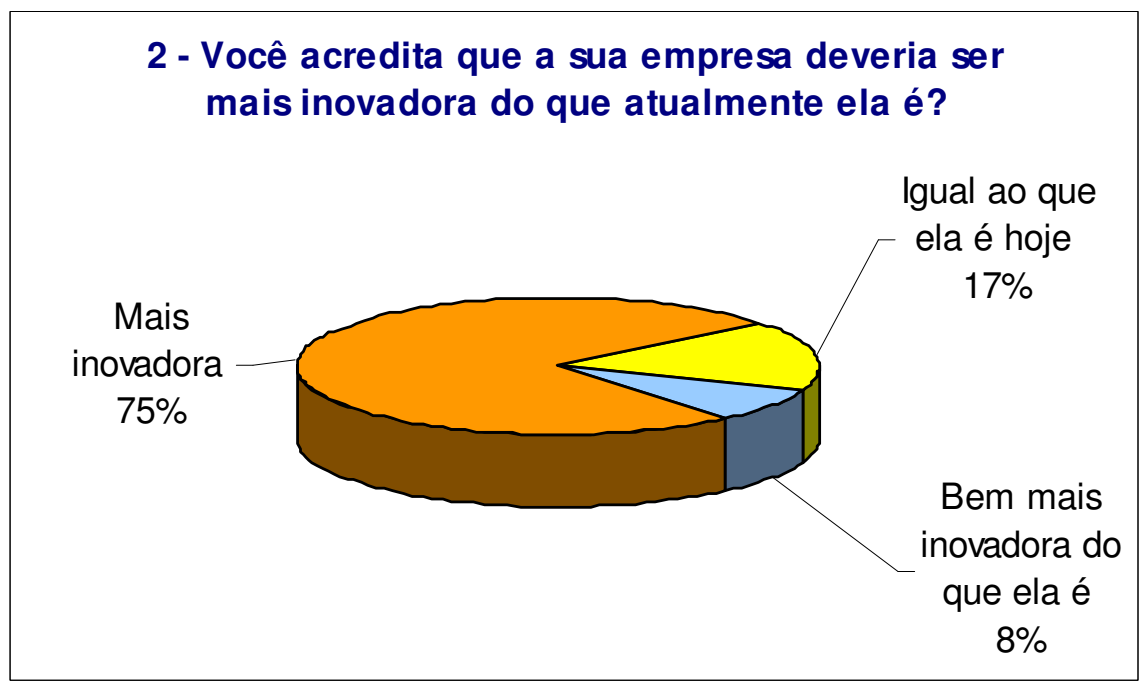

Figura 42 - Expectativa de implementação de práticas inovadoras em relação à condição atual 
A Figura 43 apresenta a relação de TI com inovação na definição de métricas de desempenho. A Figura 44 correlaciona a existência de recursos financeiros para $\mathrm{TI}$ e recursos humanos dedicados à inovação. Constata-se que maioria das empresas (83\%) discute inovação, mas somente metade delas cobra a área de $\mathrm{TI}$ a respeito. Além disso, em 58\% delas não há orçamento em TI para inovação.

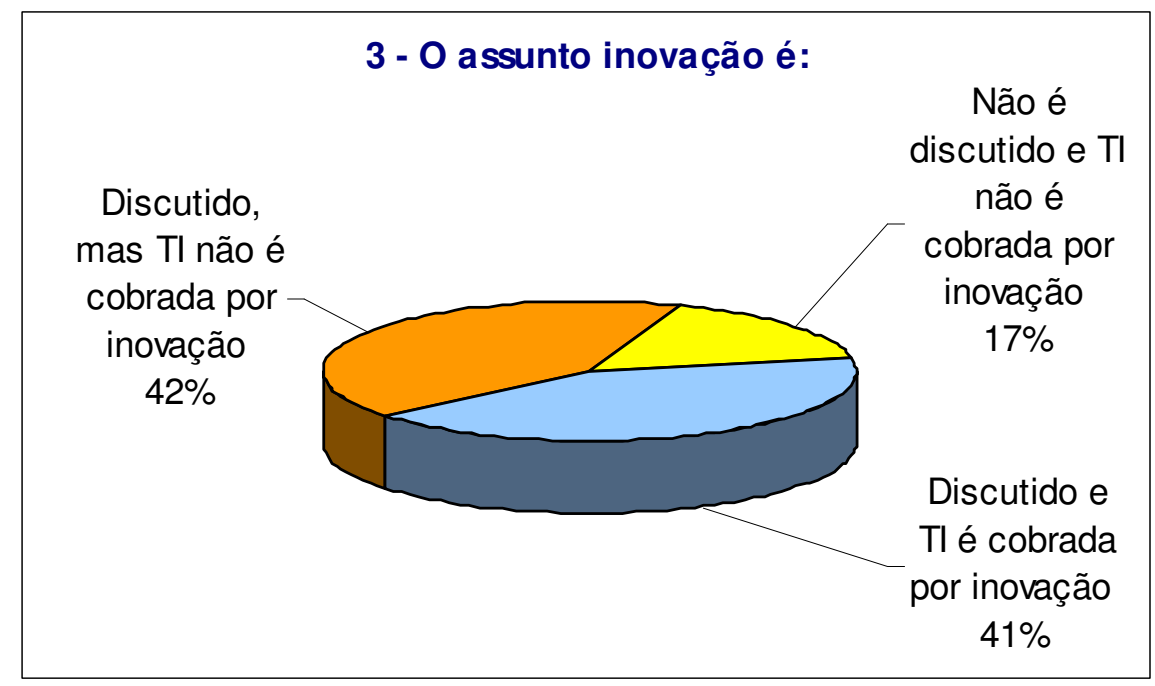

Figura 43 - Importância atribuída às práticas inovadoras pela empresa e envolvimento de TI

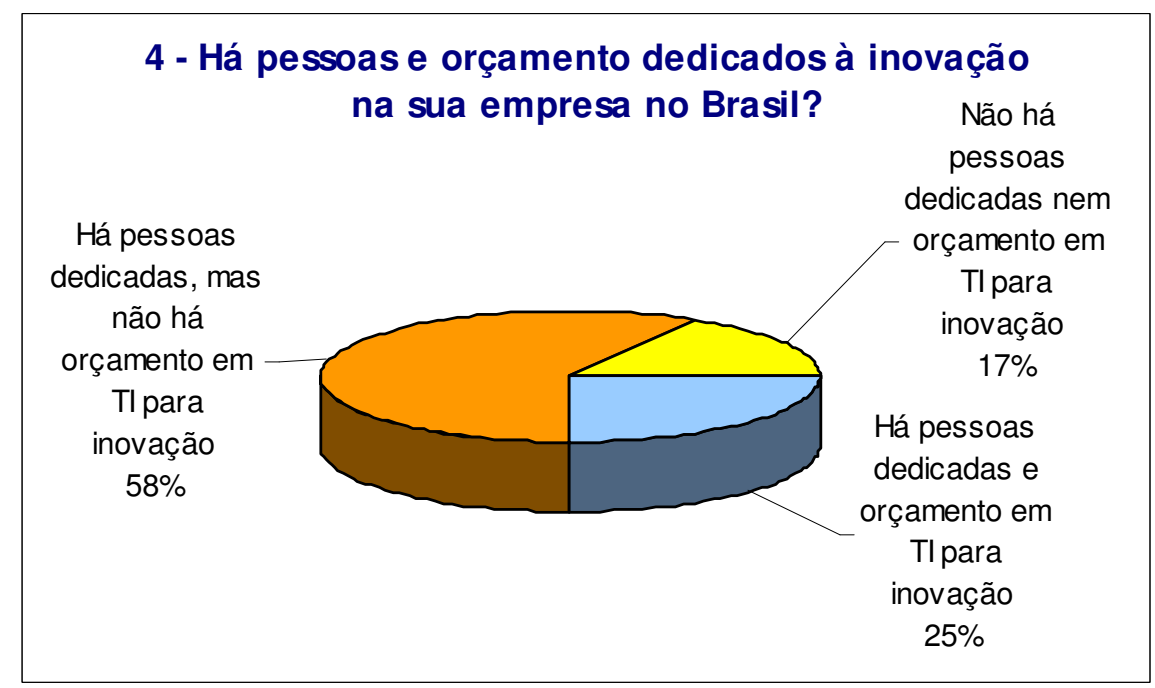

Figura 44 - Investimento de capital e pessoal em práticas inovadoras 
A Figura 45 apresenta a expectativa das EBTs de utilização de soluções sofisticadas e complexas de TI. Apenas 33\% das empresas já implantaram ou pretendem implantar pelo menos metade das soluções de TI citadas.

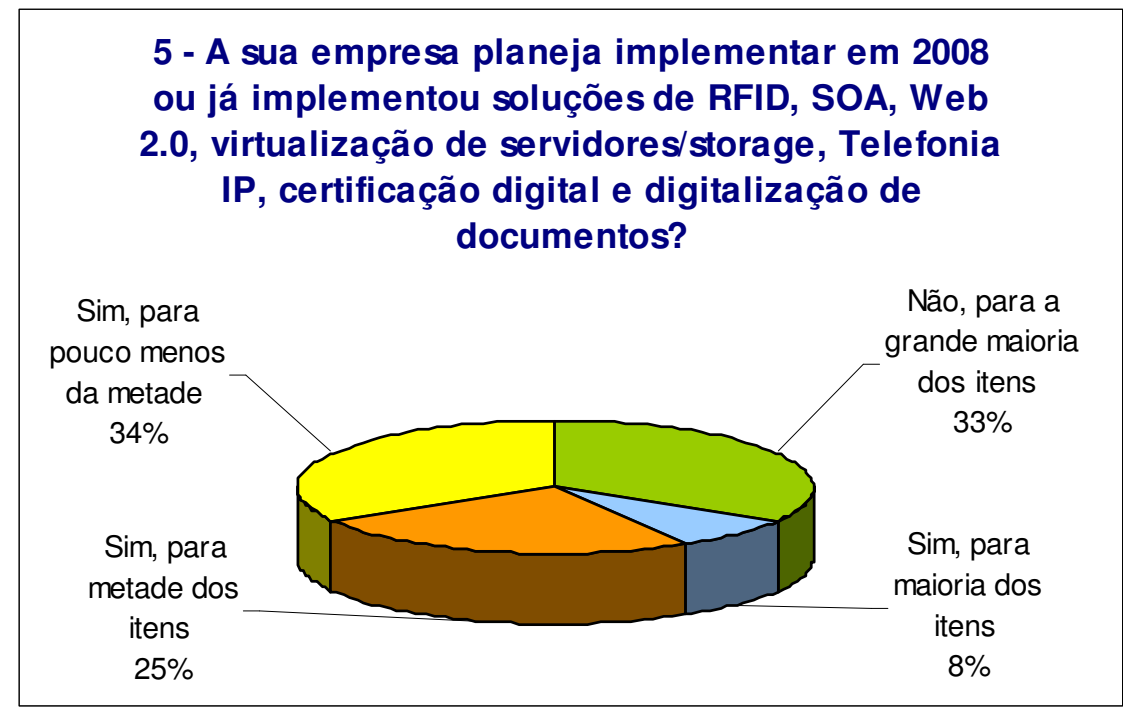

Figura 45 - Expectativa de implementação de soluções de TI para 2008

A Figura 46 mostra que as EBTs tendem a priorizar projetos que acarretam aumento de receita e diferencial competitivo.

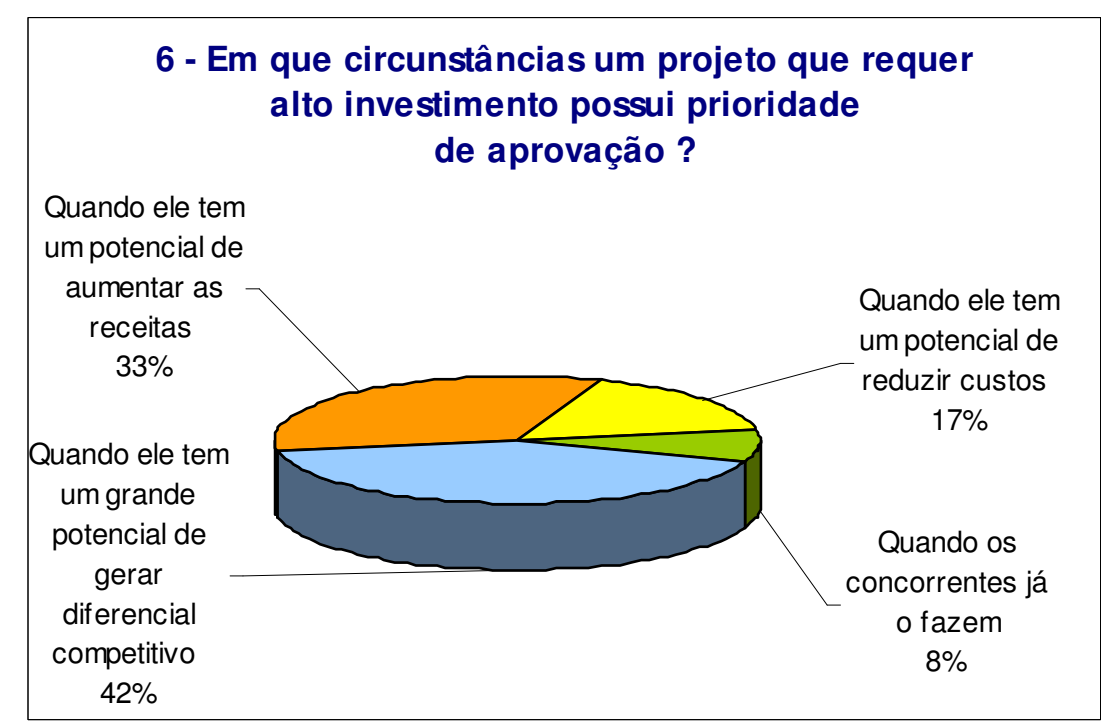

Figura 46 - Atribuição de prioridade de aprovação para práticas inovadoras de alto valor 
A Figura 47 apresenta as tendências de gestão das EBTs com relação a inovação. Constata-se que há envolvimento dos colaboradores nesse quesito; porém não existe um processo formal de premiação de idéias que possam vir a gerar inovação.

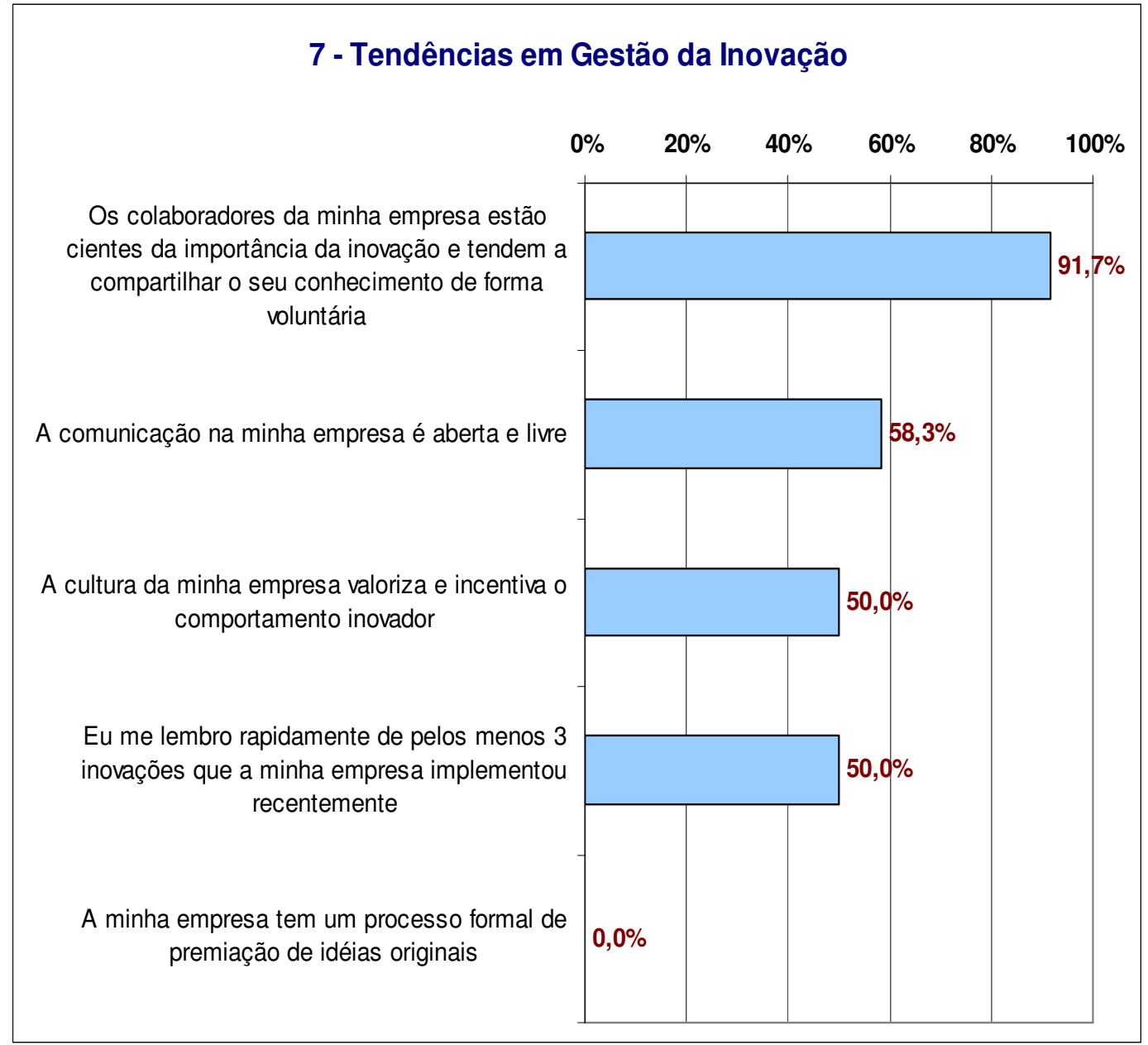

Figura 47 - Percepção de tendências de gestão em inovação 
A Figura 48 apresenta o engajamento da área de Tecnologia da Informação com os negócios da EBT. A partir das práticas constatadas no Estudo no CIETEC, destacase o envolvimento dos gestores de $\mathrm{TI}$ com as áreas de negócio e também a imaturidade das métricas de TI com a performance do negócio.

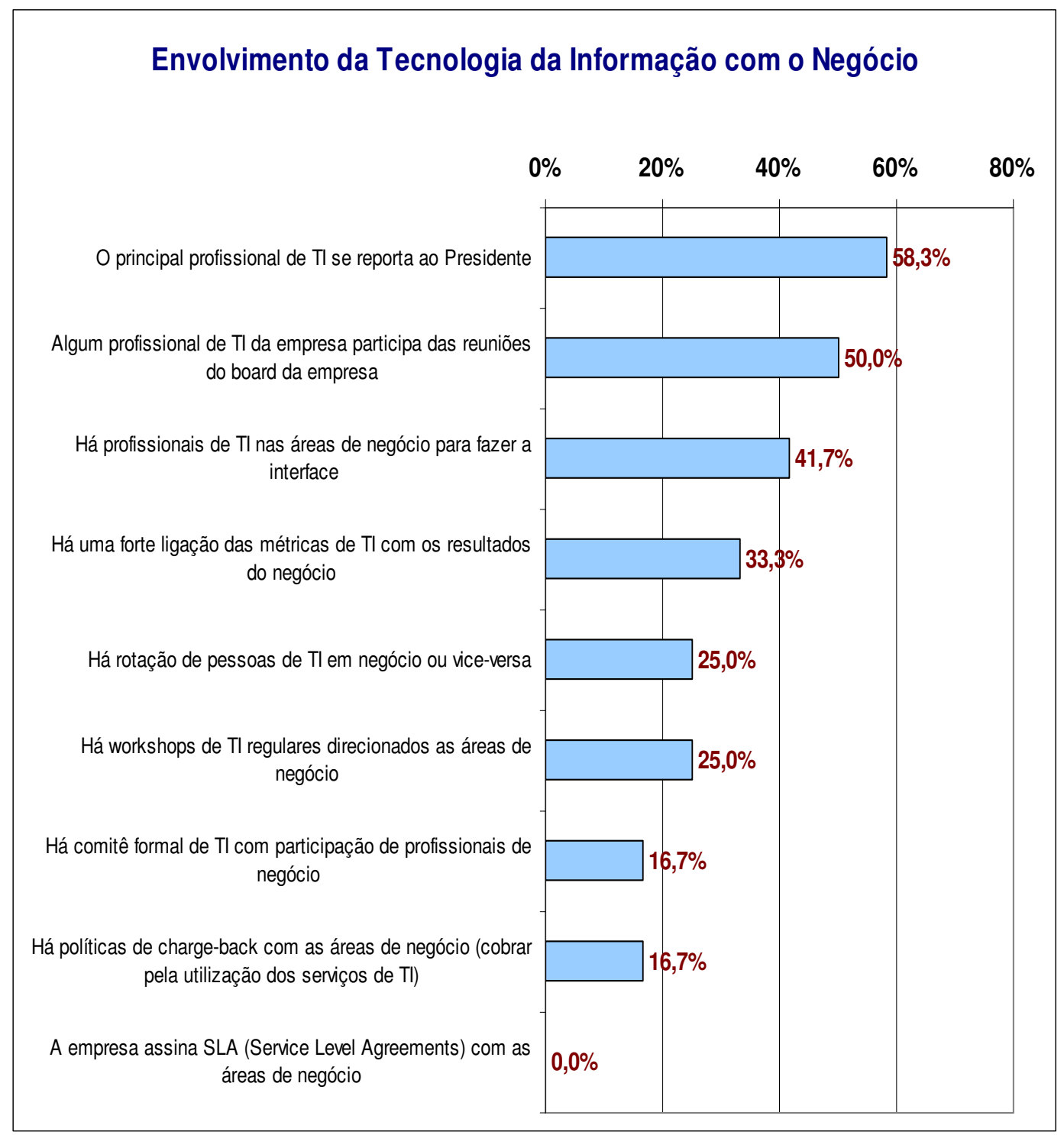

Figura 48 - Engajamento da área de Tecnologia da Informação nos negócios da empresa 
A Figura 49 apresenta a utilização de ferramentas de Governança de TI pelos gestores da EBT. Constata-se que, com relação às Ferramentas de Governança, a utilização por parte das EBTs é baixa, com exceção de CMM e Balanced Scorecard.

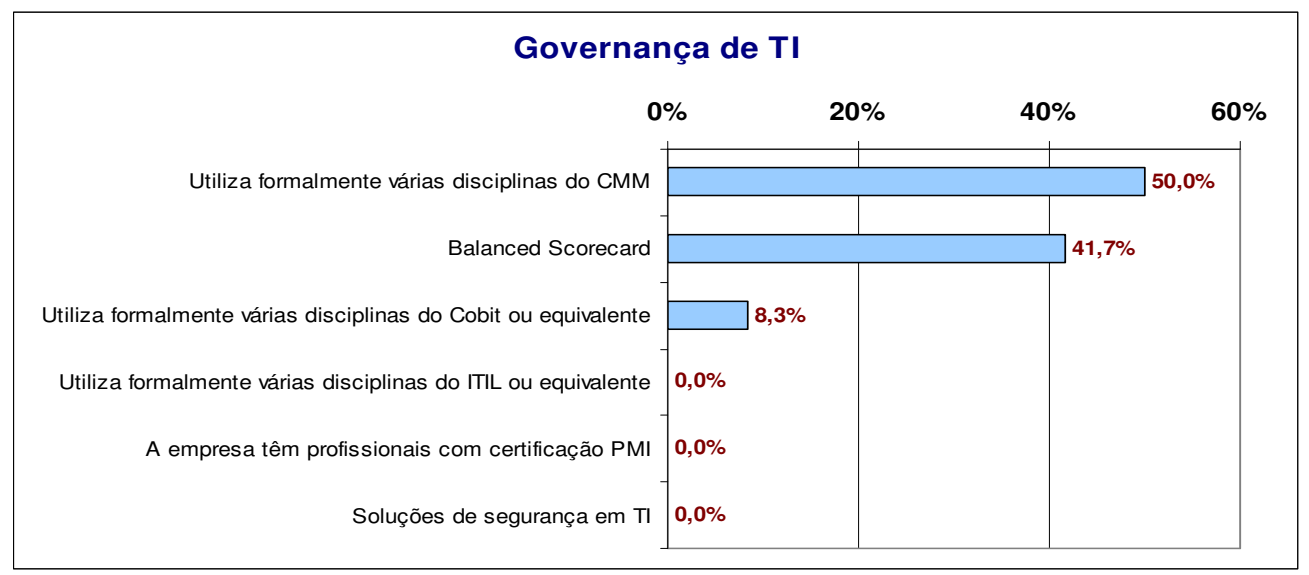

Figura 49 - Governança de Tecnologia da Informação

Na Figura 50 temos a tendência das EBTs no uso de soluções de TI. O maior foco está nas ferramentas de Gerenciamento de Sistemas; Portfólio; Ativos e Processos.

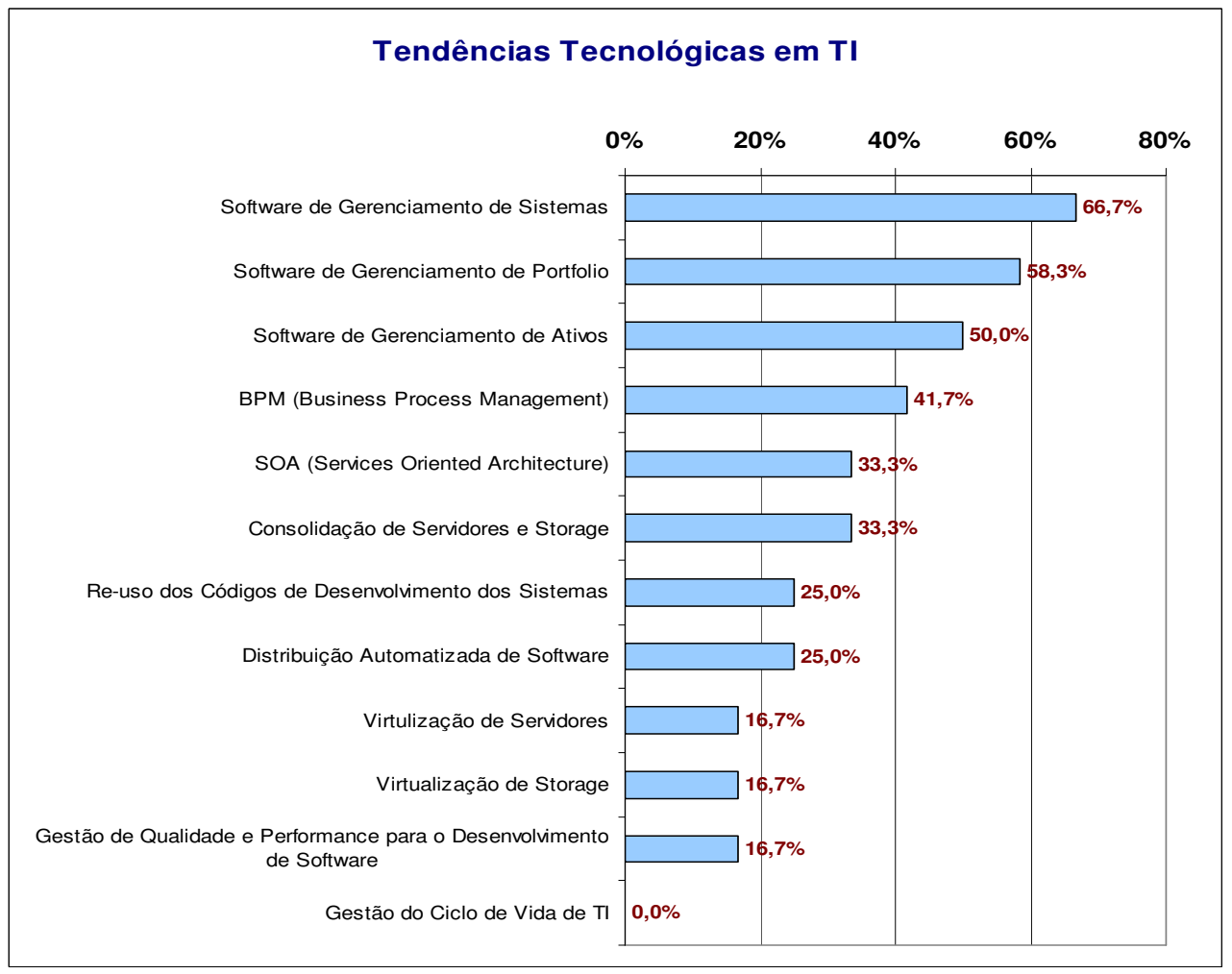

Figura 50 - Tendências em Tecnologia da Informação 
A Figura 51 apresenta as tendências de investimento em TI por parte das EBTs. Observa-se tendência de investimentos em ferramentas com foco em ganho de performance e produtividade. É característica das empresas incubadas a não prioridade de investimentos em ferramentas mais sofisticadas e complexas.

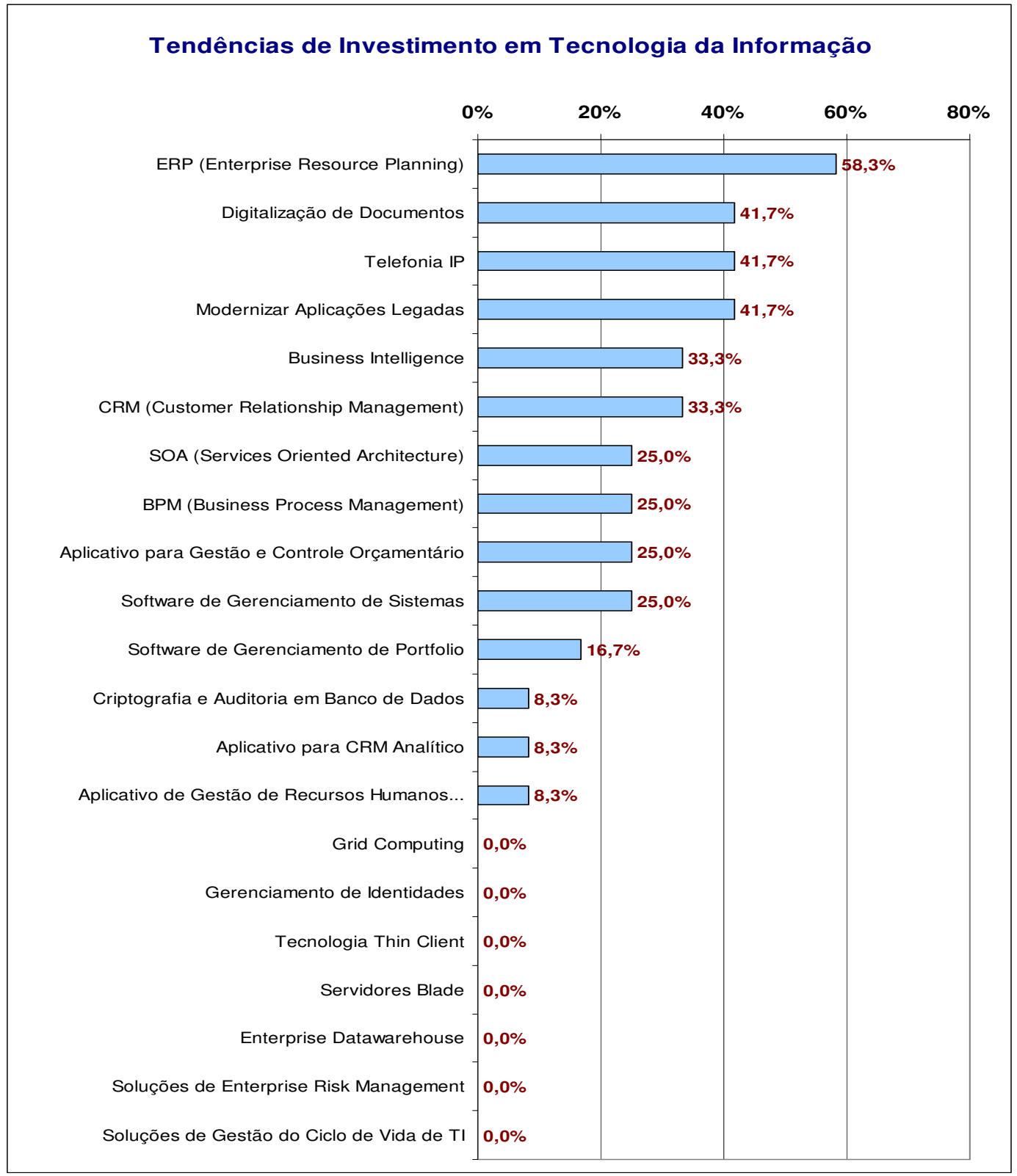

Figura 51 - Tendências de investimento em TI 


\subsection{CONTRIBUIÇÕES DA PESQUISA}

A seguir são apresentadas as principais contribuições da pesquisa.

\section{Governança}

Da análise dos resultados no que se refere a abertura de capital (Figura 17), podemos concluir que somente $40 \%$ das empresas pesquisadas utilizam práticas de Governança. Fato que representa ameaça para a estratégia de crescimento da empresa incubada de base tecnológica.

\section{Estágio de desenvolvimento}

Da Figura 10 e da 20, constata-se que o uso de ferramentas de gestão cresce à medida que as empresas passam para um estágio mais alto de desenvolvimento.

\section{Olhando para dentro}

Com quatro ferramentas voltadas para a empresa - Desenvolvimento de Planos de Negócio, Gestão de Processos, Planejamento Estratégico e Tecnologia da Informação - figurando entre as quatro do topo da lista de ferramentas mais utilizadas pelas empresas do Estudo CIETEC, conforme apresentado na Figura 22, fica evidente a importância que os gestores estão dando para a construção da estrutura necessária para o desenvolvimento e crescimento das empresas.

\section{Comparativo do Estudo no CIETEC com o Estudo Global}

Na Figura 25, constata-se que as ferramentas Gestão da Cadeia de Suprimentos, Terceirização, Benchmarking e Competências Essenciais são pontos que merecem atenção do gestor da empresa incubada ao comparar os resultados do Estudo no CIETEC com os resultados da Pesquisa Global. Já as ferramentas Inovação Colaborativa, Alianças Estratégicas e Centro de Serviços Compartilhados apresentam taxa de utilização próximas do resultado global caracterizando o meio colaborativo em que está inserida a empresa incubada no CIETEC. Planejamento 
estratégico é a principal ferramenta tanto para os gestores do Estudo no CIETEC quanto na Pesquisa Global.

A partir da Figura 24, pode-se constatar que Gestão do Conhecimento e Planejamento de Cenários e Contingências estão entre as dez prioridades dos gestores da Pesquisa Global. Isso reflete a preocupação das empresas por ferramentas que orientem no gerenciamento de empreendimentos globais. São ferramentas que ajudam as empresas a se preparar tanto para as oportunidades como para os riscos da globalização e que também contribuem para fortalecer a cultura corporativa, afetando as melhorias de processos e tomadas de decisão.

\section{Olhando para fora}

$\mathrm{Na}$ Figura 28, comparando a utilização das ferramentas de gestão por empresas em estágio inicial e avançado de desenvolvimento, verifica-se que as ferramentas Pesquisa de Mercado, Gerenciamento da Relação com o Cliente, Estratégia de Crescimento, Gestão de Marcas, Remuneração por Desempenho e Gestão de Mudanças estão no foco da atenção dos gestores das empresas em estágio avançado de desenvolvimento, mostrando que as empresas estão olhando para fora de si mesmas para inovar e crescer.

\section{Empresas de TI e EBTs atuando em redes de cooperação}

Agrupadas por áreas de atuação - Tecnologia da Informação, Meio Ambiente, Medicina \& Saúde, Eletroeletrônico e Biotecnologia -, as empresas de TI e EBT que fizeram parte do estudo no CIETEC possuem diferentes prioridades quanto ao uso de ferramentas de gestão conforme apresentado na Figura 31. Enquanto as ferramentas Pesquisa de Mercado, Missão e Visão, Análise de Valor Econômico Agregado, Benchmarking e Gestão de Conhecimento possuem maior taxa de utilização pelas empresas de $\mathrm{TI}$, as prioridades de utilização das empresas de base tecnológica estão nas ferramentas Governança, Gestão de Mudanças, CRM, Planejamento Estratégico, Gestão de Patentes e Gerenciamento da cadeia de Suprimento. 


\section{Desenvolvimento e faturamento}

$\mathrm{Na}$ Figura 34, observa-se que as empresas em avançado estágio de desenvolvimento e conseqüentemente com faturamento superior a $500.000,00$ reais estão mais preocupadas com ferramentas de Estratégia de Crescimento, CRM, Segmentação da Base de Clientes, Gestão de Marcas, Gestão da Qualidade e Planejamento Financeiro. Já as empresas de menor faturamento se ocupam com Governança e Planejamento Estratégico.

\section{Utilização de ferramentas e nível de satisfação}

Ao avaliar como a utilização das ferramentas e a satisfação obtida com elas têm mudado ao longo do tempo (Figura 37, 38 e 39), identificamos quatro categorias de ferramentas.

- Ferramentas incipientes - têm baixo nível de utilização e baixo nível de satisfação; na Figura 37 destacamos Governança, Gestão de Mudanças, Gerenciamento da Cadeia de Suprimentos.

- Ferramentas brutas - têm alto nível de utilização, mas baixo nível de satisfação. Na Figura 37, destacamos as ferramentas Pesquisa de Mercado, Segmentação da Base de Cliente, Gestão do Relacionamento com Cliente (CRM) e Gestão de Marcas.

- Ferramentas especializadas - têm baixo nível de utilização, mas alto nível de satisfação; na Figura 37 destacamos as ferramentas Planejamento de Cenários e Contingências, Seis Sigma e Competências Essenciais.

- Ferramentas de impacto - têm alto nível de utilização e alto nível de satisfação; na Figura 37 destacamos Planejamento Estratégico, Tecnologia da informação e desenvolvimento de Plano de Negócio.

De acordo com a Pesquisa Global, em geral, o uso das ferramentas inicia na categoria "incipiente", ou seja, relativamente novas e com avaliação abaixo da média em termos de utilização e satisfação. As ferramentas incipientes podem seguir quatro caminhos possíveis:

1. Continuarão a ter desempenho fraco e se mostrarão modismos passageiros. 
2. Serão melhoradas e funcionarão de forma mais efetiva, mas acabarão servindo algum nicho funcional, tornando-se "especializadas", como é o caso de Fusões e Aquisições.

3. Serão utilizadas de forma mais ampla, em virtude de necessidades reais, mas não conseguirão ficar mais efetivas, tornando-se "Ferramentas Brutas", continuadamente com baixos índices de satisfação, como é o caso de Gestão Conhecimento;

4. Irão adaptar-se, tornando-se mais efetivas, serão utilizadas mais amplamente e se tornarão "ferramenta de impacto". E podem se transformar em padrão para a maioria das empresas, como é o caso de Planejamento Estratégico, tecnologia da Informação e Plano de Negócios.

A partir da análise dos resultados apresentados na Figura 37, que mostra a utilização das ferramentas; a Figura 38, que apresenta o grau de satisfação com as ferramentas; e a Figura 39, que indica a tendência de uso das ferramentas em 2008, podemos propor o desenvolvimento de uma nova pesquisa que identificasse as causas da baixa satisfação e baixa utilização de ferramentas consideradas estratégicas para o crescimento sustentável da empresa incubada de base tecnológica como Governança, CRM, Supply Chain Management, Business Inteligence, Estratégia de Crescimento entre outras.

\section{Tendências em Gestão}

A Figura 40 apresenta as tendências de gestão das EBTs participantes do Estudo no CIETEC. Os resultados indicam um posicionamento empresarial focado em Missão e Valores, Ética Empresarial, Investimento em TI, Motivação para Inovar, Crescimento Organizacional, bem como uma visão otimista provavelmente pela baixa utilização e satisfação encontrada com a ferramenta Planejamento de Cenários e Contingências apresentado na Figura 37.

Comparando os resultados da Figura $40 \mathrm{com}$ a Figura 37, 38 e 39 encontramos baixa utilização e baixa satisfação com ferramentas de gestão diretamente associadas ao posicionamento de gestão. Esse fato pode remeter a uma nova proposta de estudo que permita ao gestor da empresa incubada de base tecnológica 
identificar os fatores críticos de sucesso no uso das ferramentas de gestão para auxiliá-lo a adquirir a solidez necessária para se graduar.

\section{Inovação e melhores Práticas de TI}

Da Figura 41 e 42, constata-se que as empresas participantes do Estudo no CIETEC adotam posicionamento gestor centrado na inovação e que todas se consideram mais inovadoras que os concorrentes.

$\mathrm{Na}$ Figura 43 e na 44 observa-se que as empresas discutem o tema inovação, mas $\mathrm{Tl}$ é cobrada por inovação somente em $41 \%$ das empresas que discutem o tema.

As soluções de $\mathrm{TI}$ que envolvem alta complexidade e investem fortemente em inovação tecnológica são adotadas por apenas 33\% das empresas conforme Figura 45.

$\mathrm{Na}$ Figura 46, constata-se que as empresas tendem a priorizar investimentos quando estes têm alto potencial de aumentar receitas (33\%) e grande potencial de gerar diferencial competitivo (42\%).

Na Figura 47, observa-se que para $91,70 \%$ das empresas do Estudo no Cietec há motivação dos colaboradores em relação a inovação, porém não existe um processo formal de premiação, e apenas $50 \%$ valorizam e incentivam a cultura inovadora.

Para as empresas participantes do estudo, na Figura 48, constata-se que há envolvimento de $\mathrm{TI}$ com as métricas do negócio em 33\% das empresas e que somente em $58,30 \%$ das empresas o profissional de TI se reporta ao presidente.

Comparando os resultados da Figura 47 e da 48 com os resultados da Figura 37, constata-se que $\mathrm{TI}$ representa uma ferramenta de alta utilização e alta satisfação, porém tem baixa participação estratégica no negócio. O resultado pode sugerir um novo estudo com o objetivo de identificar fatores críticos de sucesso no uso das ferramentas de $\mathrm{TI}$ auxiliando a produzir vantagem competitiva e desenvolvimento empresarial. 
$\mathrm{Na}$ Figura 49, observa-se que o uso das ferramentas de Governança de $\mathrm{TI}$ é muito baixo e que ferramentas ligadas ao desenvolvimento de software são utilizadas por $50 \%$ das empresas do estudo.

Na Figura 50, constata-se que as empresas têm maior foco no uso de ferramentas que proporcionam mais eficiência operacional como Software de Gerenciamento de Sistemas (66,7\%), Software de Gerenciamento de Portfólio (58,3\%) e Gerenciamento de Ativos (50\%).

$\mathrm{Na}$ Figura 51, observa-se que a ferramenta de ERP $(58,3 \%)$ aparece com a maior tendência de investimento por parte das empresas estudadas, seguida por Digitalização de Documentos, Tecnologia IP e Modernização das Aplicações Legadas de $\mathrm{TI}$, todas com o mesmo nível de prioridade. As soluções mais sofisticadas e complexas não fazem parte dos planos de investimentos das empresas estudadas.

\section{Fatores Críticos de Sucesso}

Neste trabalho definimos como Fatores Críticos para o Sucesso como um conjunto de práticas e ferramentas que tem sido incorporadas aos modelos de gestão de empresas bem sucedidas definidas por:

$>$ É uma instituição lider no seu setor

$>$ É admirada pela sociedade

$>$ Construiu uma marca

> Teve várias gerações de executivos

Passou por ciclos de vida de produtos e ou serviços

$>$ Rumunera o investimento

$>$ Sobreviveu ao teste do tempo 


\section{CONCLUSÃO}

A seguir são apresentadas as principais conclusões desta pesquisa quanto a fatores críticos de sucesso no uso de ferramentas de gestão em empresas incubadas de base tecnológica.

\section{Tendências em Ferramentas e Técnicas de Gestão}

Neste trabalho, ao monitorar quais ferramentas as empresas incubadas de base tecnológica utilizam, em quais circunstâncias e com qual nível de sofisticação, os resultados encontrados estão concentrados em quatro temas chaves :

- Desenvolvimento e Planejamento do Negócio: com quatro ferramentas voltadas para o desenvolvimento do negócio - Planejamento Estratégico, Desenvolvimento de Plano de Negócios, Gestão de Procesos e Tecnologia da Informação - figurando entre as cinco do topo da lista das ferramentas de gestão mais utilizadas, fica evidente a importância que as empresas estão dando a estruturação do modelo de negócio e dos seus processos de gestão.

- Foco no Cliente: a pesquisa mostra que as empresas estão concentrando esforços em utilizar ferramentas que permitam conhecer mais seus clientes para melhor atender suas necessidades. Destacam-se nesta categoria o uso de ferramentas de CRM, Pesquisa de Mercado e Segmentação da Base de Clientes. A pesquisa aponta que estas ferramentas são utilizadas de uma forma ampla, em virtude de necessidades reais, mas não conseguem produzir resultados efetivos, com baixo indíce de satisfação, indicando a necessidade de apoiar o gestor da empresa incubada visando otimizar o uso das ferramentas em busca de melhores resultados.

- Redes de Cooperação para Inovação: a pesquisa aponta tendências para o uso de ferramentas de gestão na área de Alianças Estratégicas, Inovação Colaborativa, Gestão de Marcas e Competências Essenciais, caracterizando 
a capacidade da incubadora em promover o modelo de trabalho em redes de cooperação.

- Ferramentas Incipientes: ferramentas com baixa utilização e baixo nível de satisfação como Governança, Gerenciamento da Cadeia de Suprimentos, Balanced Scorecard, Estratégia de Crescimento e Gestão de Mudanças, apresentadas nos resultados da pesquisa indicam a necessidade de uma maior atenção e suporte ao gestor da empresa incubada que permita a ele se preparar para competir em um cenário global utilizando instrumentos essenciais para o crescimento sustentável e a internacionalização da empresa.

\section{Inovação e Melhores Práticas de TI}

Da análise dos resultados no que se refere a inovação e melhores práticas de TI a pesquisa mostra que as empresas utilizam a tecnologia da informação em seus processos de gestão com foco em aumentar a sua competitividade criando condições para o crescimento sustentável e consolidação do negócio. A busca pela excelência na gestão é uma importante transformação que faz parte da rotina dos administradores das empresas incubadas de base tecnológica na dinâmica do crescimento sustentável.

Os resultados encontrados estão divididos em dois temas chaves:

- Inovação e Tecnologia da Informação: a pesquisa indica que a tecnologia da informação tem papel relevante no processo de inovação das empresas bem como o envolvimento de pessoas de TI com o negócio.

- Tendências Tecnológicas: as ferramentas de TI utilizadas pelas empresas de base tecnológica estão centralizadas em gerenciamento de sistemas, gestão de portfolio, gestão de ativos e gestão de processos, confirmando o alinhamento de $\mathrm{TI}$ com o desenvolvimento e planejamento do negócio. 


\section{REFERÊNCIAS BIBLIOGRÁFICAS}

ALMEIDA, M.I.R. Manual de planejamento estratégico: desenvolvimento de um plano estratégico com a utilização de planilhas Excel. 2.ed. São Paulo: Atlas, 2003. $156 p$.

ALMEIDA, M.I.R. Programa de pós-incubação de empresas de base tecnológica, estudos de casos: o condomínio de empresas de alta tecnologia da Companhia de Desenvolvimento do pólo de Alta tecnologia de Campinas (CIATEC). In: SIMPÓSIO DE GESTÃO DA INOVAÇÃO TECNOLÓGICA, 23., 19-22 out., 2004, Curitiba. Anais... São Paulo: PGT/USP, 2004. 1 CD-ROM.

ALMEIDA, M.I.R.; JOAQUIM, N.S.; COSTA, R.M. Um modelo de incubação de empresas: o caso de centro de desenvolvimento de indústrias nascentes - CEDIN. In: SEMINÁRIOS EM ADMINISTRAÇÃO - SEMEAD, 4., out., 1999, São Paulo. Anais... São Paulo: USP/FEA/PPGA, 1999. CD-ROM.

ANDRADE, A.; ROSSETTI, J.P. Governança corporativa: fundamentos, desenvolvimento e tendências. São Paulo: Atlas, 2004. 412p.

ARRUDA, M.; VELMULM, R.; HOLLANDA, S. Inovação tecnológica no Brasil. São Paulo: ANPEI, 2006. 117p.

ARBIX, G. Inovar ou inovar: a indústria brasileira entre o passado e o futuro. São Paulo: Papagaio, 2007. 186p.

BIAGIO, L.A.; BATOCCHIO, A. Plano de negócios: estratégia para micro e pequenas empresas. Barueri: Manole, 2005. 366p.

BOSSIDY, L.; CHARAN, R. Execução: a disciplina para atingir resultados. 12.ed. Rio de Janeiro: Elsevier, 2004. 262p. 
BRASIL. Ministério de Ciência e Tecnologia. Agência Brasileira de Inovação. Brasil inovador: o desafio empreendedor: 40 histórias de sucesso de empresas que investem em inovação. Brasília: IEL-NC, 2006. 160p.

BRASIL. Ministério de Ciência e Tecnologia. Secretaria de Política Tecnológica Empresarial. Empresas graduadas nas incubadoras brasileiras 2001. Brasília: IEL, 2001. 116p.

BRASIL. Ministério de Ciência e Tecnologia. Fontes de financiamento das atividades de P\&D e das demais atividades inovativas realizadas pelas empresas, segundo atividades das indústrias extrativas e de transformação, 2003. Tabela. Disponível em: http://www.mct.gov.br/index.php/content/view/9503.html Acesso em: 10 mar. 2008.

BRASIL. Ministério de Ciência e Tecnologia. Tabelas com base no Institute for Scientific Information (ISI) - Nacional Science Indicators. Disponível em: http://www.ftp.mct.gov.br . Acesso em: 12 fev. 2008.

BRASIL. Ministério da Ciência e Tecnologia. FINEP. Fundos Setoriais. Outras Chamadas: Subvenção. Chamada Pública. Seleção Pública MCT/FINEP/FNDCT: Subvenção Econômica à Inovação - 1/2008. Disponível em: http://www.finep.gov.br/fundos setoriais/subvencao economica/editais/EDITAL Sub vencao-2008.pdf. Acesso em: 14 mar. 2008.

CÂMARA BRASILEIRA DE COMÉRCIO ELETRÔNICO. Relatório final - vertical e-business. 2005. Disponível em: http://golden.softex.br/portal/softexweb/uploadDocuments/e-Business.doc. Acesso em: 19 fev. 2008.

CAMARGO JÚNIOR, A.S.; YU, A. Estratégias mais adequadas para gestão de inovações sob condições de incertezas. In: SEMINÁRIO LATINOIBEROAMERICANO DE GESTIÓN TECNOLÓGICA - ALTEC, 11., 26-28 out., 2005, Salvador. Anais... Salvador: ALTEC, 2005. CD-ROM. 
CAVALCANTE, C.; RODRIGUES, F.Z.; GABRIEL, F.; STUMP, F.V; PALETTA, F.C.; CECILIO, P.J.; SATO, R.; CRUZ, R.V.A.; MONTE, V.H.O. Levantamento das dificuldades enfrentadas por empresas no período de incubação: estudo de caso no CIETEC/SP. Disciplina TNA 5782. São Paulo: IPEN, 2004. 26p.

CEBALLOS, D.C. A inovação tecnológica como uma das três dimensões de um novo modelo de gestão em implementação no INPE. In: Brasil. Ministério da Ciência e Tecnologia. Instituto Nacional de Pesquisas Espaciais. Palestra no Instituto de Estudos Avançados.Nov.2005. Disponível em: http://www.inpe.br/dspace/bitstream/123456789/295/1/InovTecnModelGestao.pdf. Acesso em: 10 abr. 2008.

CHRISTENSEN, C.M. Dilema da Inovação: quando novas tecnologias levam empresas ao fracasso. São Paulo: Makroon, 2001. 144p.

COMITÊ GESTOR DA INTERNET NO BRASIL - (CGI). Indicadores. Hosts. 2008. Posição do Brasil no Mundo. Disponível em: http://www.cetic.br/hosts/2008/index.htm. Acesso em: 12 mar. 2008.

CIETEC 10 anos. Cases: de onde surgem as boas idéias? Cietec. Info, n.esp., p.1320, 2008.

COLLINS, J.C. Good to great: why some companies make the leap... and others don't. New York: Harper Business, 2001. 300p.

COLLINS, J.C.; PORRAS, J.I. Feitas para durar: práticas bem-sucedidas de empresas visionárias. Rio de Janeiro: Rocco, 1995. 408p.

CSILLAG, J.M.; GRAEML, A.R. Como as empresas brasileiras estão utilizando a TI. HSM Management Update, n.16, jan., 2005. Disponível em: http://www.mettodo.com.br/pdf/Como\%20as\%20empresas\%20brasileiras\%20estao \%20utilizando\%20a\%20TI.pdf. Acesso em: 24 mar. 2008.

DAGNINO, R.; STEFANUTO, G.N.; COSTA, G.T.M.; SCALCO, T.S.; GOMES, E.J.; MENEGHEL, S. Gestão estratégica da inovação: metodologias para análise e implementação. Taubaté: Cabral, 2002. 350p. 
DAVENPORT, T.H.; MARCHAND, D.A.; DICKSON, T. Dominando a gestão da informação. Porto Alegre: Bookman, 2004. 408p.

DAVILA, T.; EPSTEIN, M.J.; SHELTON, R. As regras da inovação: como gerenciar, como medir e como lucrar. Porto Alegre: Bookman, 2007. 336p.

DAY, G.S.; HUBBARD, K.J. Lições sobre clientes na Internet. Revista HSM Management Update, n.43, mar./abr., 2005.

DRUCKER, P.F. Inovação e espírito empreendedor (entrepreneurship): prática e princípios. São Paulo : Pioneira, 1986. 378p.

ENGENHAR. R\$21,5 bi para inovação. Jornal da Anpei. Disponível em: http://www.anpei.org.br/. Acesso em: 15 jan. 2008.

FISCHMANN, A.A.; ALMEIDA, M.I.R. Planejamento estratégico na prática. 2.ed. São Paulo: Atlas, 1991. 164p.

FUNDAÇÃO DE AMPARO À PESQUISA DO ESTADO DE SÃO PAULO (FAPESP). Indicadores de ciência, tecnologia e inovação em São Paulo 2004. São Paulo: FAPESP, 2004. cap.10, p.38-42.

FUNDAÇÃO NACIONAL DA QUALIDADE: excelência em gestão. Produtos e Serviços. Publicações. Cadernos de Implementação. Cadernos de Excelência Avançado. Clientes. São Paulo: FNQ/Stilgraf, 2007. 24p. Disponível em: http://www.fnq.org.br/download/CadernosExelencia2007/03-CadernoClientesebook.pdf. Acesso em: 25 mar. 2008.

FUNDAÇÃO NACIONAL DA QUALIDADE: excelência em gestão. Produtos e Serviços. Publicações. Cadernos de Implementação. Cadernos de Excelência - Avançado. Informações e Conhecimento. São Paulo: FNQ/Stilgraf, 2008. 26p. Disponível em: https://www.fnq.org.br/pdf/CadernosExcelencia2008 05 informacoes.pdf Acesso em: 29 mar. 2008. 
FUNDAÇÃO NACIONAL DA QUALIDADE: excelência em gestão. Produtos e Serviços. Modelo de Excelência. Fundamentos. Conceitos Fundamentais da Excelência em Gestão. São Paulo: FNQ/Stilgraf, 2006. 32p. Disponível em: http://www.fnq.org.br/Portals/ FNQ/Documents/ebook-ConceitosFundamentais.pdf. Acesso em: 13 maio 2008.

FUNDAÇÃO NACIONAL DA QUALIDADE: excelência em gestão. Produtos e Serviços. Publicações. Cadernos de Implementação. Cadernos de Excelência Avançado. Estratégia e Planos. São Paulo: FNQ/Stilgraf, 2007. 40p. Disponível em: http://www.fnq.org.br/download/CadernosExelencia2007/02-CadernoEstrategiasebook.pdf. Acesso em: 19 maio 2008.

FUNDAÇÃO NACIONAL DA QUALIDADE: excelência em gestão. Produtos e Serviços. Publicações. Cadernos de Implementação. Cadernos de Excelência Avançado. Liderança. São Paulo: FNQ/Stilgraf, 2007. 40p. Disponível em: http://www.fnq.org.br/download/CadernosExelencia2007/01-CadernoLiderancaebook.pdf Acesso em: 12 jun. 2008.

FUNDAÇÃO NACIONAL DA QUALIDADE: excelência em gestão. Produtos e Serviços. Publicações. Cadernos de Implementação. Cadernos de Excelência Avançado. Pessoas. São Paulo: FNQ/Stilgraf, 2007. 44p. Disponível em: http://www.fnq.org.br/download/CadernosExelencia2007/06-CadernoPessoasebook.pdf. Acesso em: 17 jun. 2008.

FUNDAÇÃO NACIONAL DA QUALIDADE: excelência em gestão. Produtos e Serviços. Publicações. Cadernos de Implementação. Cadernos de Excelência Avançado. Processos. São Paulo: FNQ/Stilgraf, 2007. 40p. Disponível em: http://www.fnq.org.br/download/CadernosExelencia2007/07-CadernoProcessosebook.pdf. Acesso em: 19 jun. 2008.

FUNDAÇÃO NACIONAL DA QUALIDADE: excelência em gestão. Produtos e Serviços. Publicações. Cadernos de Implementação. Cadernos de Excelência Avançado. Auto-Avaliação e Gestão de Melhorias.São Paulo: FNQ/Stilgraf, 2007. 48p. Disponível em: http://www.fnq.org.br/download/CadernosExelencia2007/09CadernoAuto-avaliacao-ebook.pdf. Acesso em: 23 jun. 2008. 
FUNDAÇÃO NACIONAL DA QUALIDADE: excelência em gestão. Produtos e Serviços. Publicações. Cadernos de Implementação. Cadernos de Excelência - Avançado. Introdução aos Modelos de Excelência de Gestão. São Paulo: FNQ/Stilgraf, 2007. 32p. Disponível em: http://www.fnq.org.br/download/CadernosExelencia2007/00-Cadernolntroducaoebook.pdf. Acesso em: 27 jun. 2008.

FUNDAÇÃO NACIONAL DA QUALIDADE. FNQ. Informações Gerais. Dúvidas. Disponível em: http://www.fnq.org.br/site/home/dúvidas/415/dúvidas.aspx. Acesso em: 30 jun. 2008.

FONSECA, F.R.B. Competências empreendedoras como atributos geradores de valor: um estudo de caso no setor de base tecnológica. In: ENCONTRO NACIONAL DE ENGENHARIA DE PRODUÇÃO, 26., 9-11 out., 2006, Fortaleza. Anais... Fortaleza: ABEPRO, 2006. CD-ROM.

FONSECA, S.A.; KRUGLIANSKAS, I. Aspectos da inovação em microempresas situadas em incubadoras. In: SIMPÓSIO DE GESTÃO DA INOVAÇÃO TECNOLÓGICA, 21., 7-10 nov., 2000, São Paulo. Anais... São Paulo: PGT/FEA/FIA/POLI/USP, 2000. CD-ROM.

FRASCATI MANUAL. Metodologia Proposta para a definição da investigação e desenvolvimento experimental. Coimbra: OECD, 2007. 336p. Disponível em: http://213.253.134.43/oecd/pdfs/browseit/920208UE.pdf . Acesso em: 12 jan. 2008.

FRONTINI, M.A.; PLONSKI, G.A.; LAURINDO, F.J.B. Innovation management in telecommunications: reflections about regulation model and digital convergence environment in Brazil. In: ANNUAL CONFERENCE OF THE PRODUCTION AND OPERATIONS MANAGEMENT SOCIETY (POMS), 17., Apr. 28-May $1^{\text {st }}$., 2006, Boston. Anais... Miami: Production and Operations Management Society, 2006. CDROM.

FUJITSU SERVICES. Managing the IT infrastructure for business advantage. England: s.n., 2002. 
GIL, A.C. Como elaborar projetos de pesquisa. São Paulo: Atlas, 1991. 159p.

GONÇALVES, J.E.L. As empresas são grandes coleções de processos. RAE Revista de Administração de Empresas, v.40, n.1, p.6-19, 2000.

HAYES, R.; PISANO, G.; UPTON, D.; WHEELWRIGHT, S. Produção, estratégia e tecnologia: em busca da vantagem competitiva. Porto Alegre: Bookman, 2008. $384 p$.

INSTITUTO BRASILEIRO DE GEOGRAFIA E ESTATÍSTICA - (IBGE). Economia. Indústria. Inovação Tecnológica - PINTEC. Clique aqui para consultar a PINTEC 2003. Publicação completa. Pesquisa Industrial de Inovação Tecnológica: 2003. Rio de Janeiro, 2005. 148p. Disponível em: http://www.ibge.gov.br/home/estatistica/economia/industria/pintec/2003/pintec2003.p df. Acesso em: 17 mar. 2008.

INSTITUTO DE PESQUISAS ENERGÉTICAS E TECNOLÓGICAS; CENTRO INCUBADOR DE EMPRESAS TECNOLÓGICAS. Relatório anual 2007 - CIETEC 10 anos. São Paulo: CIETEC/IPEN, 2008. 26p.

KIM, L. Da imitação à inovação: a dinâmica do aprendizado tecnológico da Coréia. Campinas: UNICAMP, 2005. 390p. (Clássicos da Inovação).

KRUGLIANSKAS, I.; SBRAGIA, R. La innovación tecnológica en las pequeñas empresas: evaluación de una proposición organizacional. Espacios, v.17, n.1, p.3035, 1996.

LAKATOS, E.M.; MARCONI, M.A. Metodologia do trabalho científico. 3.ed. São Paulo: Atlas, 1991. 214p.

LUCIANO, E.M.; TESTA, M.G.; FREITAS, H. As tendências em comércio eletrônico com base em recentes congressos. In: ASAMBLEA ANUAL DEL CONSEJO LATINOAMERICANO DE ESCUELAS DE ADMINISTRACIÓN - CLADEA, 38., 21-24 oct., 2003, Lima. Anais... Lima: CLADEA/Universidad San Ignácio de Loyola, 2003. 
LUZZARDI, C.P. O auxílio de uma incubadora empresarial no desenvolvimento de capacidades e competências das empresas incubadas: o estudo de caso da Raiar. 2005. Dissertação (Mestrado) - Faculdade de Administração, Contabilidade e Economia da Pontifícia Universidade Católica do Rio Grande do Sul, Porto Alegre.

MENDES, G.H.S.; TOLEDO, J.C.; MECENAS, D.S. Caracterização da gestão do processo de inovação em empresas de bases tecnológicas de pequeno e médio porte: estudo de casos em empresas residentes em uma incubadora de alta tecnologia. In: SIMPÓSIO DE GESTÃO DA INOVAÇÃO TECNOLÓGICA, 22., 6-8 nov., 2002, Salvador. Anais... São Paulo: PGT/SP, 2002. CD-ROM.

MONTGOMERY, C.A.; PORTER, M.E. (Org). Estratégia: a busca da vantagem competitiva. Rio de Janeiro: Campus, 1998. 502p.

MORAIS, E.F.C. Seminário de inovação 2007. Disponível em: http://www.mbc.org.br/mbc/uploads/bibliotec/1182775933.6469a.PDF. Acesso em: 25 mar. 2008.

MOREIRA, L.M.B.; FERREIRA, M.A.T. A inovação tecnológica da Universidade: representação dos indicadores de C\&T. In: SIMPÓSIO DE GESTÃO DA INOVAÇÃO TECNOLÓGICA, 21., 7-10 nov., 2000, São Paulo. Anais... São Paulo: PGT/FEA/FIA/POLI/USP, 2000. CD-ROM.

MOWERY, D.C.; ROSENBERG, N. Trajetórias da inovação: a mudança tecnológica nos Estados Unidos da América no Século XX. Campinas: UNICAMP, 2005. 232p. (Clássicos da Inovação).

ORGANIZAÇÃO DOS ESTADOS AMERICANOS. (OEA). Ciência, tecnologia, engenharia e inovação para o desenvolvimento: uma visão para as Américas no século XXI. 2006. Disponível em: http://www.mct.gov.br/upd blob/0009/9186.pdf. Acesso em : 19 mar. 2008. 
ORGANIZAÇÃO PARA COOPERAÇÃO E DESENVOLVIMENTO ECONÔMICO (OECD). Gabinete Estatístico das Comunidades Européias. Manual de Oslo: diretrizes para coleta e interpretação de dados sobre inovação. 3.ed. Rio de Janeiro: FINEP, 2005. 136p. Disponível em: http://www.finep.gov.br/imprensa/sala imprensa/manual de oslo.pdf Acesso em: 17 jan. 2008.

ORGANISATION FOR ECONOMIC CO-OPERATION AND DEVELOPMENT (OECD). Governance of Innovation Systems. Paris: OECD, 2005. v.1: Synthesis report. Disponível em: http://213.253.134.43/oecd/pdfs/browseit/9205081E.pdf Acesso em: 11 mar. 2008.

ORGANISATION FOR ECONOMIC CO-OPERATION AND DEVELOPMENT (OECD). Oslo manual: guidelines for collecting and interpreting technological innovation data. 3.ed. Paris: OECD, 2005. 166p. Disponível em: http://213.253.134.43/oecd/pdfs/browseit/9205111E.pdf Acesso em: 30 jan. 2008.

ORGANISATION FOR ECONOMIC CO-OPERATION AND DEVELOPMENT (OECD). Understanding Entrepreneurship: developing indicators for international comparisons and assessments. Report on the OECD's Entrepreneurship Indicators Project and Action Plan. Paris: OECD, 2006. 34p.

ORGANISATION FOR ECONOMIC CO-OPERATION AND DEVELOPMENT (OECD). Information Technology Outlook, 2006. Paris: OECD, 2006. 316p. Disponível em: http://213.253.134.43/oecd/pdfs/browseit/9306051E.pdf. Acesso em: 12 fev. 2008.

ORGANISATION FOR ECONOMIC CO-OPERATION AND DEVELOPMENT (OECD). Science, Technology and Industry: Scoreboard 2007. Paris: OECD, 2007. 228p.

ORGANISATION FOR ECONOMIC CO-OPERATION AND DEVELOPMENT (OECD). Information and communications technologies. Paris: OCDE, 2007. 320p. Disponível em: http://213.253.134.43/oecd/pdfs/browseit/9307021E.pdf . Acesso em: $27 \mathrm{fev} .2008$. 
ORGANISATION FOR ECONOMIC CO-OPERATION AND DEVELOPMENT (OECD). Manual de Frascati (2002). Proposta de práticas exemplares para inquéritos sobre investigação e desenvolvimento experimental. 2007e. 336p. Disponível em: http://www.mct.gov.br/index.php/content/view/69105.html. Acesso em: 16 jan. 2008.

ORGANISATION FOR ECONOMIC CO-OPERATION AND DEVELOPMENT (OECD). Framework for the evaluation of SME and entrepreneurship policies and programmes. Paris: OECD, 2007. 126p. Disponível em http://213.253.134.43/oecd/pdfs/browseit/8507041E.pdf . Acesso em: 15 abr. 2008. .

ORGANIZAÇÃO MUNDIAL DE PROPRIEDADE INTELECTUAL-(Ompi). Statistics on the PCT system. Disponível em: http://www.wipo.int/ipstats/en/statistics/pct/ . Acesso em: 15 abr. 2008.

OLIVA, F.L.; SANTOS, S.A.; SOBRAL, M.C.; BORTOLI NETO, A. A inovação nas empresas de base tecnológica. In: SEMINÁRIO LATINO-IBEROAMERICANO DE GESTIÓN TECNOLÓGICA - ALTEC 2005, 11., 25-28 out., 2005, Salvador. Anais... São Paulo: ALTEC, 2005. CD-ROM.

OLIVEIRA, F.B. (Org.) Tecnologia da informação e da comunicação: a busca de uma visão ampla e estruturada. São Paulo: Pearson Prentice Hall, 2006. 240p.

OSLO MANUAL. Guidelines for Collecting and interpreting technological innovation Data. 3.ed. Paris: OECD: Eurostat, 2005.

PLONSKI, G.A. Desafio na área tecnológica. Gazeta Mercantil, São Paulo, 18 ago. 1998, p.A-3. [Depoimento].

PLONSKI, G.A. Cooperação empresa-universidade. 2000. Tese (Livre Docência) Escola Politécnica - Universidade de São Paulo, São Paulo.

PLONSKI, G.A. Bases para um movimento pela inovação tecnológica no Brasil. Revista São Paulo em Perspectiva. v.19, p. 25-33, 2006. 
PLONSKI, G.A.; FURTADO, J.S. Estudo aponta roteiro para cooperação em ciência, tecnologia e inovação no Mercosul. Inova, v.8, n.25, p.1-2, 2001.

PLONSKI, G.A.; GUIMARÃES, R.R.R. Diferentes estratégias de instituições de P\&D públicas na cooperação com a indústria. In: SIMPÓSIO DE GESTÃO DA INOVAÇÃO TECNOLÓGICA, 22., 6-8 nov., 2002, Salvador. Anais... São Paulo: PGT/SP, 2002. CD-ROM.

PLONSKI, G.A. Tecnologia para empresa e sociedade: conhecimento para produção de bens e serviços deve aproximar demanda a oferta de instituições. Scientific American Brasil, v.2, n.13, p.25, 2003.

PLONSKI, G.A. Em busca de recursos [Depoimento]. Ensino Superior, São Paulo, p.20-23, maio 2005.

PLONSKI, G.A.; GARGIONE, L.A.; LOURENÇÃO, P.T.M. Fatores críticos de sucesso para modelagem de parques tecnológicos privados no Brasil. In: SEMINÁRIO LATINO-IBEROAMERICANO DE GESTIÓN TECNOLÓGICA - ALTEC, 11., 26-28 out., 2005, Salvador. Anais... Salvador: ALTEC, 2005a. CD-ROM.

PLONSKI, G.A. 0 papel do indivíduo $e$ do coletivo na criação do conhecimento. Disponível em:

http://www.terraforum.com.br/sites/terraforum/Biblioteca/Ary\%20Plonsky.pdf. Acesso em: 12 maio 2008.

PRADO, E.J.S.; CAMPOS, R.R. Patentes e inovação nas empresas residentes em incubadoras. In: SIMPÓSIO DE GESTÃO DA INOVAÇÃO TECNOLÓGICA, 21., 7-10 nov., 2000, São Paulo. Anais... São Paulo: PGT/FEA/FIA/POLI/USP, 2000. CDROM.

REIS, D.R. Gestão da inovação tecnológica. Barueri, SP: Manole, 2004. 204p.

RIGBY, D.K. Management tools 2007: an executive's guide. Disponível em http://www.bain.com/bainweb/PDFs/cms/Public/Management Tools 2007 Executive Guide.pdf. Acesso em: 28 fev. 2008. 
RIGBY, D.K.; BILODEAU, B. Management tools and trends 2007. Disponível em: http://www.bain.com/management tools/Management Tools and Trends 2007.pdf Acesso em: 11 mar. 2008.

RIGBY, D.K.; BILODEAU B. Management tools and trends 2007. Disponível em: http://www.bain.com/bainweb/PDFs/cms/Marketing/Management\%20Tools\%202007 \%20BB.pdf. Acesso em: 19 mar. 2008.

RIGBY, D.K.; BRIDELLI, S.; ALVES, V. Ferramentas de gestão 2003. Disponível: http://www.bain.com/bainweb/PDFs/cms/Public/Ferramentas de gestao MT 2003 Portuguese.pdf . Acesso em: 26 mar. 2008.

ROSS, J.W.; WEILL, P.; ROBERTSON, D.C. Arquitetura de TI como estratégia empresarial. São Paulo: M. Books, 2008. 200p.

SANTOS, S.A.; ALMEIDA, F.R.; TAKAHASHI, A.R.W.; Confronto das barreiras e das facilidades para a criação e desenvolvimento de novas empresas de base tecnológica (NTBFS) no Brasil e no Exterior. In: SIMPÓSIO DE GESTÃO DA INOVAÇÃO TECNOLÓGICA, 23., 19-22 out., 2004, Curitiba. Anais... São Paulo: PGT/USP, 2004. 1 CD-ROM.

SBRAGIA, R. Trabalho em equipe e inovação tecnológica. Revista de Administração, v.28, n.1, p.36-43, 1993.

SBRAGIA, R.; STAL, E. (Eds.) Tecnologia e inovação: experiência de gestão na micro e pequena empresa. São Paulo: PGT/USP, 2002. 293p.

SBRAGIA, R.; GALINA, S.V.R. (Eds.) Gestão da inovação no setor de telecomunicações. São Paulo: PGT/USP, 2004. 336p.

SBRAGIA, R.; PEREIRA, E.C.O. Determinantes de êxito de empresas tecnológicas de base universitária: um estudo de casos múltiplos no âmbito do CIETEC/USP. Revista de Economia e Administração, v.3, n.4, p.1-15, 2004.

SBRAGIA,R.;STAL, E.;CAMPANÁRIO, M.;ANDREASSI, T. Inovação: como vencer esse desafio empresarial. São Paulo: Clio, 2006. 328p. 
SERVIÇO BRASILEIRO DE APOIO ÀS MICRO E PEQUENAS EMPRESAS (SEBRAE). Dados da pesquisa. Disponível em: http://www.sebraesp.com.br/principal/conhecendo\%20a\%20 mpe/mortalidade\%20de \%20empresas/sobr mortalidade versao 2004 2005.aspx. Acesso em: 19 jun. 2008.

SCHLEMM, M.M. Empreendedorismo no Brasil: 2006. Curitiba: IBQP, 2007. 228p. SCHUMPETER, J.A. Capitalism, socialism and democracy. New york: Harper \& Brothers, 1934.

SCHWATZ, P. A arte da visão de longo prazo: caminhos para um insight estratégico para você e a sua empresa. 3.ed. São Paulo: Best Seller, 2004. 216p.

SHANE, S.A. Sobre solo fértil: como identificar grandes oportunidades para empreendimentos em alta tecnologia. Porto Alegre: Bookman, 2005. 178p.

SILVA, J.C.T.; PLONSKI, G.A. Inovação tecnológica: desafio organizacional. Produção, v.6, n.2, p.183-193, 1996.

STOKES, D.E. O quadrante de Pasteur: a ciência básica e a inovação tecnológica. Campinas: Unicamp, 2005. 248p.

TREPPER, C. Estratégias de e-commerce. Rio de Janeiro: Campus, 2000.

UNITED NATIONS ICT TASK FORCE - UN (ONU). Measuring ICT: The global status of ICT indicators. Partnership on measuring ICT for development. 2005. 176p.

VIOTTI, E.B.; MACEDO, M.M. Indicadores de ciência, tecnologia e inovação no Brasil. Campinas: Unicamp, 2003. 614p.

WEILL, P.; ROSS, J.W. Governança de TI, tecnologia da Informação. São Paulo: M. Books, 2006. 276p.

WESTERMAN, G.; HUNTER, R. O risco de TI: convertendo ameaças aos negócios em vantagem competitiva. São Paulo: M. Books do Brasil, 2008. 204p. 


\section{ANEXOS}

Questionários utilizados

na pesquisa de campo 


\section{QUESTIONÁRIO INOVAÇÃO E MELHORES PRÁTICAS DE TI Questionário para Ferramenta de Autodiagnóstico}

Importante: O objetivo deste questionário é avaliar quão inovadora é a sua empresa e o grau de maturidade na adoção de melhores práticas de governança e de TI .

Obs.: Todas as perguntas possuem quatro alternativas, sendo que a cada uma delas atribui-se 1, 3, 5 ou 7 pontos, conforme a ordem em que aparecem abaixo.

\section{I - Inovação}

1. Em relação aos seus competidores, você considera a sua empresa?
a) Muito mais inovadora ( 7 )
b) Mais inovadora ( 5 )
c) Igual as demais ( 3 )
d) Menos inovadora (1)

2. Você acredita que a sua empresa deveria ser mais inovadora do que atualmente ela é?
a) Bem mais inovadora do que ela é (1)
b) Mais inovadora ( 3 )
C) Igual ao que ela é hoje ( 5 )
d) Menos inovadora do que ela é ( 7 ) 
3. O assunto inovação é:

a) Amplamente discutido na minha empresa, e a área de TI é cobrada por gerar inovação ( 7 )

b) Amplamente discutido na minha empresa, mas a área de TI não é cobrada por gerar inovação ( 5 )

c) Não é amplamente discutido na minha empresa, mas a área de TI é cobrada por gerar inovação ( 3 )

d) Não é amplamente discutido na minha empresa, e a área de TI não é cobrada por gerar inovação ( 1 )

4. Há pessoas e orçamento dedicados à inovação na sua empresa ?

a) Há pessoas dedicadas a inovação na minha empresa e há orçamento separado em TI para inovação ( 7 )

b) Há pessoas dedicadas a inovação na minha empresa, mas não há orçamento separado em TI para inovação ( 5 )

c) Não há pessoas dedicadas a inovação na minha empresa, mas há orçamento separado em TI para inovação ( 3 )

d) Não há pessoas dedicadas a inovação na minha empresa, e também não há orçamento separado em TI para inovação (1)

5. A sua empresa planeja implementar em 2008 ou já implementou soluções de RFID, SOA, Web 2.0, virtualização de servidores/storage, Telefonia IP, certificação digital e digitalização de documentos?

a) Sim para maioria dos itens ( 7 )

b) Sim para metade dos itens ( 5 )

c) Sim para pouco menos da metade ( 3 )

d) Não para a grande maioria dos itens ( 1 ) 
6. Qual é a maior chance de um projeto que exija investimentos altos na sua empresa seja aprovado?
a) Quando ele tem um grande potencial de gerar diferencial competitivo ( 7 )
b) Quando ele tem um potencial de aumentar as receitas ( 5 )
c) Quando ele tem um potencial de reduzir custos ( 3 )
d) Quando os concorrentes já o fazem ( 1 )

7. Por favor indique se você concorda ou não com as seguintes afirmações em relação a sua empresa? (múltipla escolha)
a) A minha empresa tem um processo formal de premiação de idéias originais ( 5 )
b) Os colaboradores da minha empresa estão cientes da importância da inovação e tendem a compartilhar o seu conhecimento de forma voluntária ( 5 )
c) A comunicação na minha empresa é aberta e livre ( 5 )
d) A cultura da minha empresa valoriza e incentiva o comportamento inovador ( 5 )
e) Eu me lembro rapidamente de pelos menos 3 inovações que a minha empresa implementou recentemente. ( 5 ) 


\section{II - Melhores práticas de TI}

8. Por favor indique se a sua empresa tem as seguintes práticas atualmente: (múltipla escolha)

a) O principal executivo de TI se reporta ao Presidente ( 5 )

b) Há comitê formal de TI com participação de executivos de negócio ( 5 )

c) Há rotação de pessoas de TI em negócio ou vice-versa ( 5 )

d) Há profissionais de TI nas áreas de negócio para fazer a interface ( 5 )

e)Há políticas de charge-back com as áreas de negócio (cobrar pela utilização dos serviços de TI) ( 5 )

f) Algum executivo de TI da empresa participa das reuniões do board da empresa ( 5 )

g) Há uma forte ligação das métricas de TI com os resultados do negócio ( 5 )

h) A empresa assina SLA (Service Level Agreements) com as áreas de negócio ( 5 )

i) Há workshops de TI regulares direcionados as áreas de negócio ( 5 )

9. A sua empresa utiliza as seguintes práticas/diciplinas/frameworks? (múltipla escolha)

a) Balanced Scorecard ( 5 )

b) Utiliza formalmente várias disciplinas do ITIL ou equivalente ( 5 )

c)Utiliza formalmente várias disciplinas do Cobit ou equivalente ( 5 )

d) Utiliza formalmente várias disciplinas do CMM ( 5 )

e) A empresa têm profissionais com certificação PMI ( 5 ) 
10. A sua empresa utiliza ou pretende utilizar as seguintes ecnologias? (múltipla escolha)
a) $\operatorname{SOA}(5)$
b) Re-uso e componentização dos códigos dos sistemas ( 5 )
c) Consolidação de servidores e storage ( 5 )
d) Virtulização de servidores ( 5 )
e) Virtualização de storage ( 5 )
f) Information Lifecycle Management (ILM) ( 5 )
g) Software de gerenciamento de portfolio ( 5 )
h) Software de gerenciamento de sistemas ( 5 )
i) BPM (Business process management) ( 5 )
j) Distribuição automatizada de software ( 5 )
k) Software de gerenciamento de ativos ( 5 pontos) 